\title{
PERCEPTIONS OF AUTHENTICITY TOWARDS MĀORI BRANDING: \\ CONGRUENCE AS DETERMINATOR?
}

\author{
BY \\ BRITTANY BALTUS
}

\begin{abstract}
A thesis
submitted to Victoria University of Wellington

in partial fulfilment of the requirements for the degree of

Master of Commerce
\end{abstract}

Victoria University of Wellington

2019 


\begin{abstract}
Increasingly, both local and global organisations are implementing indigenous branding in their market offerings, regardless of whether they have ancestral connections to indigenous culture. However, numerous criticisms and claims of cultural appropriation have been raised in response to organisations' commercialisation and commodification of indigenous culture through indigenous branding. This raises questions about the authentic and appropriate use of indigenous culture, language and iconography in commerce, particularly with regards to consumers perceptions of authenticity towards this use. As such, the purpose of this study was to understand consumers' perceptions of authenticity in the context of indigenous (Māori) branding and organisational values.
\end{abstract}

In this study a $2 \times 2 \times 2$ between subjects experimental design was conducted using an online questionnaire. Subjects in the study were presented with a scenario communicating information about a brands values (either conventional or tikanga Māori), and their proposed brand concept (either orthodox or Māori branding). As the purpose of the study was to investigate both Māori and non-Māori perspectives, the sample was comprised of 570 adult Māori and non-Māori consumers currently living in New Zealand. These subjects were randomly distributed to one of the eight experimental conditions. Data from the questionnaire was analysed using a factorial ANOVA.

The findings indicate that congruence among branding, organisational values and consumers" ethnic identification exerts the most leverage on consumers' authenticity perceptions. Although, Māori consumers also perceived congruent (conventional) organisational values and (orthodox) branding as highly authentic. Interestingly, consumers in general found incongruent Māori branding and conventional values to be the least authentic, a finding attributed to issues of cultural appropriation. The results of the analyses contributes to the current understanding of perceived authenticity and indigenous brands. Moreover, this indigenous branding congruence effect extends social identity theory as it illuminates the fluidity of indigenous consumers social experiences and understandings. Managerially, marketers should be cognizant of the effects of congruence among branding, values and their target market, and make efforts to achieve congruence among these factors. If congruence cannot be achieved, then marketers should make efforts to be perceived as congruent through only communicating those factors which are congruent. 


\section{Acknowledgements}

Ehara taku toa, i te toa takitahi, engari, he toa takitini

Mine is not my strength alone, it is the strength of many

I would firstly like to thank the academic support I have had throughout my studies. First and foremost to my academic supervisors, Dr. Janet Davey and Dr. Djavlonbeck Kadirov; without your kindness, guidance, and occasional reminders of how to properly use apostrophes - I surely would have been lost. So, thank you both. I would also like to thank Dr. Jesse Pirini for your help with navigating the kaupapa Māori paradigm, and encouraging me to take the path less travelled, thank you. Finally, I would like to thank Victoria University for the financial assistance that I received throughout my study, specifically through the Tū Horomata Scholarships.

I would also like to thank my friends for always being such amazing people who constantly make my life better and brighter. To my post grad pals - we made it! Hons class of 2018 you were simply the best. Of course the biggest thank you goes to Guy for sticking it out with me on this Masters journey. Having you there with me to work with, laugh with and to comiserate with has been made this journey so much more enjoyable/bearable.

Of course, thank you to my immediate whānau - Mum, Dad, Helen, Lincoln - your unwavering love and belief in me has always motivated me to make you proud. I hope I have. To my little sisters, Hinewai and Mia, thank you for your care packages and cuddles, you are two of the brightest little lights in my life. I would also like to thank my wider whānau, all your support and encouragement with my studies has meant the world to me.

Finally, the biggest thank you to my best friend and favourite person, Andrew. Thank you for all the work you've put in to help me reach my goals, and for never letting a single day pass without making me feel happy, loved and supported. You have been everything to me on this journey and I can't wait to see what's next instore for us!

This thesis is the end result of a lot of care, thought and support from so many people. Without their contribution this journey would not have been possible, and this thesis incomplete. Thank you all. 


\section{Table of Contents}

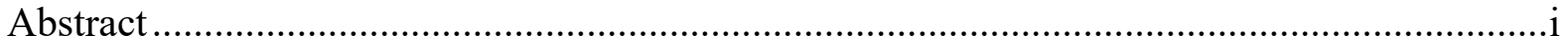

Acknowledgements............................................................................................... ii

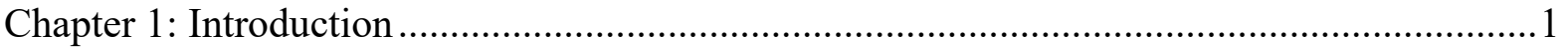

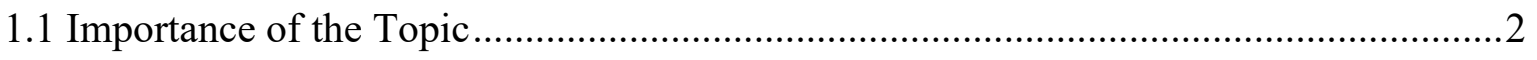

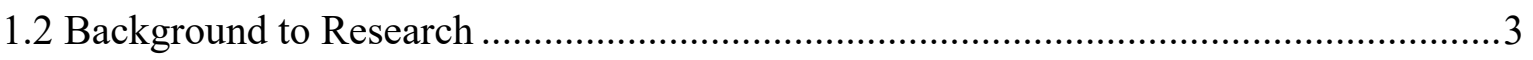

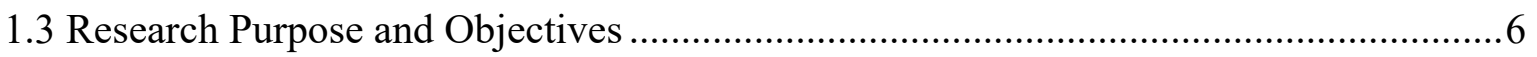

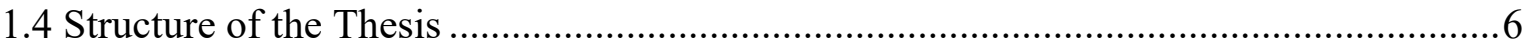

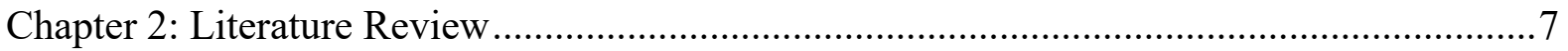

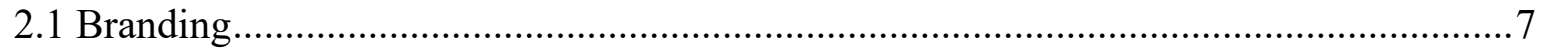

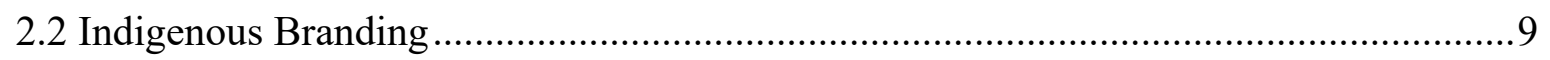

2.2.1 Indigenous Branding and Self Identity (Ethnic Identification)..............................11

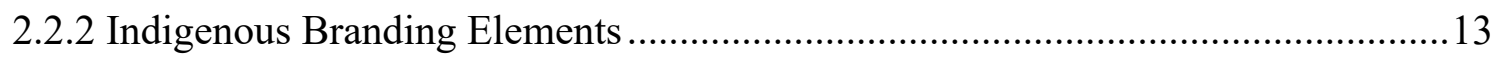

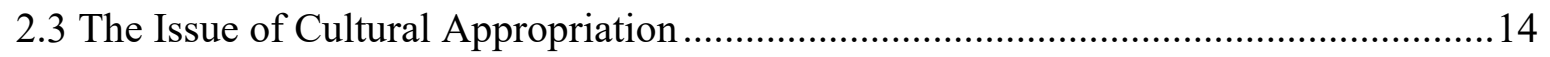

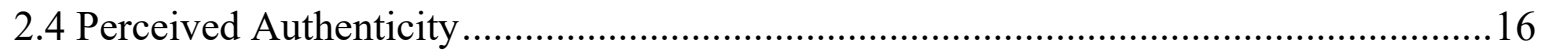

2.4.1 Authenticity and Indigenous Organisational Values ..............................................17

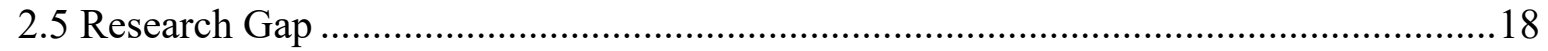

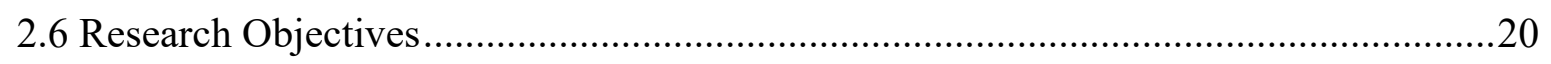

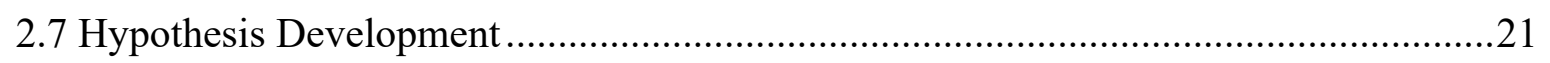

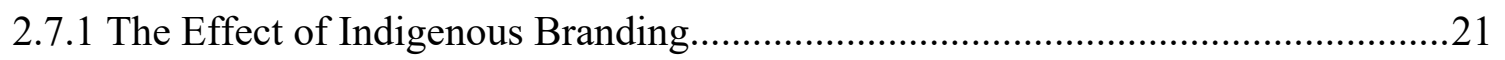

2.7.2 The Moderating Effect of Organisational Values...................................................21

2.7.3 The Three-way Moderating Effect of Indigenous Ethnic Identification ................22

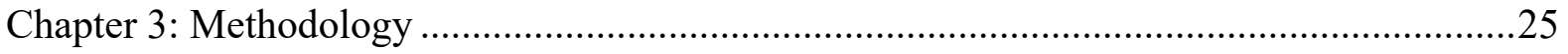

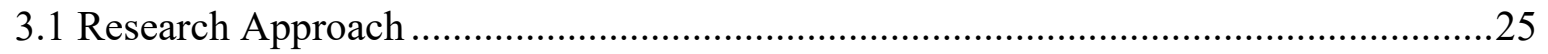

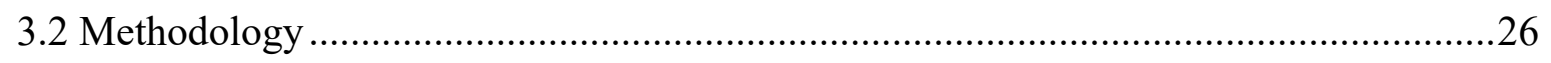

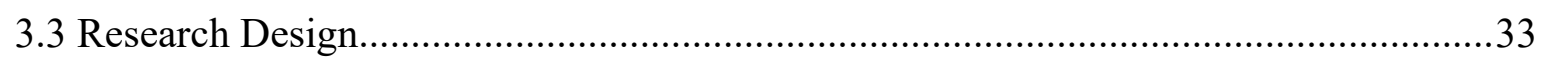

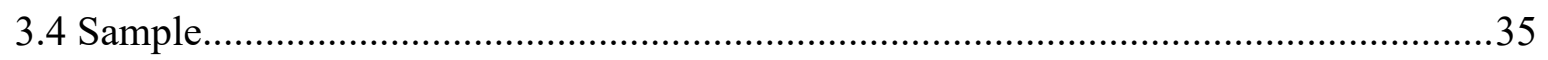

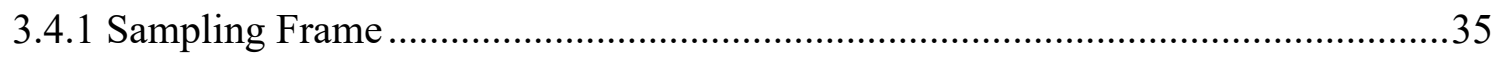

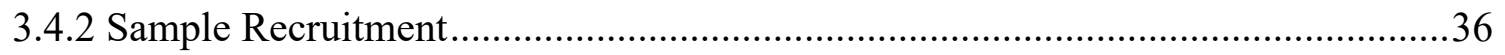

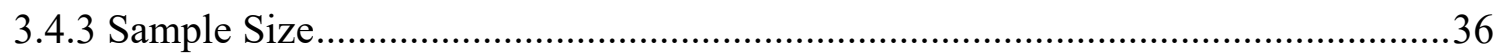

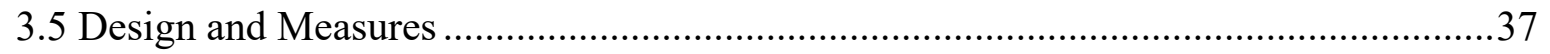

3.5.1 Dependent Variable: Perceived Authenticity........................................................38

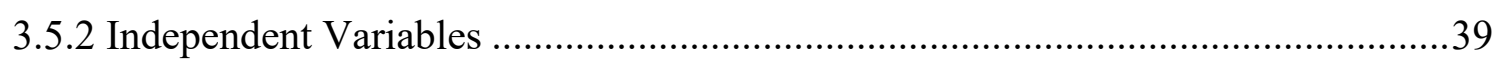

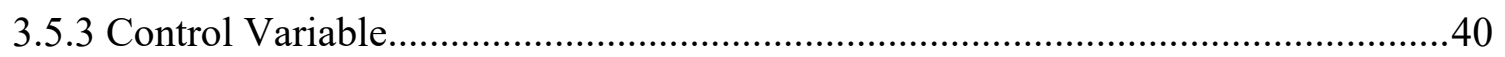

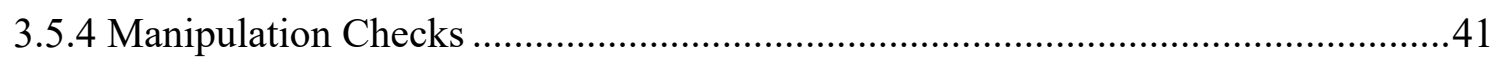

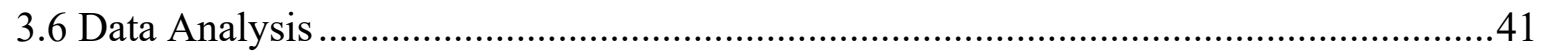

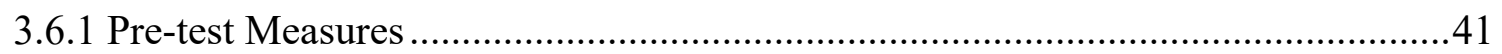




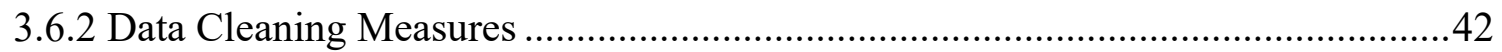

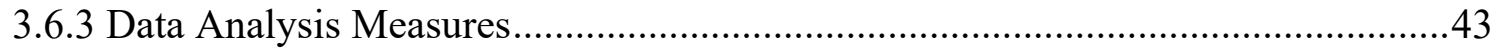

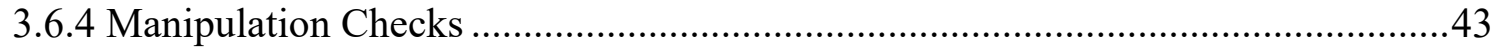

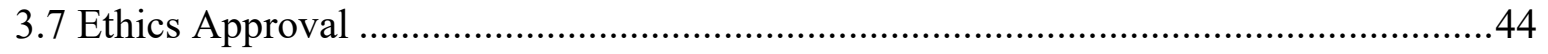

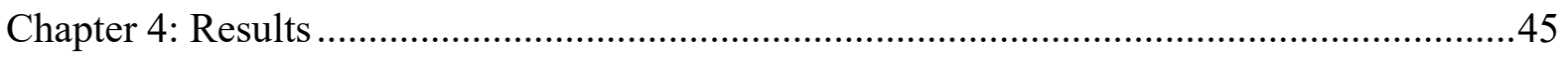

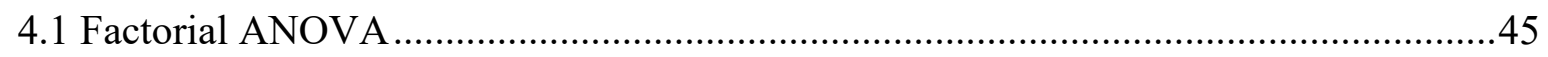

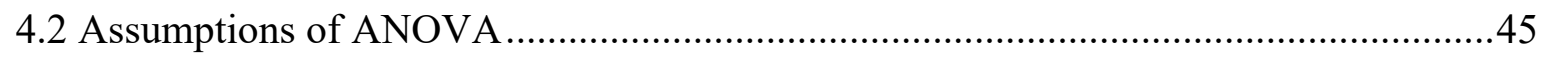

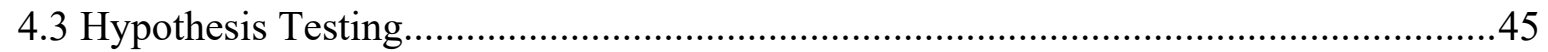

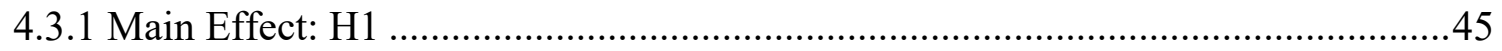

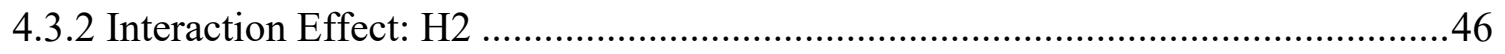

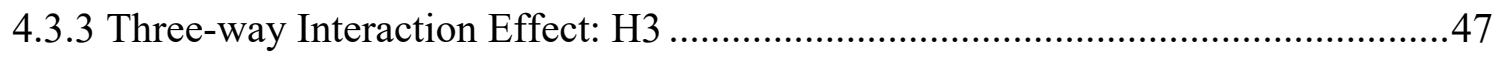

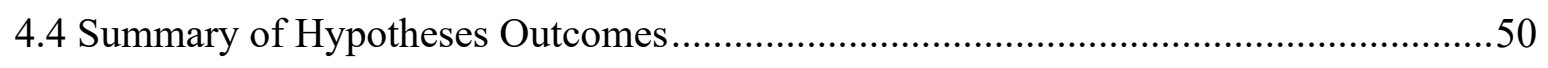

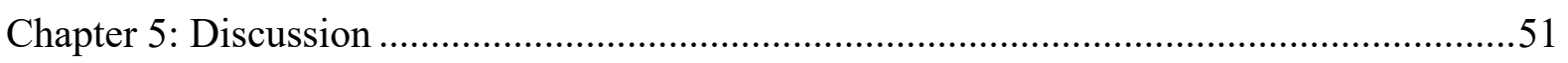

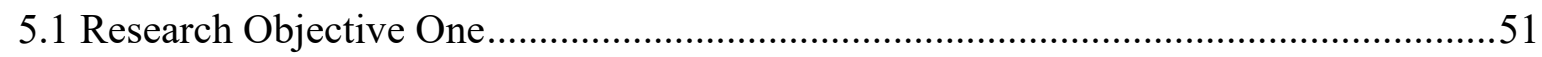

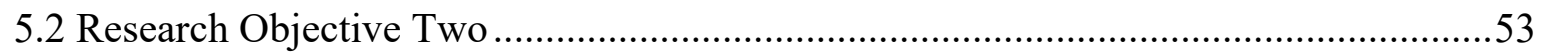

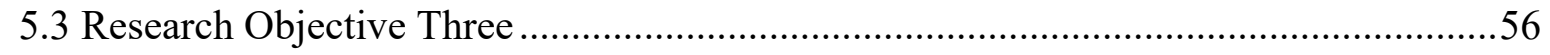

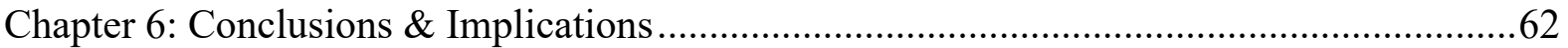

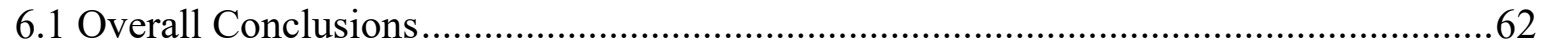

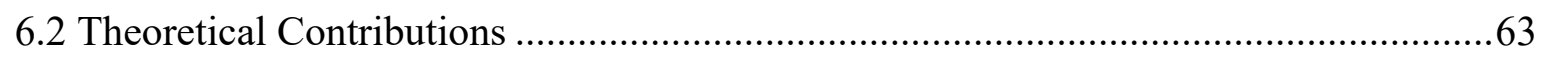

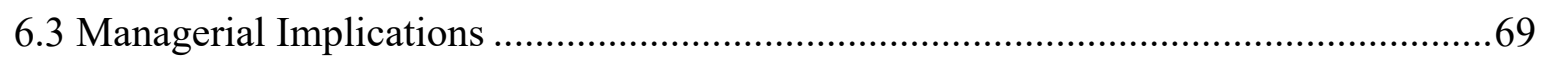

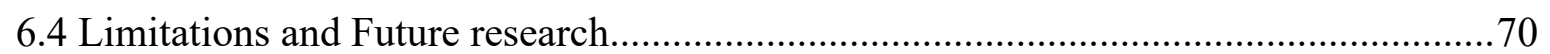

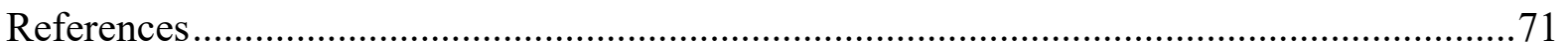

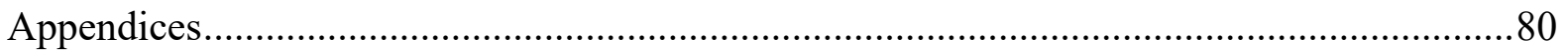

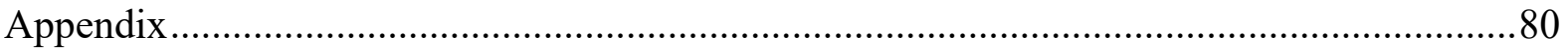

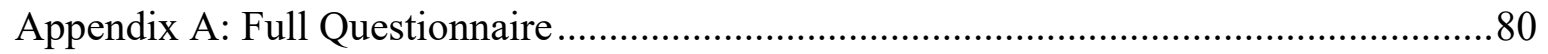

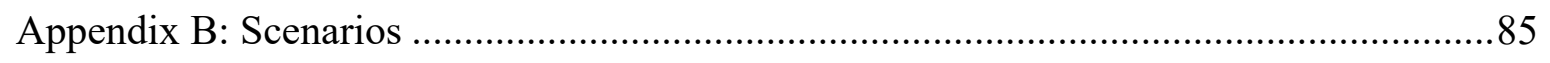

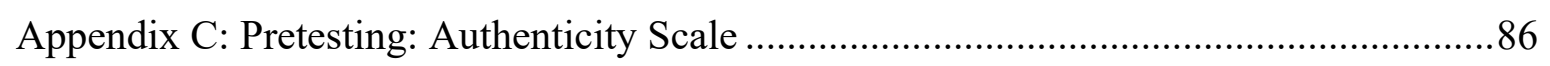

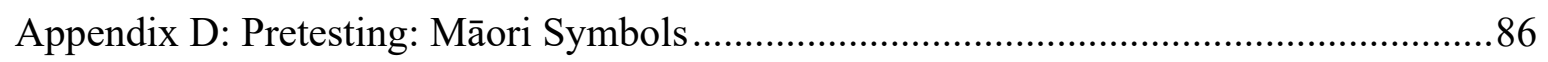

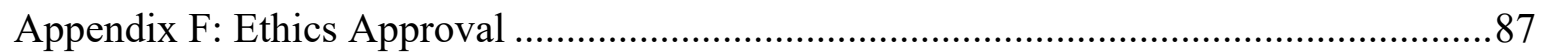




\section{List of Tables}

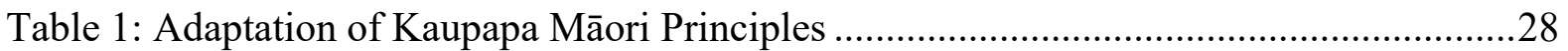

Table 2: Adaptation of Kaupapa Māori Ethical Principles .......................................................30

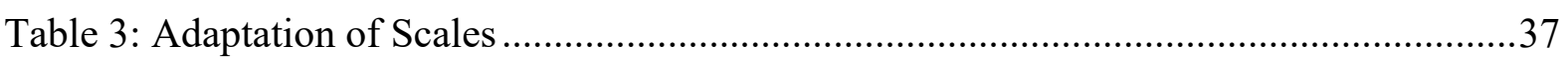

Table 4: Summary of Hypotheses Outcomes.................................................................. 50

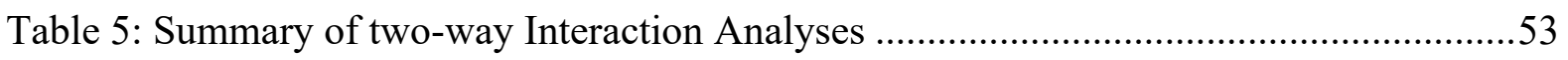

Table 6: Summary of Three-way Interaction Analyses ......................................................56

\section{List of Figures}

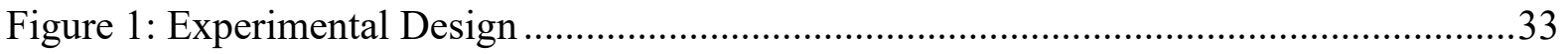

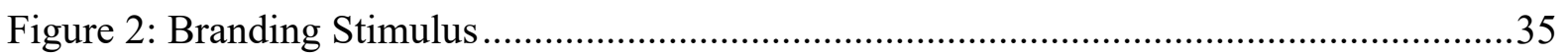

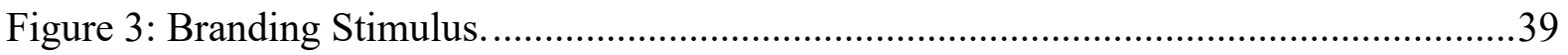

Figure 4: Two-way Interaction Effect of Branding and Values .........................................46

Figure 5: Three-way Interaction Effect of Ethnic Identification, Values and Branding .........48 


\section{Chapter 1: Introduction}

On both local and global stages, organisations are recognising the benefits of utilising indigenous branding and indigenous organisational values in their businesses, not only to differentiate themselves, but to enhance meaningful emotional and cultural connections with consumers (Balmer, 2013; Harmsworth \& Tahi, 2008; Holland \& Gentry, 1997; Rigby, Mueller \& Baker, 2007). In New Zealand, many organisations utilise aspects of the indigenous Māori culture of New Zealand, such as language and iconography, for their products and services to express a unique statement of identity, and connect with consumers (Harmsworth \& Tahi, 2008; Wilson, 2005). Furthermore, it is not just organisations with ancestral connections to indigenous cultures that are utilising aspects of indigenous culture, but also organisations devoid of such connections (Feetham, Wright \& Joe, 2018). The diversity of New Zealand organisations utilising aspects of Māori culture, however, contributes to broader issues of the commercialisation and commodification of Māori intellectual property.

Public concern over the commercialisation and commodification of Māori intellectual property through the use of Māori branding has contributed to one of the largest Waitangi Tribunal claims in New Zealand history, namely the WAI262 Waitangi Tribunal claim on Māori intellectual property rights (Waitangi Tribunal, 2011). Due to the extensiveness of the WAI262 claim, and the surrounding issues of commercialisation and commodification of Māori intellectual property that this claim raised in public discourse, it is likely that New Zealand consumers will be sensitive towards the authentic and appropriate use of Māori culture in commerce. As such, it is important for organisations wishing to implement aspects of Māori culture into their organisation to understand how to do so authentically, as to minimise criticisms of cultural appropriation and enhance perceptions of brand authenticity.

This dissertation recognises the increased desirability and popularity of indigenous cultural representations in a range of organisational contexts (Harmsworth \& Tahi, 2008), and hopes to provide clarity for organisations considering implementing indigenous branding in an authentic manner. Yet, at the same time, this dissertation also acknowledges that the commodification and commercialisation of Māori culture can be perceived as cultural appropriation. Cultural appropriation is defined as instances where dominant groups utilise aspects of marginalised groups' culture, effectively gaining from and speaking for these marginalised groups, as well as perpetuating power asymmetries and reinforcing homogenising stereotypes of these 
marginalised groups (Matthes, 2016). While the connection between the commodification of culture and cultural appropriation is clear in academic literature (e.g. Lai, 2016), it is less clear whether consumers are cognizant of, and sensitive towards, these situations. More specifically, this raises questions of whether these situations affect consumers' authenticity perceptions. This study therefore contributes to the current understandings of perceived authenticity through its examination of consumers' perceptions of authenticity towards the commodification and commercialisation of Māori culture.

The study of indigenous branding is particularly relevant to New Zealand, because despite accounting for only $15 \%$ of New Zealand's population, Māori have a significant presence (Stats NZ, 2017; 2018). This presence can be largely attributed to the numerous and ongoing revitalisation efforts regarding Māori culture (Albury, 2016), and New Zealand's unique sociocultural history (e.g. New Zealand's colonial history and its ongoing ramifications) (Sibley \& Barlow, 2009). The significance of Māori indigenous culture in New Zealand means that both Māori and non-Māori are knowledgeable (albeit at varying levels) of this culture (Sibley \& Barlow, 2009). Therefore, one could assume that New Zealand consumers are likely to be discerning of the legitimate use of Māori cultural elements in branding. As such, it is important to understand how organisations can authentically utilise Māori branding in order to minimise criticisms of cultural appropriation and enhance perceptions of brand authenticity.

\subsection{Importance of the Topic}

The current study is important as it centres around the concept of authenticity, an issue currently prominent in the marketing discipline (Brown, 2001), and and is particularly relevant to brands utilising indigenous cultural representations. However, despite being one of marketing's central themes, the current body of research has yet to address how branding elements might promote perceived authenticity (Fritz, Schoenmueller \& Bruhn, 2017; Kolar \& Zabkar, 2010); the intersection between indigenous culture and perceived authenticity (Balmer, 2013); nor the role of a person's indigenous identity in their negotiation of authenticity (Hunter, 2011). Through examining these gaps, it is hoped that light will be shed on the issues arising from the competing perspectives of cultural appropriation and commercial gain.

The topic of this dissertation is also pertinent as it investigates indigenous branding. Indigenous branding is a salient issue in New Zealand, not only because of the presence of the indigenous Māori population, but also the prevalence of Māori culture, language and iconography featured 
in the branding of many New Zealand organisations (Harmsworth \& Tahi, 2008; Wilson, 2005). Alongside the popularity of indigenous branding, there is also a considerable amount of contention surrounding the use of Māori branding, specifically, contention regarding intellectual property rights over the commodification and commercialisation of Māori culture. The popularity of indigenous branding, and the associated issues such branding raises, is exemplified by a long list of organisations - both local and global - which have utilised aspects of Māori culture in a manner that resulted in public contention, negative social goodwill, and financial losses. Examples include Lego (trivialised Māori iconography and mythology in their range of toys) (NZPA, 2001), Kapiti cheese (named a product after a prominent Māori historical figure - Tuteremoana) (Taiuru, 2019), Jean Paul Gaultier (used moko kauae/Māori chin tattoos on catwalk models) (Taiuru, 2019), and New Zealand's national air carrier - Air New Zealand (who have repeatedly used the koru symbol throughout their organisation and even attempted to legally claim the koru is an iconic symbol exclusively associated with Air New Zealand) (E Tū, 2006; Sachdeva, 2010). These are just some of the many local and international organisations utilising Māori culture ineffectively in their marketing efforts, resulting in adverse and costly outcomes. Nonetheless, these organisations, and many others, continue to use Māori indigenous branding - an issue only compounded by the lack of legal guidance and protection over the commodification and commercialisation of Māori culture (Lai, 2016. Therefore, it is paramount that scholars provide value, and not contribute to further exploitation, through investigating how organisations might engage in the use of indigenous branding in an authentic manner as to avoid public contention, negative social goodwill, and financial losses.

\subsection{Background to Research}

The background of this research is situated in the Waitangi Tribunal WAI262 claim, and as such, also relates to Te Tiriti o Waitangi (the Treaty of Waitangi) (TOW). Consequently, this dissertation will now briefly explain the relevant aspects of the TOW, the Waitangi Tribunal, and the WAI262 claim.

Te Tiriti o Waitangi is the founding document of New Zealand, signed by representatives of the Crown and Māori iwi (tribes) and hapū (subtribes) in 1840. The TOW was written in both English and Māori, with seemingly subtle differences between the two texts. However, 501 out of 540 Māori representatives signed the Māori text. Soon after the signing of the TOW, it became apparent that the seemingly subtle differences were, in fact, very significant differences 
(Suter, 2014). These differences resulted in the reality for Māori falling very short of what was expected, with land confiscations, suppression of language and suppression of cultural traditions and norms (Suter, 2014). While many countries with indigenous populations have faced similar issues and applied the Contra Proferentum law to resolve said issues, such as the United States of America when dealing with the interpretation of treaties with Native Americans, the New Zealand government has failed to do so (Suter, 2014). Contra Proferentum states that the meaning of a Treaty should be construed in sense that would naturally make sense to the indigenous party, and not interpreted or construed in a way that is to the prejudice of the indigenous party (Suter, 2014). As a result of the self-preferential interpretation and application of the TOW by the New Zealand government, the relationship between Māori and the government has been fraught with continuous issues reflective of the ongoing legacies of colonialism (Suter, 2014).

The issue over the cultural appropriation and Māori intellectual property rights that occurs in Māori branding stems from the deviation in article two of the TOW. It should be noted that article two was also the central concern of WAI262. In article two, the English text promises to protect Māori in the exclusive and undisturbed possession of their properties, whereas the Māori text guarantees Māori "te tino rangatiratanga o rātou taonga katoa", absolute authority and control over all of their treasured things (Waitangi Tribunal, 2011). It is clear to see that the Māori text implies that Māori would be awarded a much more extensive level of power and control over their treasured things, full sovereignty as opposed to idea of governorship conveyed in the English text. In 1991, issues regarding cultural appropriation and Māori intellectual property rights were taken to The Waitangi Tribunal for redress. The Tribunal was formed in 1975 as an avenue for Māori to seek redress from instances where the Crown's actions negatively affected Māori, most often stemming from deviations in the two TOW texts (Hayward, 2015; Waitangi Tribunal, 2016). The Waitangi Tribunal utilised the TOW as a framework to analyse the issues put forth, which consequently formed the WAI262 claim. Unlike the Crown, the Waitangi Tribunal does apply Contra Proferentum when interpreting and applying the TOW (Suter, 2014). However, the recommendations of the Tribunal are not binding upon the government, and as such, the powers of the Waitangi Tribunal are limited (Suter, 2014).

One of the primary concerns of WAI262 was that aspects of Intellectual Property (IP), such as trademarks or copyright, have not adequately protected the kaitiaki (guardian) relationship with 
taonga works (treasured things) and mātauranga Māori (Māori ways of knowing), which has resulted in misuse and misappropriation (Waitangi Tribunal, 2011). The claimants argued that this inadequate protection illuminates the government's undermining of the second article of the TOW and is evidenced by both the culturally offensive use of taonga works and non-kaitiaki claims for IP rights over taonga works and economic benefit (Waitangi Tribunal, 2011). As such, the Waitangi Tribunal was tasked with answering whether the current IP law could expand to meet the desires of the kaitiaki of taonga works and mātauranga Māori (Waitangi Tribunal, 2011).

The Waitangi Tribunal (2011) concluded by offering differing recommendations for Taonga Works and Taonga Derived Works. Taonga Works were defined as products of mātauranga Māori with kaitiaki (guardians), whakapapa (genealogy), kōrero (they tell a story) and mauri (life force) (Waitangi Tribunal, 2011). In contrast, Taonga Derived Works were defined as works with a Māori element, which were often modern yet still inspired by taonga works or by underlying mātauranga Māori (Waitangi Tribunal, 2011). For Taonga Works, the Tribunal found that the second article of TOW guarantees absolute authority and control over taonga; they thus argued that kaitiaki should have the right to be consulted with and to give consent over commercialised use of Taonga Works (Waitangi Tribunal, 2011). However, the Tribunal thought that Taonga Derived Works required less protection than Taonga Works, instead only suggesting protection against offensive and derogatory use (Anyon-Peters, 2017).

Within a branding context, Taonga Derived Works are most prevalent; however, the recommendations of the Waitangi Tribunal have only afforded negative protections for Taonga Derived Works (Anyon-Peters, 2017). Specifically, protection is only awarded against the offensive and derogatory use of Taonga Derived Works, and even then, there are no concrete legal terms that would defend a claim in court or seek a remedy (Anyon-Peters, 2017). Moreover, Māori have not been awarded any rights to commercially benefit from the commodification and commercialisation of Māori culture. Even considering the absence of positive protection, it is both interesting and saddening to note that in the eight years since the publication of WAI262, the government has failed to respond to the report or implement any of its' recommendations (Anyon-Peters, 2017). Thus, Māori are still facing the same issues around offensive use and benefit sharing stemming from the appropriation and commercialisation of Māori IP. 
From a broader perspective, the result is that no parties - neither Māori nor non-Māori - have any clarity around accessing, utilising and benefit sharing of taonga Māori. Therefore, it is imperative that Māori continue to engage with Māori IP issues and investigate it from a number of viewpoints, including the consumer view of the commodification and commercialisation of taonga Māori. From these investigations, Māori can continue to shed light on Māori IP rights and create sustainable pathways forward to guide the commercial use of taonga Māori.

\subsection{Research Purpose and Objectives}

The purpose of this research is to understand consumers' perceptions of authenticity, specifically in the context of indigenous (Māori) brands and values. Precisely, the three primary research objectives are:

- Firstly, to investigate the effect of indigenous branding practices (exemplified in the cultural appropriation of Māori language and symbols) on consumers' authenticity perceptions.

- Secondly, to investigate the boundary conditions of the effect of indigenous branding practices (exemplified in the cultural appropriation of Māori language and symbols) on consumers' authenticity perceptions, involving indigenous organisational values (exemplified in tikanga Māori values).

- Lastly, to investigate the boundary conditions of the interaction effect between indigenous branding practices (exemplified in the cultural appropriation of Māori language and symbols) and indigenous organisational values (exemplified in tikanga Māori values) on consumers' authenticity perceptions based on ethnic identification.

\subsection{Structure of the Thesis}

This thesis contains six chapters - first beginning with an introductory chapter, which is then followed with a review of relevant literature. Here, literature pertaining to branding, indigenous branding, identity theories, cultural appropriation, perceived authenticity, and indigenous organisational values, are examined. The second chapter also details the research objectives, and the three hypotheses of the study. Chapter three details the methodological approach of the study, including research approach, design, sample, data collection, and analysis. Chapter four details the results of the hypotheses testing. Chapter five provides a discussion of the results of the hypothesis testing in light of the literature examined in chapter two. Finally, chapter six provides a summary of the conclusions, theoretical and practical contributions of the study, limitations and future research directions. 


\section{Chapter 2: Literature Review}

This chapter outlines two main streams of research from the marketing domains of branding and authenticity. However, this chapter is not limited to marketing research and encompasses research from an array of outside disciplines such as tourism and psychology. This chapter begins by reviewing the principal concepts within branding literature. Following this broader discussion of branding literature, the literature review narrows its scope to indigenous branding. The links between indigenous branding and consumer psychology are then discussed, alongside the associated benefits and issues that emerge within indigenous branding. Following the discussion of indigenous branding, this chapter turns to explore the concept of authenticity in marketing, highlighting the underexplored intersection between indigenous branding and authenticity. Finally, scholarship on organisational values is discussed, and the relationship between indigenous branding, authenticity and organisational values is explored.

\subsection{Branding}

During the 20th century, the concept of a brand underwent immense development from its early conception circa 1920 being limited to merely a name (Stern, 2006), to something indicative of a product's attributes and its functional benefits (Clark, 1927), and finally to becoming wholly inclusive of a product's emotional and self-expressive benefits (Arvidsson, 2005). Interestingly, it was also during this period of evolution that the perception of brand ownership simultaneously underwent a democratic transformation, as consumers became increasingly involved in the creation and maintenance of the meaning of brands (Bastos \& Levy, 2012). Branding now plays an important role in most organisations as a result of the growing realisation of the symbolic value of brands (Aaker, 1996; Cova, 1997; Cova \& Cova, 2001; Kates, 2002; Holt, 2002; Dong \& Tian, 2009; Schulz \& Stout, 2010), the desire of organisations to enhance their marketing effectiveness (Keller, 1993; Keller, 2003; Keller \& Lehmann, 2006), and the mounting evidence of the financial value of brands (Arvidsson, 2005).

Levy's (1959) "Symbols for sale" is a cornerstone piece of literature which spurred mainstream recognition of the symbolic value of brands. This article proved pivotal during this transitional period for three reasons. Firstly, it challenged the thought that consumers are - or ever were functionally oriented, arguing instead that "people buy things not for what they are, but what they mean" (Levy, 1959, p. 118). Secondly, it argues that brands are symbols which in some way connect with, or serve to reinforce, the way that consumers think about themselves, and 
differentiate themselves from others (Levy, 1959). Lastly, the article proposed that the meanings of symbols are co-constructed by consumers and organisations (Levy, 1959). Levy's (1959) article was essential in expanding the concept of branding from "a name, term, sign, symbol, or design, or combination of them which is intended to identify the goods and services of one seller or group of sellers and to differentiate them from those of competitors" (Kotler, 1991, p. 442), to a ubiquitous concept which is symbolically constructed and consumed by a multitude of social actors in the marketplace (Aaker, 1996; Cova, 1997; Cova \& Cova, 2001; Kates, 2002; Holt, 2002; Dong \& Tian, 2009; Schulz \& Stout, 2010).

Numerous academic works which have contributed to the modern concept of branding have sought to establish a better understanding of how to make brands more effective, with the aim of improving brand equity and enhancing marketing productivity (Keller, 1993; Keller, 2003; Keller \& Lehmann, 2006; Li \& Wyer, 1994; McCracken, 1986; Park, Jun \& Shocker, 1996). Of particular importance are the studies by Keller $(1993,2003)$ and Keller \& Lehmann (2006). Keller (2003) argued that better market segmentation and improved linking of bands to other entities such as people, places, things, or additional brands, allowed for enhanced brand equity. In support of Keller's (2003) argument, several scholars have investigated and established that transfer effects occur from linking brands to other entities. Examples of transfer effects between brands and other entities include country of origin effects (Li \& Wyer, 1994), celebrity source effects (McCracken, 1986), and co-branding or ingredient brand effects (Park, Jun \& Shocker, 1996). However, gaps still exist in this research domain, specifically as to whether transfer effects exist between brands and indigenous culture.

Keller (1993) also contributed to the theme of branding effectiveness by suggesting that congruity among brand attributes enhances brand equity. Keller, along with Lehmann, expanded on this idea in 2006, suggesting that the success of brands can be enhanced when brand attributes work together to create synergistic effects (Keller \& Lehmann, 2006). These works have enabled marketers to improve their marketing productivity and efficiency (Keller, 1993), and create stronger brands that connect better with their audiences (Bastos \& Levy, 2012). Although research has recognised that brands can benefit from congruence among brand attributes and synergistic effects, there is a lack of clarity around the differing ways in which brands can benefit from congruence and synergistic effects when viewed from different perspectives. For example, it is unclear what impact congruence and synergistic effects would have on the perceived authenticity of a product. Given Brown's (2001) argument that the 
negotiation of authenticity is one of marketing's central themes, it would be of interest to explore whether congruence among brand attributes would have synergistic effects, and in turn, influence consumers' authenticity perceptions.

\subsection{Indigenous Branding}

Indigenous branding is a specific subset of branding which is present when a combination of names, terms, signs, symbols and stories that have unique associations with an indigenous culture are utilised as brand attributes (Thomas, 2015). These brand elements are used to express organisational values and brand identity, and establish a differentiated brand (Thomas, 2015). Furthermore, indigenous branding forms links with indigenous culture enables thus enabling the brand to connect to a wealth of cultural meanings, and effectively use such associations as leverage (Balmer, 2013; Holland \& Gentry, 1997; Keller, 2003). Previous research investigating indigenous brands has shown that indigenous branding gives valuable cultural distinctiveness to a brand (Harmsworth \& Tahi, 2008), and potentially creates a platform for organisations organisations to charge a premium price (Forbes \& Dean, 2013). However, it is interesting to note that despite previous research providing some indicators as to what indigenous branding is, and why it may be of value (Thomas, 2015), as a whole, indigenous branding remains a relatively underexplored concept in marketing literature. A potential reason put forth for this elementary exploration of indigenous branding is that market segmentation and the linking of brands to other entities, such as culture and indigeneity, is more of a recent phenomenon (Keller, 2003)

Despite there being scant marketing literature on indigenous branding, tourism research has developed a more nuanced understanding of this concept. Given that indigenous cultures are often a focal point drawing travellers into particular tourist destinations, tourism literature offers a breadth of insights into both indigenous branding and indigenous tourism. Indigenous tourism is defined by Hinch and Butler $(1996$, p.6) as "tourism activity in which indigenous people are directly involved either through control and/or by having their culture serve as the essence of the attraction". This dissertation will now turn to discuss two key issues which have emerged across indigenous tourism literature: power and control, and authenticity. These two issues are especially relevant to a discussion of indigenous branding and perceived authenticity in marketing, as the scholarship emerging from both issues can be used to inform branding decisions and influence consumers' authenticity perceptions. 
Due to the substantive influence dominating powers and control have upon indigenous groups, there exists a considerable body of research investigating notions of power and control. Such studies have developed dichotomous descriptions of tourism as either a tool of colonialisation, or a tool of decolonization (Bunten, 2010); as something which either silences indigenous voices, or serves to articulate them (Butler \& Hinch, 2007). Butler and Hinch (2007) continue to note that despite the fact that indigenous peoples have been involved with tourism since their pre-colonial encounters, indigenous ownership and control of indigenous tourism ventures is a relatively new phenomenon worldwide. The overwhelming control by non-indigenous peoples over indigenous tourism has meant that non-indigenous peoples have dictated the dialogue of indigenous peoples, often resulting in the misrepresentation of indigenous culture and history (Bunten, 2008; McIntosh, 2004; McIntosh \& Ryan, 2007; McIntosh, Zygadlo, \& Matunga, 2004). These patterns of power and control in tourism are similarly reflected in marketing yet are only recently coming to light in marketing literature. In contrast, tourism literature is continuing to make strides as studies are not only investigate power and control within indigenous tourism, but they are also focussing on solutions to transfer power and control back to indigenous populations so that they are able to exercise self-determination (Bunten, 2010; Butler \& Hinch, 2007).

The solution-centred investigations in tourism literature have found positive outcomes for organisations when indigenous peoples have power and control over tourism ventures. Moreover, Butler and Hinch (2007) suggest that there is a positive trend towards greater involvement of indigenous peoples in the planning, development and marketing of indigenous tourism ventures, which indicates that indigenous people are experiencing greater power and control in indigenous tourism. However, they argue that greater involvement and empowerment is still needed from indigenous people to ensure that tourism ventures communicate authentic indigenous stories and experiences (Butler \& Hinch, 2007). Similar to the finding of Butler and Hinch (2007), other recent studies identify the need for indigenous tourism ventures to embed indigenous values into their business model, in order to empower indigenous peoples within the organisation and foster cultural authenticity throughout the organisation (Bunten, 2010; McIntosh, 2004; McIntosh \& Ryan, 2007; McIntosh, Zygadlo, \& Matunga, 2004). Prior literature investigating the impact indigenous involvement and indigenous values upon internal (e.g. employees) notions of authenticity, has found a positive relationship between these factors (Bunten, 2010; McIntosh, 2004). However, these investigations do not model for consumers' perceptions of authenticity. Thus, an investigation 
of the impact of indigenous values upon consumer perceptions of authenticity would extend literature within both fields of tourism and marketing.

Alongside establishing ways in which organisations can create more authentic offerings, indigenous tourism studies have also worked to understand consumer perceptions of authenticity. These works can be used to informed marketers as the current body of marketing literature has yet to illuminate this concept in a marketing context. A number of indigenous tourism studies find that both indigenous and non-indigenous consumers are cognizant of the authentic use of indigenous culture in tourism offerings. For example, Butler and Hinch (2007, p. 322) argue that tourists exhibit sensitivity towards authenticity, even when they are "ignorant at an academic level about indigenous culture". Similarly, Bunten (2010) states that nonindigenous consumers can "sense the internal colonisation" in inauthentic tourism offerings, resulting in the rejection of such offerings. A limitation of these studies is that they tend to focus on non-indigenous use of indigenous culture, rather than the reverse. Notwithstanding this shortfall, these studies have emphasized the importance of authentic offerings and provide evidence that both indigenous and non-indigenous consumers are sensitive towards inauthentic use of indigenous culture. Moreover, these studies find that consumers enact their sensitivity towards inauthenticity by not endorsing tourism services which are perceived as inauthentic. While this literature is not indicative of how to promote authenticity, it does highlight that organisations should be wary of creating inauthentic offerings to either indigenous and nonindigenous consumers, as both indigenous and non-indigenous consumers create and maintain their sense of self through consuming goods and services which they perceive as being authentic (Ahearne, Bhattacharya \& Gruen, 2005; Cornwell \& Coote, 2005, Tajfel \& Turner, 1979).

\subsubsection{Indigenous Branding and Self Identity (Ethnic Identification)}

Marketing literature as a whole suggests that consumers' beliefs and values are important in the construction and consumption of brand meaning, as famously posited by Levy (1959), "people buy things not for what they are, but what they mean" (p. 118). A statement which reflects the widespread position of marketing scholars who agree that consumers buy goods not because of their functional benefits, but because of their symbolic value (Aaker, 1996; Cova, 1997; Cova \& Cova, 2001; Dong \& Tian, 2009; Kates, 2002; Holt, 2002; Schulz \& Stout, 2010). Furthermore, consumers' beliefs and values are important in the construction of brand meaning due to the democratisation of brand ownership which has occurred in recent 
years (Bastos \& Levy, 2012). As such, it is pertinent to consider the role of self, specifically consumers' social and ethnic identities, in the consumption of indigenous brands.

This present study draws upon the social identity theory to suggest that consumers' demand of indigenous brands is perhaps driven by their self-concept. Social identity theory posits that a person's sense of belonging to a particular group motivates that person to seek out and endorse products and experiences that are authentically characteristic of their group (Tajfel \& Turner, 1979). Consumers shape their sense of self and distinguish themselves from others in social situations through associating with organisations that have distinctive characteristics which they value (Ahearne, Bhattacharya \& Gruen, 2005; Cornwell \& Coote, 2005). Social identity theory has been thoroughly examined by marketing scholars who have established that social identity theory can explain how group membership positively influences consumer behaviour outcomes (e.g., purchase intention) (Ahearne, Bhattacharya \& Gruen, 2005; Cornwell \& Coote, 2005, Tajfel \& Turner, 1979). From the considerable body of literature regarding social identity theory, it is possible to infer that consumers will prefer, and therefore purchase, brands which have attributes which are congruent with the consumers' self-concept.

Another, more nuanced self-concept is ethnic identification, which measures how strongly individuals identify with their ethnicity (Minor-Cooley \& Brice, 2007). Ethnic identification is measurable as it is an affiliative construct which is influenced by racial, natal, symbolic and cultural factors (Minor-Cooley \& Brice, 2007), such as feelings of belongingness, thoughts and associated behaviours (Stayman \& Deshpande, 1989). The strength of ethnic identification is dependent on one's level of cultural immersion, and reflective of their levels of cultural knowledge (Appiah, 2001; Grier \& Brumbaugh, 1999). Previous research has suggested that consumers with high levels of ethnic identification, and therefore high levels of cultural knowledge, are better able to understand, evaluate, and be more discerning of the authentic use of marketing messages targeted at their specific ethnicity (Appiah, 2001; Grier \& Brumbaugh, 1999; Holland \& Gentry, 1997). Therefore, it is likely that a consumer's ethnic identification will influence their ability and motivation to understand and perceive the authenticity of indigenous brands.

However, to the author's knowledge, studies have yet to examine how the ethnic identification of Māori participants may influence how authentically they perceive brands to be. It is possible that the results of studies examining Māori participants could differ to other ethnicities, due to 
the urbanisation of Māori. The urbanisation of Māori occurred in NZ in the 1950's, whereby a substantive wave of migration saw traditionally rural dwelling Māori move inwards towards urban centres, thus resulting in a permanent change to the traditional Māori dynamic as many cultural ties were weakened or lost (Bargh, 2016). Many urbanised Māori today are still disconnected from their culture, and therefore may have lower levels of ethnic identification and cultural knowledge. In turn, this may result in different Māori groups exhibiting heterogeneous perceptions and behaviours in response to marketing messages. Therefore, it is of interest to further examine the role of ethnic identification in Māori consumers' perception of authenticity to better understand this relationship.

\subsubsection{Indigenous Branding Elements}

Although previous research has thoroughly examined the reason for, and use of, branding elements (e.g. brand name and symbol) for organisations, the complexities of indigenous branding elements, and how they can be utilised in order to influence consumers' perceptions of authenticity, has yet to be fully investigated.

Many studies find that branding elements (e.g. brand name and symbols) are important for organisations as they communicate deeper meanings, and positively affect consumers' perceived quality of a brand and purchase intention (Baker, 2003; Dodds, Monroe \& Grewal, 1991; Keller, Heckler \& Houston, 1998, Levy, 1959). Moreover, research has established that the meanings derived from branding elements are co-constructed by organisations and consumers, as consumers play a pivotal role in assigning value to symbols (Bastos \& Levy, 2012; Pierce, 1974). Therefore, organisations must fully consider what their symbols mean to their specific consumers, or risk adverse reaction. For example, ethnic marketing research finds that branding elements reflective of ethnic minorities must be relevant to the product or brand they are attached to, or otherwise risk members of the ethnic minority displaying unfavourable attitudes or rejection towards the product or brand (Cui, 1997; Pires \& Stanton, 2000, 2002; Wilkinson \& Cheng 1999).

Indigenous branding elements have particularly strong associations with indigenous cultures and are seen to represent institutionalised values and beliefs of that culture (Holland \& Gentry, 1997; Koeman, Jaubin, \& Stesmans, 2010; Sung \& Tinkham, 2005; Thomson, 2015). As indigenous branding elements have strong, unique associations with an indigenous culture (Thomson, 2015), it is possible that they can be used to communicate authentic attributes such 
as a connection to the past, and a commitment to values and principles (Napoli, Dickinson, Beverland \& Farrelly, 2014). However, it is not clear whether the communication of authentic attributes results in enhanced authenticity perceptions for consumers. Moreover, it is not clear whether both indigenous and non-indigenous consumers are motivated and able to discern the meaning of cultural symbols, or whether this is limited to indigenous consumers. If further research were able to confirm that indigenous branding elements are able to communicate authentic attributes, then that would provide strong guidance for practitioners who wish to utilise indigenous brands.

\subsection{The Issue of Cultural Appropriation}

The concept of cultural appropriation has been examined from a multitude of views within academic literature. Rogers (2006) defines cultural appropriation as instances where symbols, artefacts, genres, rituals or technologies are taken out of their original context and placed in a commercial context. Similarly, Schneider (2003) defines cultural appropriation as instances where cultural knowledge and customs are used outside of their original context, such as when they are commercialised and commodified. In contrast, Matthes (2016) defines cultural appropriation as instances where dominant groups gain from and speak for marginalised groups, which in turn perpetuates power asymmetries and homogenises the stereotypes of marginalised groups. Following Matthes (2016) definition of cultural appropriation, this study posits that cultural appropriation occurs when dominant groups (e.g. Pākehā) gain from and speak for marginalised groups (e.g. Māori). This study acknowledges the perspectives of Rogers (2006) and Schneider (2003), who argue that cultural appropriation occurs when cultural elements are used outside their original context, as this does encapsulate its negative connotations. However, for this study, this definition is argued to be too broad.

Negative connotations surrounding the use of indigenous cultural elements by organisations typically arise due to concerns that incidences of cultural appropriation degrade the culture in some way, or perpetuate power imbalances (Matthes, 2016; Riley \& Carpenter, 2015; Schneider, 2003). However, it is important here to highlight that not all cultural appropriation degrades cultures or perpetuates power imbalances. Cultural appropriation exists on a continuum, with some instances (e.g. those that degrade the culture) being worse than others. It is the degree of cultural appropriation that is likely to influence perceptions of indigenous brands (Schneider, 2003). Cultural appropriation that degrades indigenous cultures and perpetuates power imbalances, is most likely to negatively influence consumer perceptions of 
an organisation (Matthes, 2016; Riley \& Carpenter, 2015). However, consumer perceptions of cultural appropriation should not be conceptualised as homogenous, as there are many conflicting views between Māori and Pākehā over the commodification and commercialisation of Māori culture (Lai, 2016). Moreover, perceptions of cultural appropriation should not be thought to be homogeneous among groups, nor individuals (Mattes, 2016). The conflicting views between Māori groups and individuals (Solomon, 2000) means that while some may be in support of the dissemination of culture, others may be firmly opposed to it at any extent (Lai, 2016). Therefore, organisations wishing to utilise aspects of Māori indigenous culture should be wary of criticisms of cultural appropriation emerging from a broad and diverse audience and make efforts to understand some of the underlying reasons for different groups' potential adversity.

One factor which may influence an individual's perceptions of cultural appropriation is their ethnic identification. Matthes (2016) finds that group members have the most in-depth understanding of their group membership and are therefore likely to have the most active interest in distinguishing between insiders and outsiders. However, Matthes' (2016) study focused on appropriation in the arts, rather than in commerce. Thus, further investigations are needed in order to establish whether differences exist between indigenous group members and non-members for distinguishing insiders and outsiders who use indigenous cultural brand elements. This is a particularly salient issue in New Zealand as aspects of Māori culture are a part of the nation brand, meaning that both indigenous and non-indigenous New Zealand consumers may perceive themselves to be Māori cultural insiders.

In summary, there exist a myriad of views which question the commercialisation and commodification of Māori culture. Some categorically oppose the use of Māori cultural heritage, some only support the use if it is within the confines of Māori customary law, and some fully endorse its use irrespective of context (Lai, 2016). Moreover, the body of research indicates that some uses of Māori culture in a commercial context (e.g. uses which constitute cultural appropriation) result in consumers forming negative perceptions of organisations. Yet despite these risks, organisations continue to commercialise and commodify indigenous cultural elements, thus risking cultural appropriation. As such, there is a need for researchers to establish how organisations can successfully implement Māori culture into their organisations, not only for the organisations themselves, but for Māori and non-Māori consumers alike. In response to this need, this study seeks to understand how organisations can 
authentically utilise Māori branding in order to minimise criticisms of cultural appropriation and enhance perceptions of brand authenticity.

\subsection{Perceived Authenticity}

Authenticity is defined as something genuine, real, and true (Beverland \& Farrelly, 2010). It is important for both practitioners and academics to understand the implications of authenticity, as the negotiation of authenticity is arguably one of marketing's central themes (Brown, 2001). Numerous studies aiming to establish the mechanisms and outcomes of achieving authentically perceived brands further highlight the centrality of the concept of authenticity (e.g. Beverland, Lindgreen \& Vink, 2008; Holt, 2002; Napoli, et al., 2014). Studies have shown a myriad of positive correlations between perceived brand authenticity and purchase intention, emotional brand attachment, and brand choice likelihood (Morhart, et al., 2015; Napoli, et al., 2014). However, gaps remain in the current body of research. For example, the relationship between indigenous culture and perceived authenticity is not clear, nor is it clear how organisations can utilise indigenous branding elements to influence perceptions of authenticity (Fritz, Schoenmueller \& Bruhn, 2017; Kolar \& Zabkar, 2010).

Despite the lack of clarity surrounding the intersection between indigenous branding and authenticity, research has shown that organisations are engaging with indigenous branding (therefore engaging in cultural appropriation) in order to create stronger connections with their consumers (Cui, 1997; Knobloch-Westerwick \& Coates, 2006). Additionally, consumers seek to affirm their identity by endorsing brands which possess authentic representations of their culture (Cui, 1997; Knobloch-Westerwick \& Coates, 2006). This suggests that despite the lack of research specifically devoted to authenticity and indigenous branding, both consumers and organisations continue to endorse indigenous branding. Therefore, scholars should seek to bridge this theoretical gap and further examine authenticity and indigenous branding.

Research investigating authenticity in general, have found that perceptions of authenticity can be enhanced through implementing symbols that communicate alignment between the audience, consumption context, and brand (Grayson \& Martinec, 2004), and the symbols that communicate authentic messages (Beverland, Lindgreen \& Vink, 2008; Morhart, et al., 2015). The findings of previous research on the relationship between symbols and authenticity may lend itself to the use of indigenous symbols as brand elements. Further research should confirm this relationship, as the current body of literature which has addressed the role of symbols in 
the determination of perceived authenticity has not specifically focussed on symbols as brand elements (Holland \& Gentry, 1999), nor has it focussed on indigenous symbols.

Scholars have also demonstrated a cursory exploration of the intersectionality between ethnic identification and authenticity. Research in this area finds that consumers draw on cultural knowledge in order to determine the stylistic and contextual use of a symbol, which then leads to attributions of authenticity (Appiah, 2001; Grier \& Brumbaugh, 1999). Due to the role cultural knowledge plays in consumers' determination of authentic symbols, consumers who strongly identify with the culture conveyed in the symbol are more likely to be discerning of the authentic use of the symbols. Unfortunately, the role of ethnic identification in authenticity perceptions has yet to be confirmed in literature; however, if this relationship were to be confirmed, it would provide interesting insights for both practitioners and academics alike.

In conclusion, research tends to suggest that a relationship could exist between indigenous culture and perceived authenticity, and that indigenous branding elements may enhance perceptions of authenticity. However, these relationships have yet to be confirmed. If these relationships were to be confirmed, it would provide strong guidance for practitioners who wish to employ the use of indigenous branding elements in an authentic manner.

\subsubsection{Authenticity and Indigenous Organisational Values}

Organisational values are a mechanism through which organisations can communicate to their consumers' information about who they are, how they connect with individuals and groups in society (Auster \& Freeman, 2013), and also set the standard for how an organisation is expected to act (Blodgett, Dumas \& Zanzi, 2011). Indigenous organisational values are values which are influenced by elements of indigenous culture and are often geared towards financial, environmental, social and cultural development (Best \& Love, 2010).

While many recent studies have investigated indigenous organisational values present in organisations (e.g. Best \& Love, 2010; Davies, Lattimore \& Ikin, 2005; Harmsworth, 2002; Harmsworth, Barclay-Kerr \& Reedy, 2002), there has been a tendency among scholars to focus on the identification of values. In contrast, few studies have sought to examine how values can be used as a communications tool, nor what effects these values may have on consumers' brand perceptions. Nonetheless, there are a number of studies which do suggest that indigenous organisational values could have an effect on perceived authenticity. Firstly, research on 
organisational values in the mainstream has found that organisational values can enhance consumers' perceptions of authenticity towards a company, product or brand (e.g. Auster \& Freeman, 2013; Mazutis \& Slawinski, 2015). Secondly, other studies find that indigenous businesses are identifiable by their embedded indigenous values (Best, Adds \& Mercier, 2013; Best \& Love, 2010). Specifically, those with practices which acknowledge indigenous values and philosophies that are important for indigenous peoples but may not be the best practices from a commercial perspective (Best, Adds \& Mercier, 2013; Best \& Love, 2010). As indigenous values are a distinctive attribute of indigenous organisations, consumers may perceive organisations with indigenous values as more authentically indigenous than those without indigenous values. It would, however, be valuable to further investigate the relationship between indigenous organisational values and perceived authenticity, in order to confirm such effects.

Auster \& Freeman's (2013) study suggests that there exists a relationship between organisational values, authenticity and self-identity, which indicates that organisational values can be used as a communications tool. Specifically, Auster and Freeman (2013) suggest that organisational values are able to exert the most leverage from attributions of authenticity when value fit occurs. Value fit is said to occur when the values of an organisation connect with the values of the consumer, and when the values of the organisation are actioned (Auster \& Freeman, 2013). Despite providing an indication that there exists a relationship between organisational values, authenticity, and self-identity, the study by Auster and Freeman (2013) was nonetheless rudimentary and contained three significant gaps which other researchers have yet to fill. Firstly, the study did not directly examine consumers' ethnic identification as a part of their self-identity. Secondly, the focus was on organisational values in general, rather than indigenous organisational values. Finally, the study did not look beyond organisational values to consider possible synergistic effects across organisational communications, such as indigenous branding. A further investigation into these gaps identified in Auster and Freeman's (2013) research would be a logical progression of their study, and a valuable contribution to the current body of literature.

\subsection{Research Gap}

There are six prominent gaps emerging from the above literature: two gaps specific to indigenous branding and authenticity, two gaps specific to ethnic identification, and two gaps concerning indigenous organisational values. In respect to indigenous branding, it was first 
found that few studies have examined the relationship between perceived authenticity and indigenous culture (Ko, Lee \& Wang, 2013), and to the author's knowledge, no studies have examined the relationship between indigenous branding and perceived authenticity. Secondly, few studies have attempted to understand how indigenous product brand elements (e.g. brand name) influence perceived authenticity (Fritz, Schoenmueller \& Bruhn, 2017; Kolar \& Zabkar, 2010). It is important to further investigate both of these research gaps because within New Zealand, because within New Zealand, the use of Māori indigenous branding is not only present but increasing in its use by both indigenous and non-indigenous organisations alike (Feetham, Wright, Joe, 2018). However, little research has examined consumers' perceptions of these Māori indigenous brands, nor whether these perceptions are influenced by the type of organisation implementing them. Further clarity would not only fill this theoretical gap, but also provide valuable insights for marketers to inform their marketing strategies, specifically if they were to consider adopting a Māori indigenous branding approach.

Concerning ethnic identification, it was first found that few studies have examined the effect ethnic identification has on consumers' perceptions of authenticity. Secondly, to the author's knowledge, no studies have examined the effect of Māori ethnic identification on consumers' perceptions of authenticity. An investigation of Māori ethnic identity and its influence on Māori consumers' authenticity perceptions is of value for academia and practitioner marketing communities, as Māori consumers are unique to many other ethnic minorities and even other indigenous populations. These differences are largely owed to actions by the crown (e.g. Native Schools Act, 1867), and the urbanization of Māori which resulted in the majority of Māori experiencing a Westernised upbringing. Experiencing a Westernised upbringing may mean that Māori consumers walk in two worlds, and as such, are not strongly biased towards one world (e.g. Māori) over the other (e.g. Western). Conversely, the colonial history that has led to Māori experiencing a Westernised upbringing, coupled with the ongoing fight for their selfdetermination, may mean that Māori consumers are heavily biased towards Māori offerings. Not only would research investigating the impact of Māori ethnic identification on perceived authenticity help to answer some of these theoretical gaps, but this research would also provide valuable insights for marketers whose target audience is Māori.

Finally, concerning indigenous organisational values, it was first found that, to the author's knowledge, no studies have examined the relationship between indigenous organisational values and perceived authenticity. Secondly, to the author's knowledge, no studies have sought 
to understand whether synergistic effects occur when organisations implement indigenous branding elements and indigenous organisational values, and what effect these have on consumers' perceptions of authenticity. It is important to investigate the effect of indigenous organisational values upon consumers' authenticity perceptions, as consumers are becoming increasingly sceptical towards marketing efforts, and instead turn to other organisational cues to form their opinions of organisations (Skarmeas \& Leonidou, 2013). As indigenous organisational values are a distinctive characteristic of indigenous organisations, consumers may use this information to ascertain their authenticity perceptions, however this has yet to be confirmed by the literature. Greater clarity on the relationship between indigenous organisational values and perceived authenticity would aid in the strategizing of organisations with indigenous organisational values, in particular, whether to communicate these values or not.

\subsection{Research Objectives}

To contribute to the current body of literature, and specifically to shed light upon the aforementioned gaps in the literature, the purpose of this research is to understand consumers' authenticity perceptions in the context of indigenous (Māori) brands and values.

Specifically, the three primary research objectives are to:

- Firstly, investigate the effect of indigenous branding practices (exemplified in the cultural appropriation of Māori language and symbols) on consumers' authenticity perceptions.

- Secondly, investigate the boundary conditions of the effect of indigenous branding practices (exemplified in the cultural appropriation of Māori language and symbols) on consumers' authenticity perceptions, involving indigenous organisational values (exemplified in tikanga Māori values).

- Lastly, investigate the boundary conditions of the interaction effect between indigenous branding practices (exemplified in the cultural appropriation of Māori language and symbols) and indigenous organisational values (exemplified in tikanga Māori values) on consumers' authenticity perceptions based on ethnic identification.

In addressing these objectives, this research will add to the current understanding of how consumers' perceptions of authenticity are influenced by indigenous (Māori) brand elements and values, and explore the moderating impact of ethnic identification. 


\subsection{Hypothesis Development}

\subsubsection{The Effect of Indigenous Branding}

Indigenous branding utilises elements (e.g. brand names and symbols) that represent the values and beliefs of a culture (Holland \& Gentry, 1997; Sung \& Tinkham, 2005; Thomson, 2015). As indigenous branding is inextricably linked to a specific indigenous culture, these brands can leverage off the associations of the culture they are connected to (Balmer, 2013; Holland \& Gentry, 1997; Keller, 2003). However, research on the subject of indigenous branding tends to focus on identification, rather than the examination of potential outcomes. This has resulted in a limited body of research seeking to quantify the value and effects of indigenous branding (Feetham, Wright \& Joe, 2018). Despite this, numerous studies in broader marketing literature have examined the effect of branding in general, and its effects on authenticity and purchase intention. These studies will serve to inform the first hypothesis and are discussed below.

There is consensus among scholars that branding elements (e.g., brand name and symbols) can communicate deeper meanings, as well as positively affect consumers' perceived quality of a brand and their purchase intention (e.g., Baker, 2003; Dodds, Monroe \& Grewal, 1991; Keller, Heckler \& Houston, 1998, Levy, 1959). Moreover, Napoli, et al., (2014) suggest that branding elements (e.g. brand name and symbol) can be used to communicate authentic attributes, such as a connection to the past and a commitment to values and principles. Finally, numerous researchers find that symbols which communicate alignment between the audience, consumption context, and brand, can enhance consumer perceptions of authenticity (Beverland, Lindgreen \& Vink, 2008; Grayson \& Martinec, 2004; Morhart, et al., 2015). As a significant number of studies have established that symbols can enhance consumers' perceptions of authenticity (Baker, 2003; Dodds, Monroe \& Grewal, 1991; Keller, Heckler \& Houston, 1998, Levy, 1959) there is reason to believe that indigenous symbols in a branding context will also enhance consumers' perceptions of authenticity. Thus, this study hypothesises:

H1. Indigenous (e.g. Māori) branding will positively affect consumers' perception of brand authenticity.

\subsubsection{The Moderating Effect of Organisational Values}

Keller and Lehmann (2006) suggest that the success of brands can be enhanced when brand attributes work together to create synergistic effects. Therefore, this hypothesis aims to 
determine whether synergistic effects occur when indigenous branding and indigenous organisational values are used in conjunction.

Literature tends to suggest that organisations can implement branding elements (e.g. brand name and symbol) in order to communicate authentic attributes, such as a connection to the past and a commitment to values and principles, and thus, enhance consumer perceptions of authenticity (Beverland, Lindgreen \& Vink, 2008; Grayson \& Martinec, 2004; Morhart, et al., 2015; Napoli, et al., 2014). As such, the first hypothesis of this study (H1) suggests that indigenous branding elements will also enhance consumer perceptions of authenticity. However, it is not only branding elements which have been found to influence consumers' perceptions of authenticity, but also organisational values (Auster \& Freeman, 2013; Mazutis \& Slawinski, 2015). Thus, the second hypothesis of this study (H2) suggests that indigenous organisational values will also enhance consumer perceptions of authenticity.

When viewed in conjunction, the conclusion that emerges from the aforementioned literature on branding elements (e.g. Beverland, Lindgreen \& Vink, 2008; Grayson \& Martinec, 2004) and organisational values (e.g. Auster \& Freeman, 2013; Mazutis \& Slawinski, 2015), is that both brand elements and organisational values can enhance consumer perceptions of authenticity. Similarly, one can predict that indigenous brand elements and indigenous organisational values can enhance consumers' perceptions of authenticity. Moreover, in keeping with the ideas expressed by Keller and Lehmann's (2006) that brand attributes can work together to create synergistic effects, it is expected that when indigenous brand elements and indigenous organisational values are used together, synergistic effects will occur.

H2: Brand communication emphasising indigenous (Māori) organisational values (e.g. tikanga Māori) will moderate the effect of indigenous (e.g. Māori) branding on consumers' perception of brand authenticity.

2.7.3 The Three-way Moderating Effect of Indigenous Ethnic Identification This hypothesis investigates a three-way interaction between indigenous branding elements, indigenous organisational values, and ethnic identification. As mentioned previously, the body of literature tends to suggest that both branding elements (e.g. (Beverland, Lindgreen \& Vink, 2008; Grayson \& Martinec, 2004; Morhart, et al., 2015; Napoli, et al., 2014) and organisational values (e.g. Auster \& Freeman, 2013; Mazutis \& Slawinski, 2015) can enhance consumer 
perceptions of authenticity. Similarly, it was predicted that indigenous brand elements and indigenous organisational values could enhance consumers' perceptions of authenticity. Moreover, in light of the ideas expressed by Keller and Lehmann's (2006) study that brand attributes can work together to create synergistic effects, it is expected that when indigenous brand elements and indigenous organisational values are used together, synergistic effects will occur. However, the success of these synergistic effects is predicted to be mostly dependent on the extent to which a consumer identifies with the indigenous ethnicity that is present in the indigenous brand elements and indigenous organisational values.

While there appears to be no research at present which specifically investigates the intersection between indigenous brand elements, indigenous organisational values, ethnic identification and perceived authenticity, Auster and Freeman's (2013) study does investigate organisational values, self-identity and perceived authenticity. In their study, Auster and Freeman (2013) find that organisational values can exert the most leverage off attributions of authenticity when value fit occurs (when the values of an organisation connect with the values of the consumer, and when the values of the organisation are actioned). Therefore, this study indicates that indigenous organisational values will exert the most leverage off attributions of authenticity when the indigenous organisational values are actioned, and when they connect with the ethnic identification of an individual.

The ethnic identification of an individual is dependent on their level of cultural immersion and reflective of their levels of cultural knowledge (Appiah, 2001; Grier \& Brumbaugh, 1999). As mentioned, there is a significant body of research which indicates that consumers with high levels of ethnic identification are better able to understand, evaluate and discern the authentic use of marketing messages targeted at their specific ethnicity (Appiah, 2001; Grier \& Brumbaugh, 1999; Holland \& Gentry, 1997). Similarly, social identity theory posits that a consumers' sense of belonging to a particular group motivates them to seek out and endorse products and experiences that are authentically characteristic of their group to distinguish themselves from cultural outsiders (Tajfel \& Turner, 1979).

In light of the aforementioned literature, it is hypothesised that the synergistic effects that occur from using congruent indigenous brand elements and indigenous organisational values are likely to exert more leverage on consumers' perceptions of authenticity when the consumers' ethnic identity matches that of the brand. Moreover, when the indigenous brand elements and 
indigenous organisational values are incongruent, consumers with high ethnic identification will likely be more discerning of this incongruence, and in turn, negatively influence their perceptions of authenticity.

H3. The three-way interaction between indigenous (e.g. Māori) branding, brand communication emphasising indigenous (e.g. Māori) organisational values and ethnic (Māori) identification will be significant. 


\section{Chapter 3: Methodology}

The following chapter outlines the methods employed to conduct the study. The chapter begins by discussing the research paradigm; it then continues to justify the research approach, methodology, and specific methods chosen for the study.

\subsection{Research Approach}

The research approach is a set of philosophical assumptions which represents the way in which the researcher views the world, and their perception of the construction of knowledge (Creswell, 2014; Deshpanade, 1983). The research paradigm guides the researcher's interpretation of problems and creation of solutions (Kuhn, 1996). Academic literature is dominated by Western research paradigms, which range from positivist to constructivist. However, they are not the only research paradigms, and through embracing non-dominant research paradigms, researchers can bring new perspectives and life to the research community. The research paradigm for the current study is a Kaupapa Māori research paradigm, which is research about Māori, conducted by Māori, and in the interests of Māori (Smith, 2015).

Kaupapa Māori research emerged as part of a broader resistance by Māori to the ongoing legacies of colonisation in New Zealand, and its disproportionately adverse effects on the Māori population (Mihaere, 2015). Western research was specifically identified as a mechanism through which power imbalances between Māori and Pākehā were reinforced, which highlights the need for a Māori alternative (Smith, 1999). Western research has served to both create and maintain power imbalances through reinforcing the superiority of Pākehā knowledge and denying the legitimacy of Māori knowledge and experiences (Smith, 1999). As such, research on, or about Māori has often been deficit-based and resulted in disproportionally unfavourable outcomes for Māori (Jahnke \& Taiapa, 2003; Walker, Eketone \& Gibbs, 2006). Therefore, Kaupapa Māori research is not just a methodological approach, but also a form of resistance to the dominant Western research paradigms (Walker, Eketone \& Gibbs, 2006). Researchers who embrace Kaupapa Māori research are able to reflect a Māori worldview and empower strong, positive Māori aspirations (Te Ariki \& Spoonley, 1992).

As mentioned, the research paradigm represents the way in which the researcher views the world (Creswell, 2014, Deshpanade, 1983), and as such, is influenced by the researchers lived experiences. Perhaps the most obvious influence on my life is my own Māori and Pākehā heritage. This heritage has meant I have walked in two worlds my whole life, constructing my 
identity between the Māori and Pākehā worlds, which has opened me up to a plethora of racial and social challenges, and in all honesty, a lot of confusion over my own cultural identity. Many facets of mainstream society contributed to this confusion, most especially the educational system. When the voices of mainstream society complimented me, it was often remarks about me being pretty, bright or talented for a Māori. Through my formative years in the education system, I learnt that Māori are more likely to be poor, unhealthy, in jail, addicted to drugs and less educated, than Pākehā. I learnt that the differences in the Treaty of Waitangi were superficial and unintentional. I learnt that colonialism is a part of history and is situated in the past. As a person who has always loved to learn, I could not reconcile what I learned of Māori and what I knew I wanted for my future. So, I learnt to be ashamed of being Māori, to hide it, and to cling to my Pākehā side.

It was not until I came to university and took an interest paper about "Māori in the workplace" in my second year, that I began to challenge the information I had been fed and the thoughts I had grown up with. From this one paper, I changed one of my majors to Māori Resource Management, which is taught through Te Kawa a Māui - the Māori faculty. It was here that I learnt to dig beneath statistics on wealth and health, and to question why these statistics exist. I learnt that Māori people are bright and successful too. Negative statistics about Māori are not a result of personal fault, but come to manifest through the ongoing, systemic effects of colonialism and its legacies. In Te Kawa a Maui - a place that privileged Māori ways of knowing and of being - I learnt to be proud of both sides of my heritage. So, it comes naturally to me to privilege a paradigm which empowers rather than subjugates, that has teased my mind open rather than forcing it shut. The paradigm I choose is Kaupapa Māori.

\subsection{Methodology}

Kaupapa Māori research is guided by six general principles and seven ethical principles (Walker, Eketone \& Gibbs, 2006). Many of these principles (e.g. kanohi kitea - present yourself to people face to face) lean themselves more naturally toward qualitative research (e.g. interviews), rather than quantitative research (e.g. experimental research). However, it has been argued that the primary concern of Kaupapa Māori research is to answer the research questions in the most appropriate way, and as such, Western based research methods (e.g. quantitative experiments) may be used (Barnes, 2000; Walker, Eketone, \& Gibbs, 2006). The current study uses a quantitative, experimental approach, yet at the same time adhering to the general and ethical principles of Kaupapa Māori. 
A quantitative, experimental approach is most appropriate to answer the research questions and objectives of the current study for a number of reasons. Firstly, the current study has identified relationships between constructs based on previous literature and seeks to test these relationships (Creswell, 2014). Secondly, previous research on authenticity has utilised a quantitative, experimental approach (e.g. Morhart, et al., 2014). Third, an experimental design allowed the researcher to manipulate the variables while holding other factors constant, thus mitigating the effects of unknown factors (Zikmund, Babin, Carr \& Griffin, 2013). Given that the current study utilises a quantitative, experimental approach, and that the principles of Kaupapa Māori research typically align with qualitative methods, the researcher has operationalised the principles and ethics of Kaupapa Māori to better align with quantitative experimental methods. The adaptation of the Kaupapa Māori principles can be seen in Table 1. Additionally, Kaupapa Māori research necessitates the application of additional ethics which must be honoured in research, over and above requirements determined by an ethics committee or research methodology (Brewer, Harwood, McCann, Crengle, \& Worrall, 2014). These ethical requirements have been operationalised below in Table 2. 
Table 1: Adaptation of Kaupapa Māori Principles

\begin{tabular}{|l|l|}
\hline Original Principle & Explanation of Principle \\
\hline $\begin{array}{l}\text { Tino } \\
\text { Rangatiratanga }\end{array}$ & $\begin{array}{l}\text { This principle requires that Māori should have } \\
\text { greater autonomy in the choice and making of key } \\
\text { decisions and are able to exercise control over } \\
\text { processes and outcomes (Smith, 1997). }\end{array}$ \\
\hline $\begin{array}{l}\text { Taonga tuku iho } \\
\text { Cultural aspiration }\end{array}$ & $\begin{array}{l}\text { This principle emphasises that Māori ways of } \\
\text { doing, knowing, and understanding are valid in } \\
\text { their own right (Smith, 1997). As such, aspects of } \\
\text { Te Ao Māori should guide and be implemented in } \\
\text { the research process. }\end{array}$ \\
\hline
\end{tabular}

Ako Māori

Culturally preferred pedagogy

Kia piki ake i nga raruraru o te kainga

Socioeconomic mediation
This principle requires researchers to prioritise Māori ways of teaching and learning that are unique to tikanga Māori (Pihama, Smith, Taki \& Lee, 2004). However, it is important to not ignore "borrowed" pedagogies from other cultures (Smith, 1997). Moewaka-Barnes (2000) argues that methods such as qualitative and quantitative approaches can be adopted to serve the purpose of the Kaupapa Māori research.

This principle requires researchers to consider ways in which they might, through their research, alleviate the negative pressures and socioeconomic disadvantage faced by Māori communities (Smith, 1997).

\section{Interpretation of Principles}

The researcher is Māori; she has full autonomy in key decision making and has exercised control over processes and outcomes.

The researcher is a Māori researcher. Because of this, Māori ways of doing and understanding have informed the study. This principle has been expressed in a number of ways, such as adapting the ethnic identification scale to better suit a Māori context.

The purpose of the current study is to examine the effects of Māori branding practices and values on consumers' perceptions of authenticity. Quantitative approaches (specifically an online questionnaire) have been both adopted and adapted.

Negative pressures and socioeconomic disadvantage can be exacerbated by dominant cultures benefitting from the commercialization of Māori culture, and making it more difficult for Māori to become competitive in this space.

By understanding the antecedents and outcomes of the commercialization of Māori culture, this study may enable 


\begin{tabular}{|l|l|l|}
\hline $\begin{array}{l}\text { Whānau } \\
\text { Extended family } \\
\text { structure }\end{array}$ & $\begin{array}{l}\text { Māori organisations to become more competitive in this } \\
\text { space. } \\
\text { collective responsibility, and to emphasise } \\
\text { cultural values, customs and practises throughout } \\
\text { the research process (Pihama, Smith, Taki \& Lee, } \\
2004\end{array}$ & $\begin{array}{l}\text { While this principle lends itself more towards qualitative } \\
\text { research, researchers employing quantitative research } \\
\text { methods can embrace the spirit of this principle through } \\
\text { engaging with multiple Māori stakeholders to help guide them } \\
\text { through the creation, analysis and dissemination of the } \\
\text { research. }\end{array}$ \\
\hline $\begin{array}{l}\text { Kaupapa } \\
\text { Collective } \\
\text { philosophy }\end{array}$ & $\begin{array}{l}\text { This principle requires the researcher to adopt a } \\
\text { broad, collective perspective that looks to achieve ongoing engagement, Kaupapa Māori } \\
\text { aspirations of the Māori community (Pihama, } \\
\text { researchers ensure there is an element of collective } \\
\text { responsibility and can create research that aligns with the } \\
\text { cultural values, customs and practices of Māori. }\end{array}$ \\
\hline $\begin{array}{l}\text { Smith, Taki \& Lee, 2004). } \\
\text { aspirations of the Māori community, as it aids in creating a } \\
\text { better understanding of consumers' perceptions of the } \\
\text { commercialisation of Māori intellectual property. This is an } \\
\text { area which has been much debated, as evidenced by its } \\
\text { significant role in the WAI262 report. }\end{array}$
\end{tabular}




\begin{tabular}{|c|c|c|}
\hline & Explanation of Principle & Interpretation of Principles (if necessary) \\
\hline $\begin{array}{l}\text { Aroha ki te } \\
\text { tangata } \\
\text { A respect for the } \\
\text { people }\end{array}$ & $\begin{array}{l}\text { This principle requires the researcher to ensure that } \\
\text { participants are able to meet on terms that the } \\
\text { participants create and ensure that the participants } \\
\text { can define their own space (Cram, 2001). }\end{array}$ & $\begin{array}{l}\text { An online experimental study is fully voluntary and anonymous, } \\
\text { meaning that participants are not pressured in any way to participate in } \\
\text { the research. If they do choose to engage with the research, participants } \\
\text { are able to choose when and where they wish to do so, thus enabling } \\
\text { them to both create and define their own space. }\end{array}$ \\
\hline $\begin{array}{l}\text { Kanohi kitea } \\
\text { Present yourself } \\
\text { to people face to } \\
\text { face }\end{array}$ & $\begin{array}{l}\text { This principle requires the researcher to be willing } \\
\text { and comfortable to cross the role divide between } \\
\text { the researchers and the researched (Cram, 2001). }\end{array}$ & $\begin{array}{l}\text { Questionnaire-based research does not allow for face to face } \\
\text { presentation. However, by presenting their contact details at the } \\
\text { beginning of the questionnaire, the researcher opens the door for } \\
\text { communication if the participant chooses to pursue it. Moreover, steps } \\
\text { were taken prior to, and post data collection to create and maintain } \\
\text { communication with stakeholders. These steps included engaging with } \\
\text { Māori stakeholders, and planning the dissemination to share the } \\
\text { research with key community groups and stakeholders. }\end{array}$ \\
\hline $\begin{array}{l}\text { Titiro, } \\
\text { whakarongo } \\
\ldots \text { kōrero } \\
\text { Look, listen ... } \\
\text { speak }\end{array}$ & $\begin{array}{l}\text { This principle requires the researcher to learn } \\
\text { through first looking and listening to the } \\
\text { participants, before speaking themselves } \\
\text { throughout the entire research process (Cram, } \\
\text { 2001). }\end{array}$ & $\begin{array}{l}\text { During the researcher's undergraduate studies in Māori Resource } \\
\text { Management (MRM), the researcher underwent a process of looking } \\
\text { at and listening to both the historical and contemporary issues faced by } \\
\text { Māori. Of particular importance in MRM, were the issues surrounding } \\
\text { the WAI262 report (e.g., intellectual property rights). } \\
\text { Additionally, the researcher's undergraduate studies in marketing } \\
\text { resulted in her becoming more attuned to trends within marketing. } \\
\text { From this process of looking and listening, driven by both } \\
\text { undergraduate schools (MRM and Marketing), the researcher began to } \\
\text { notice examples in her everyday life of the issues surrounding Māori } \\
\text { intellectual property rights, as highlighted in WAI262. A key example }\end{array}$ \\
\hline
\end{tabular}




\section{Manaaki ki te} tangata

Share and host people; be generous

\section{Kia tupato}

Be cautious and careful

Kaua e takahia te mana o te tangata

Do not trample over the mana of people
This principle is guided by the idea of sharing and reciprocity (Cram, 2001; Smith 2005). Researchers are encouraged to view the research process as an equally constructed collaboration with participants. This principle also requires the researcher to share the research findings with participants. is the brand Tī Ora, which utilises Māori branding in the name, however Tī Ora is owned by JDE - a Dutch company.

In the current study, the location which participants were hosted was the online questionnaire. Therefore, the researcher took steps to ensure that guests were comfortable and respected on this platform. These steps included:

- A clean professional design.

- Clear concise language - no overly technical language, but also no overly informal language (slang) used.

- A reasonable length of survey, as to not waste participants time.

The current study required a minimum of 240 participants; therefore, it was not feasible to offer everyone something in return for their participation. However, all participants were equally presented with the opportunity to win one of four $\$ 50 \mathrm{New}$ World vouchers. Also, the researcher tried to account for all participants when creating the dissemination plan.

This principle cautions researchers' to be "politically astute, culturally safe, and reflective about their insider/outsider status" (Smith, 2005, p. 98).

In the current study, the researcher strove to be politically astute, culturally safe, and reflective about her insider/outsider status. In addition to this, the researcher engaged with multiple Māori researchers, family and friends throughout the research process to ensure that the study met the above criteria.

The researcher has upheld engagement with all groups that have been involved in the formation of the research. However, due to the nature of experimental research, it is not possible to have engagement with the participants. 


\begin{tabular}{|l|l|l|}
\hline & $\begin{array}{l}\text { Notwithstanding its limitations, the researcher's dissemination plan } \\
\text { aims to give all key stakeholders an equal opportunity to learn the } \\
\text { outcomes of the study. }\end{array}$ \\
\hline $\begin{array}{l}\text { Kia mahaki } \\
\text { Do not flaunt } \\
\text { your knowledge }\end{array}$ & $\begin{array}{l}\text { This principle requires the researcher to be humble } \\
\text { when sharing knowledge. It is argued that through } \\
\text { following the other ethical guidelines, this principle } \\
\text { will be naturally achieved (Cram, 2001; Brewer, } \\
\text { Harwood, McCann, Crengle, \& Worrall, 2014). }\end{array}$ & $\begin{array}{l}\text { Alongside following the other ethical guidelines, this principle is met } \\
\text { through the communication by the researcher. In experimental } \\
\text { research, communication is largely mediated through the online } \\
\text { questionnaire. In this regard, the researcher consistently sought to } \\
\text { achieve a respectful tone in the construction of the survey and avoided } \\
\text { writing in overly technical language. Thus, the researcher created a } \\
\text { platform that enabled participants from a wide range of backgrounds } \\
\text { to understand the questionnaire. }\end{array}$ \\
\hline
\end{tabular}




\subsection{Research Design}

A quantitative approach with an experimental design was utilised in this research. The study employed an experimental, 2 (indigenous branding: orthodox vs. Māori) x 2 (organisational values: conventional vs. tikanga) x 2 (ethnic identification: identifies as Māori vs. identifies as other) factorial design (as depicted in Figure 1). Moreover, the design ensured that respondents were randomly assigned to one of the conditions.

Figure 1: Experimental Design

\begin{tabular}{|c|c|c|c|}
\hline \multirow{4}{*}{ 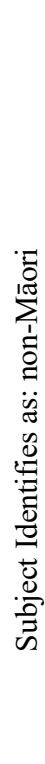 } & $\begin{array}{l}\text { Indigenous } \\
\text { (Māori) Branding }\end{array}$ & $\begin{array}{l}\text { Orthodox } \\
\text { branding }\end{array}$ & \\
\hline & $\bar{A}_{i \theta}$ & Bestuce & 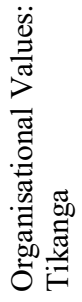 \\
\hline & $\bar{A} i \theta$ & Bistue & 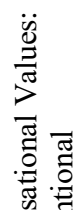 \\
\hline & & & 00 \\
\hline
\end{tabular}

\begin{tabular}{|l|l|l|l|}
\hline & $\begin{array}{l}\text { Indigenous (Māori) } \\
\text { Branding }\end{array}$ & $\begin{array}{l}\text { Orthodox } \\
\text { branding }\end{array}$ & \\
\cline { 2 - 4 } & & \\
\hline & & \\
\hline
\end{tabular}

The Qualtrics online survey hosting website was used to host data collection. Through this website, the author created an online experimental questionnaire (Appendix A). An online experimental questionnaire was thought to be an appropriate method for data collection for its ease of dissemination (Hair, Black, Babin, Anderson, \& Tatham, 2010), time efficiency (Wright, 2005), and relatively lower costs (when compared to offline methods) (Evans \& Mathur, 2005; Ilieva, Baron, \& Healey, 2002). Moreover, online questionnaires have been used by researchers investigating similar constructs to those in the current study. For example, Morhart, et al. 's (2014) study utilised an online questionnaire to investigate consumers' perceptions of authenticity.

Some critics of online questionnaires claim that the sample recruited may not be representative of the population (Hair, et al., 2010), and self-reporting errors may occur, whereby some participants may not spend adequate time processing the information in the survey and 
responding appropriately (Wright, 2005). In response to the first criticism, that the sample may not be representative of the entire population, the author argues that the online population is reflective of New Zealand's broader population as evidenced by there being over 3 million New Zealanders have Facebook accounts (whom are therefore internet users) - including over 280,000 users over age 65 (Statista, 2018). In response to the second criticism, the researcher conducted a number of quality control checks to minimise bias, including analysing the length of time taken to complete the survey (Geuens \& De Pelsmacker, 2017), and checking for careless response patterns, such as middle response patterns (Meade \& Craig, 2012). Moreover, participants were randomly assigned to the conditions, thus negating problems associated with questionnaire design.

In the experiment, the subjects were presented with a scenario (Appendix B), which informed them that an organisation was interested in their opinions on the proposed product design. The product chosen for this study was fortified water due to its current popularity and predicted future growth (Euromonitor, 2018). Moreover, in the broader fortified drinks market, there are brands which are currently using Māori branding. For example, the fortified tea brand Tī Ora has a Māori brand name and uses ingredients which have been used medicinally by Māori (e.g. kawakawa, horopito). However, to the author's knowledge, fortified water in New Zealand has yet to use Māori branding. As no fortified water brands have utilised Māori branding, and to avoid preconceived biases, the current study created fictitious fortified water brands for the scenario.

The experiment manipulated both branding elements and organisational values. The branding elements were manipulated by presenting participants with a stimulus image which featured either a Māori brand name and symbol, or an orthodox brand name and symbol (Figure 2). The hei matau was chosen as the Māori brand symbol due to its strong associations with Māori culture, which is exemplified through the Intellectual Property Office of New Zealand's (n.d.) identification of the hei matau as one of six traditional Māori designs. Furthermore, pretesting measures concluded that New Zealand consumers perceive the hei matau as the most symbolic of Māori culture. The fictitious Māori brand name (Āio) was selected as it shares a similar meaning to the fictitious English brand name BeStill. To the author's knowledge, no water brands in New Zealand are called BeStill. Therefore, consumers should not have any preconceived biases. 
Figure 2: Branding Stimulus
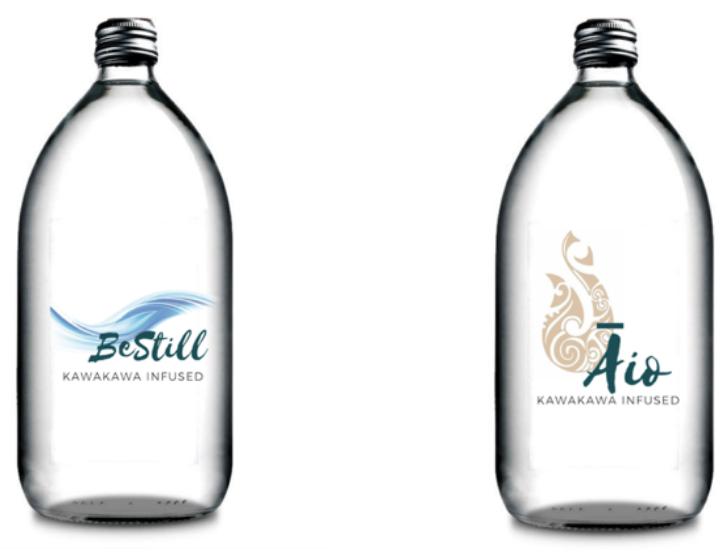

To manipulate values, a scenario was presented to participants which communicated either conventional or tikanga values. For the condition with conventional values, participants were informed that the organisation wanting to introduce the product was owned by the Duke of Sussex Trust, in partnership with Wengbao Corporation, and conventional, corporate social responsibility values drove the organisation. For the condition with tikanga values, participants were informed that the organisation was owned by Te Puni Kōkiri Community Trust, and driven by tikanga Māori values, such as kaitiakitanga, whanaungatanga and manaakitanga. Both scenarios gave examples of how the values were actioned (e.g. lunches provided for all staff), and these examples were the same across both value sets.

Following the stimulus product which presented the branding manipulations, and the scenarios with the organisational values manipulations, participants were asked how authentic they perceived the brand concept to be, and their likelihood of purchasing the product. Next, participants were asked questions relating to the manipulation checks (brand elements and values), and Māori ethnic identification. Finally, participants were asked a series of demographic questions.

\subsection{Sample}

\subsubsection{Sampling Frame}

The sample frame for this study was New Zealand consumers, aged 18 years and over. Given that this study aimed to understand perceptions towards a product (fortified water) which could be purchased by anyone, it was not necessary to further segment the sample frame. Moreover, 
a diverse group of respondents was targeted to ensure that the findings of this study are generalizable to the public.

However, to adequately examine the moderating effect of ethnic identification, roughly half of the participants in each of the eight conditions in the study needed to identify as Māori. This targeted selection was necessary, given that the research specifically addresses Māori indigenous branding, and it was expected that Māori ethnic identification would moderate the effect of indigenous branding and indigenous organisational values on perceived authenticity.

\subsubsection{Sample Recruitment}

To recruit the sample, the researcher utilised a range of networks to access a broader diversity of participants, and thus enhance the generalisability of the study. The networks utilised included Victoria University of Wellington (Āwhina, Te Kawa a Maui \& School of Marketing and International Business), as well as personal (Facebook and email) networks. Facebook was used due to its cost-effectiveness, as well as its ease of dissemination, with over 2.9 million Facebook users who are 18 years and over in New Zealand alone (Statista, 2018). The same recruitment message was posted on all networks, which briefly introduced the researcher and the study, and incentivised potential subjects to participate through offering the chance to win one in four $\$ 50$ New World vouchers.

Victoria University of Wellington's Māori group Āwhina, and faculty Te Kawa a Māui helped the researcher to recruit the Māori sample, which was thought to have been the more difficult group to recruit, due to the relatively smaller population size. These groups were chosen as they have established connections with a significant proportion of the Māori student population (estimated 2,420 Māori students) at Victoria University (Victoria University, 2018a, 2018b). With the help of these groups, the issue of attaining Māori participants was ameliorated.

\subsubsection{Sample Size}

A general consensus among scholars is that experimental designs need at least 30 subjects per cell in order for the results to be reliable and valid (e.g. Geuens \& De Pelsmacker, 2017; Hair, et al., 2010; McDaniel, 2010). Therefore, the minimum sample size required for this study was 240 responses, due to there being eight conditions, and thus allowing for 30 responses per condition. 


\subsubsection{Sample Description}

In terms of ethnicity, the majority of the sample identified as non-Māori (72.5\%), and the remainder identified as Māori. The sample was evenly split in terms of gender with $56 \%$ of participants identifying as female, and $44 \%$ identifying as male. The average income for the sample was less than $\$ 76,000$ per year $(68.7 \%)$, which was perhaps reflective of the youthful skew of the sample, comprising mainly of millennials and generation X. More specifically, the majority of the sample were aged 18-24 (47.9\%) and 36-55 (29.2\%). The remainder of the sample were aged $25-35(10.8 \%)$ and $56+(12 \%)$. An additional reflection of the youthful skew of the sample was that roughly half of the sample identified as current students $(47.9 \%)$, whereas the other half (52.1\%) did not.

\subsection{Design and Measures}

This section presents the study variables and the associated measurement scales (refer to Table 3, adaptations in italics). It was necessary to adapt Kadirov's (2015) scale to fit the context of a proposed brand concept, and it was necessary to adapt Phinneys (1992) ethnic identification scale to within fit the context of Māori ethnic identification.

Table 3: Adaptation of Scales

\begin{tabular}{|c|c|c|}
\hline Scale / Source & Original Items & Adapted Items (if necessary) \\
\hline $\begin{array}{l}\text { Perceived } \\
\text { Authenticity } \\
\text { (Kadirov, } \\
2015 \text { ) }\end{array}$ & $\begin{array}{l}\text { In the category } \mathrm{X}, \text { most of the } \\
\text { manufacturer brands are: } \\
\text { Phoney...............Real } \\
\text { Imitation...........Genuine } \\
\text { Inauthentic.......Authentic }\end{array}$ & $\begin{array}{l}\text { In my opinion, the brand concept } \\
\text { appears to be: } \\
\text { Phoney...............Real } \\
\text { Imitation...........Genuine } \\
\text { Inauthentic.......Authentic }\end{array}$ \\
\hline $\begin{array}{l}\text { Ethnic } \\
\text { Identification } \\
\text { (Phinney, } \\
\text { 1992) }\end{array}$ & $\begin{array}{l}\text { I have a strong sense of } \\
\text { belonging to my ethnic group. } \\
\text { - I am happy that I am a } \\
\text { member of the group I belong } \\
\text { to. } \\
\text { - I participate in cultural } \\
\text { practices of my own group } \\
\text { such as special foods, music or } \\
\text { customs. } \\
\text { - I really have not spent much } \\
\text { time trying to learn more } \\
\text { about the culture and history } \\
\text { of my ethnic group. } \\
\text { - I don't try to become friends } \\
\text { with people from other ethnic } \\
\text { groups. }\end{array}$ & $\begin{array}{l}\text { - I have a strong sense of } \\
\text { belonging to Māori culture. } \\
\text { - I am happy that I am Māori. } \\
\text { - I participate in Māori cultural } \\
\text { practices, such as spending } \\
\text { time at the marae, going to } \\
\text { hui, or kapa haka. } \\
\text { - I have not spent much time } \\
\text { trying to learn about Māori } \\
\text { culture and history, and I don't } \\
\text { intend to. } \\
\text { - I only try to become friends } \\
\text { with people who are Māori. }\end{array}$ \\
\hline
\end{tabular}


3.5.1 Dependent Variable: Perceived Authenticity

The dependent variable of this study was perceived authenticity, which was measured using Kadirov's (2015) authenticity scale. Kadirov's (2015) original scale comprised of three questions and was measured using an 11-point bipolar scale ranging from -5 to +5 . However, for this study, the scale was reduced to a 7-point bipolar scale ranging from -3 to +3 . In Kadirov's (2015) study, participants were asked to rate on the 11-point bipolar scale how phoney to real, imitation to genuine, and inauthentic to authentic they felt that the shop's own labels and manufacturer brands were. In contrast, the current study asked participants to rate their opinion of the brand concept on the 7-point Likert scale. Both the original and adapted scales can be seen above in Table 3 .

One reason for which Kadirov's (2015) perceived authenticity scale was appropriate for this study was that Kadirov's scale required participants to measure their perceptions towards the brand on three bipolar scales - phoney to real, imitation to genuine, and inauthentic to authentic. In contrast, the perceived authenticity scale by Morhart, et al. (2015) comprised of 15 items, and the scale by Napoli, et al. (2014) comprised of 19 questions. Using a scale with fewer items is preferable as it decreases the overall time taken to complete the survey, which has been said to improve response completion rates (Bethlehem \& Biffignandi, 2011).

Another reason that Kadirov's (2015) scale was appropriate to use was that it fit within the context of this study, specifically, the use of a hypothetical brand. In contrast, other established authenticity scales (e.g. Morhart, et al., 2015; Napoli, et al., 2014) asked questions which required knowledge of an existing brand, e.g. "The brand refuses to compromise the values upon which it was founded" (Napoli, et al., 2014, p. 1093) or "A brand that accomplishes its value promise" (Morhart, et al., 2015, p.204).

In the pretesting stage of this study, an adapted version of the scale by Napoli, et al. (2014) was used (Appendix C). However, participants found the questions awkward and difficult to answer because they were unable to draw upon pre-existing knowledge of the hypothetical brand in the scenario given. In contrast, when Kadirov's (2015) adapted perceived authenticity questions were used, participants felt they were better able to answer the questions. The pretesting measures, therefore, underscored the appropriateness of Kadirov's perceived authenticity scale. 


\subsubsection{Independent Variables}

\subsubsection{Indigenous Branding Elements}

To manipulate branding, participants were presented with a fortified water drink that featured either a Māori brand name and symbol, or a non-Māori brand name and symbol (Figure 3). The Māori brand name was "Āio", meaning to be calm and peaceful, which is most often used to describe water conditions. In contrast, the non-Māori brand name was "BeStill". The Māori symbol was a hei matau (fish hook). This symbol was chosen as it is commonly associated with Māori culture. For example, the Intellectual Property Office of New Zealand (n.d.) identifies the hei matau as one of six traditional Māori designs. Furthermore, pretesting measures concluded that New Zealand consumers perceived the hei matau as most symbolic of Māori culture, relative to other options presented in the pretesting (e.g. tiki, koru, fern) (Appendix D).

Figure 3: Branding Stimulus.
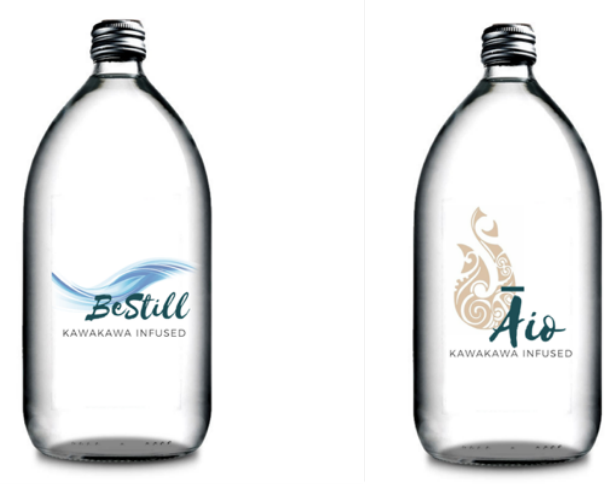

\subsubsection{Organisational Values}

To manipulate the organisational values, participants were presented with a scenario which communicated either tikanga Māori values (see text below) or conventional values. How such values were actioned was also described, for example "lunches are always provided for all staff". It should be noted that the actions of the values remained constant across both value sets.

As an organisation, Aio is directed by a range of tikanga Māori values such as kaitiakitanga (guardianship of resources), whanaungatanga(a sense of belonging), and manaakitanga (respect and sharing). Aio enacts these values in a number of ways, for example, the staff at Äio spend one weekend of every month working around New Zealand on a range of activities to make our waterways cleaner and clearer (kaitiakitanga). Aio also provides school uniforms, shoes and 
stationary equipment for all of the children of their staff (whangaungatanga). And lunches are always provided for all staff (manaakitanga).

The Māori organisational values used in the scenario centred around Māori cultural values, such as whanangatanga and kaitiakitanga (Morgan \& Mulligan, 2006). In contrast, the conventional values used in the scenario were based on corporate social responsibility value set (e.g. people, planet). Moreover, tikanga Māori values and triple bottom line values are similar in their orientation towards valuing broader social and environmental concerns, rather than merely financial success.

\subsubsection{Ethnic Identification}

The ethnic identification of participants (Māori and non-Māori) was included within this study, as previous literature indicated that ethnic identification is likely to impact the relationship between indigenous brand elements, indigenous organisational values, and perceived authenticity (Appiah, 2001; Grier \& Brumbaugh, 1999; Holland \& Gentry, 1997). An ethnic identification scale was thought to be a more robust measure of ethnic identification than a single question on ethnicity. As such, this scale was used to ensure that as a whole, the Māori sample strongly identified as Māori.

To measure this construct, participants were first asked what ethnicity they identified with. Later in the questionnaire, participants were asked a series of questions which were adapted from Phinney's (1992) ethnic identification scale (refer to Table 3). Participants were thus asked to rate how strongly they agreed with a series of statements on a 5-point Likert scale. This included, for example, "I have a strong sense of belonging to Māori culture", and "I participate in Māori cultural practices such as spending time at the marae, going to hui, or kapa haka." It was important to adapt these scales specifically to Māori cultural practices (e.g. kapa haka), as they are more relevant to the participants than the original items in the scale. This scale was appropriate to use as it is applicable for ethnically diverse samples (Phinney, 1992).

\subsubsection{Control Variable}

The following construct has been included as a control variable as they were predicted to affect the dependent (perceived authenticity) and independent variables (indigenous branding and indigenous values). The inclusion of this construct as a control variable thus enabled the researcher to account for any confound effects. 


\subsubsection{Purchase Intention}

Previous literature indicates that perceived authenticity is positively correlated with intention to purchase (Morhart, et al., 2015; Napoli, et al., 2014). As the literature has confirmed a positive relationship between purchase intention and perceived authenticity, this construct was used in the data cleaning stage to check for careless response patterns. Therefore, any noticeable outliers were identified and examined to ensure that purchaser intention and perceived authenticity were positively associated. If these values were extremely negatively associated, the outlier was removed from the dataset.

To measure this construct, participants were asked to provide a rating on a 7-point Likert scale in response to the following question: "how likely is it that you would purchase this product for yourself?"

\subsubsection{Manipulation Checks}

Both branding elements and organisational values were manipulated in this study. The results of the study could have been adversely affected had the participant realised that these factors had been manipulated.

For the manipulation check of indigenous brand elements, subjects were asked to measure on a 7-point Likert scale the extent to which they agreed with the statement "I think that this product has a Māori brand name and symbol". For the manipulation check of tikanga values, subjects were asked to measure on a 5-point Likert scale the extent to which they agreed with the statement "I think that Māori values are embedded in the values of this brand."

\subsection{Data Analysis}

SPSS statistics processing software was used to prepare and analyse the data collected in this study. In preparing the data, incomplete responses were first removed from the data set. The total number of participants involved in this study was 729; however, only 579 of these provided complete responses.

\subsubsection{Pre-test Measures}

Pretesting for the current study consisted of two separate stages. In the first stage, the researcher aimed to establish what symbol was perceived as the most representative of Māori culture. This was examined using an online questionnaire with 130 participants. It was found that the hei matau (fish hook) was the symbol perceived to be most representative of Māori culture (M= 
$4.38, \mathrm{SD}=0.64)$, relative to the other options presented in the pretesting (e.g. tiki, koru, fern) (Appendix D). As such, the hei matau symbol was used in the Māori branding condition for the current study.

The second stage of pretesting aimed to ensure that the questionnaire used in the current study was appropriate and understandable. As this research centres on Māori branding and Māori ethnic identity, it was important that the research was politically astute and culturally safe as to satisfy the Kaupapa Māori kia tupato ethical requirement (Smith, 2005). As such, the questionnaire was sent to Māori academics at Victoria University of Wellington including Dr Meegan Hall (AVC Māori), and Dr Maria Bargh (Head of school at Te Kawa a Maui), in addition to several Māori friends and family of the researcher. Feedback from these individuals was then integrated into the study. For example, adaptations were made to the ethnic identification scale so that it better suited a Māori context. The questionnaire was also sent to non-Māori family, friends and associates. It was important that all participants understood the concepts conveyed, and that these were communicated in respectful but not overly technical manner or use of language as to meet the Kaupapa Māori ethical requirement of kia mahaki do not flaunt your knowledge (Cram 2001).

\subsubsection{Data Cleaning Measures}

Following the removal of the incomplete datasets, the data cleaning process continued by identifying outliers in each condition using the explore function in SPSS. Sixteen outliers were identified as being further than $2 \mathrm{x}$ the interquartile range, and as such, were inspected for evidence of careless response type. The key indicators for careless responses were drawn from Meade and Craig's (2012) article "Identifying Careless Responses in Survey Data". These indicators included straight-line responses and responses that were inconsistent with relationships already well established in the literature. Specifically, participants who scored one response for multiple constructs (including the dependent variable) were removed from the dataset. Also, participants who scored $<2$ on authenticity measures, and at the same time $>6$ on purchase intention were removed. This removal was appropriate as the relationship between authenticity and purchase intention has been well established in the literature (e.g. Morhart, et al., 2015; Napoli, et al., 2014). Following inspection, nine outliers were identified to indicate careless response type, and as such, were removed from the study. All outliers and their responses can be seen in Appendix E. Please note that the responses which were removed have been coloured red. 
Following the removal of incomplete data sets and outliers with careless response types, 570 total useable responses remained. These responses were coded based on each of the three manipulations (Māori branding; tikanga values; Māori ethnic identification). After coding, it was revealed that there were between 32 to 113 useable responses in each of the eight conditions (brand $\mathrm{x}$ values $\mathrm{x}$ ethnicity). Therefore, the minimum sample size requirement (30 per condition) was met (Hair, et al., 2010).

\subsubsection{Data Analysis Measures}

To test the main effects and interactions of the manipulated variables on consumers' perceptions of authenticity towards the proposed product, an ANOVA was conducted, with post-hoc analyses being conducted to investigate additional differences within the conditions. Significance was accepted at $p=.10$ in this study. Limitations stemming from using Qualtrics (an online platform) (Illieva, Baron, \& Healey, 2002; Bethlehem \& Biffignandi, 2011) will be addressed in the data interpretation.

3.6.4 Manipulation Checks

Following the data cleaning measures, the manipulation checks were conducted through independent sample t-tests.

Firstly, an independent samples t-test was conducted to ensure that participants in the Māori branding (MB) condition $(n=295)$ perceived that the brand was more Māori than participants in the orthodox branding $(\mathrm{OB})$ condition $(n=274)$. The $\mathrm{t}$ test was statistically significant $\left(M_{\text {Māori }}=4.3966, S D=.87403\right.$ vs. MWestern $=2.8540, S D=1.12930 ; t(513)=-18.124, p<$ .001 ; two-tailed, $d=1.53)$, therefore the manipulation was successful.

Secondly, an independent samples t-test was conducted to check that participants in the tikanga values (TV) condition $(n=282)$ perceived that the values were more Māori than participants in the conventional values $(\mathrm{CV})$ condition $(n=288)$. This t-test was also statistically significant $\left(M_{\text {Māori }}=3.8830, S D=.70265\right.$ vs. Mwestern $=2.5165, S D=.88714 ; t(561)=-5.324, p<.001$; two-tailed, $d=0.45$ ), therefore this manipulation was also successful.

Finally, an independent samples t-test was conducted to check that the group of subjects identifying as Māori $(n=157)$, strongly identified as Māori, and significantly more so than those identifying as non-Māori $(n=413)$. The t-test was statistically significant (MMāori $=$ 4.4926, $S D=.96770$ vs. MWestern $=3.4201, S D=1.10457 ; t(353)=27.806, p<.001 ;$ two- 
tailed, $d=2.47)$. From these results, we can infer that Māori participants strongly identified as Māori.

The Kaupapa Māori research design served as an ethical compass to guide the entire research approach. This research approach served as a constant reminder to the researcher of the responsibility owed to the participants of the study, and the wider Māori community - to produce something which is, in some way, perceived as a positive contribution to Māori. This approach, therefore, influenced the analysis of the data.

\subsection{Ethics Approval}

This research was granted ethics approval by Victoria University's Pipitea Human Ethics Committee (\#26910) (Appendix F). Hosting the survey on the online survey site Qualtrics ensured that participants anonymity was upheld. Moreover, the survey did not request any identifiable information from the participants. 


\section{Chapter 4: Results}

This chapter provides an analysis of the quantitative results of the experiment. As such, this chapter will discuss the data cleaning, descriptive statistics, and factorial analysis of variance (ANOVA) which was used to test the hypotheses.

\subsection{Factorial ANOVA}

A factorial between groups analysis of variance (ANOVA) was conducted in order to examine the impact that branding, values, and ethnic identification (Māori) had on participants' perceptions of authenticity towards the product. Please refer to Appendix G for the ANOVA table.

\subsection{Assumptions of ANOVA}

The first two assumptions of ANOVA, scale of measurement and independence, are methodological assumptions, and as such, were addressed prior to data collection. These two assumptions were met as the design of the experiment is a between-subjects factorial design. The third assumption of ANOVA, normality, requires a normal distribution of scores, and it should be noted that ANOVA is robust to violations of this assumption. To assume normality, the skewness and kurtosis values should be within \pm 1.96 (Allen et al., 2014). All data met this required cut-off. The final assumption of ANOVA, homogeneity of variance, requires that there is approximately the same amount of variance in each group of scores, and is tested as part of the ANOVA. The assumption of homogeneity of variances was violated, as assessed by Levene's test for equality of variances, $\mathrm{p}<.001$. However, it was appropriate to continue analysis through ANOVA, as ANOVA is robust to violations when the sample size is large, as in this study (Allen, et al., 2014).

\subsection{Hypothesis Testing}

\subsubsection{Main Effect: $\mathrm{H} 1$}

A three-way ANOVA was conducted to determine the effects of branding, organisational values, and ethnic identification on perceived authenticity. The main effects were first analysed, revealing a main effect of branding that was statistically significant $(F(1,561)=$ 4.200, $p=.04$ ). Therefore, it can be ascertained that branding does enhance consumers' authenticity perceptions. However, subjects in the orthodox branding (OB) condition reported higher levels of perceived authenticity $(M=5.496$, Std. Error $=.096)$, compared to those in the MB condition $(M=5.219$, Std. Error $=.096)$. This finding is contrary to what was 
expected, as it was expected that $\mathrm{MB}$ would have a stronger, more positive effect on consumers' authenticity perceptions. Thus, the findings indicate that MB (relative to OB) does not significantly enhance consumers' authenticity perceptions. Therefore, H1 Indigenous (Māori) branding will positively affect consumers' perception of brand authenticity was not supported.

\subsubsection{Interaction Effect: $\mathrm{H} 2$}

Next, the interaction effects were analysed. For the general population, values were found to moderate the effect of branding on perceived authenticity. This was evidenced by a statistically significant interaction between organisational values and branding on perceived authenticity $(F(1,561)=19.372, p<.001)$. This interaction indicates that the degree to which branding is successful in enhancing perceived authenticity is dependent upon the type of organisational values present. Therefore, H3, Brand communication emphasising indigenous (Māori) organisational values (e.g. tikanga Māori) will moderate the effect of indigenous (e.g. Māori) branding on consumers' perception of brand authenticity, is supported and is illustrated in Figure 4.

Figure 4: Two-way Interaction Effect of Branding and Values

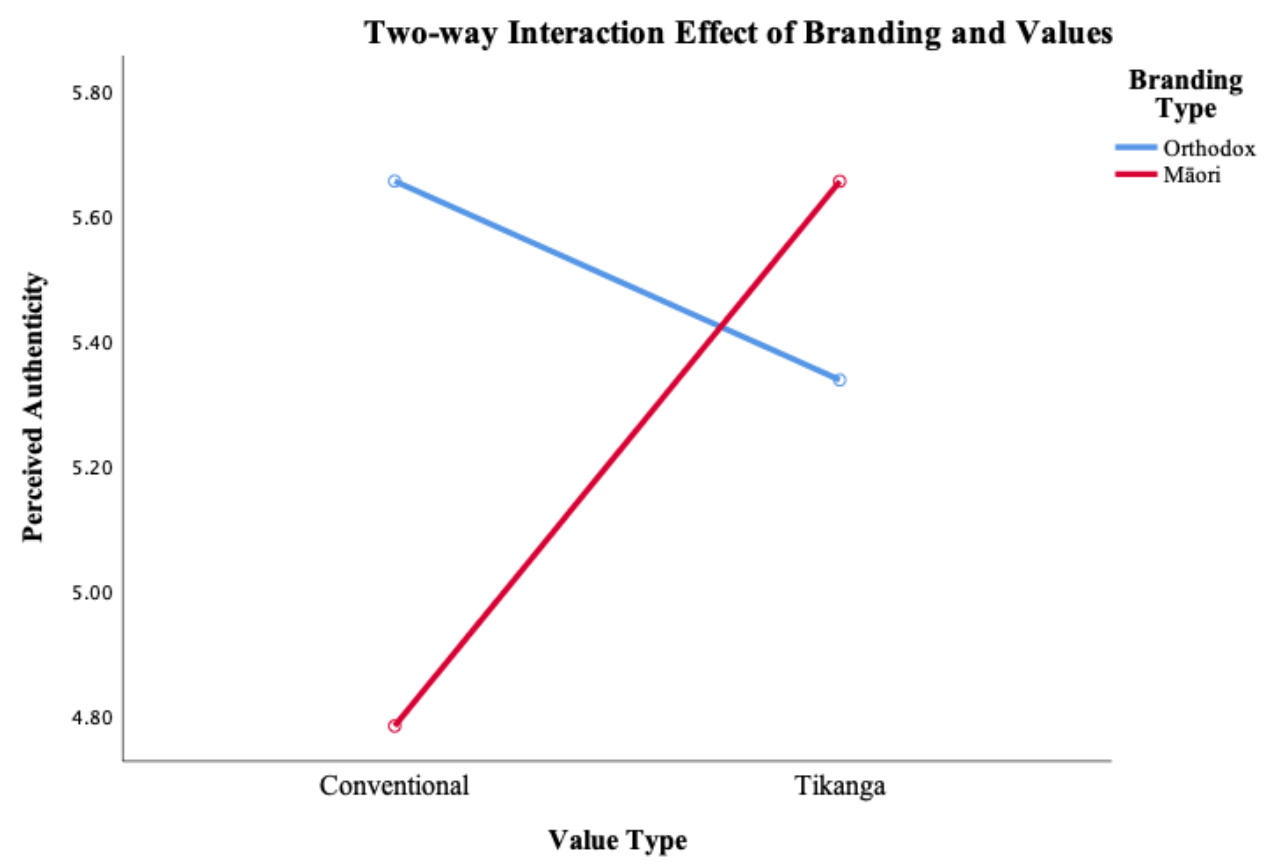

Simple Effects and Pairwise Comparisons for Branding

Simple effects analyses were conducted to further examine the interaction between branding and values. These analyses indicated that branding has a statistically significant effect on 
perceived authenticity when conventional values $(\mathrm{CV})$ are present, $(F(1,565)=26.379, p<$ $.001)$, but not when tikanga values (TV) are present $(F(1,565)=.447, p=.504)$. From these results, it can be inferred that the effect of branding on consumers' authenticity perceptions is influenced by the presence of CV. However, if a brand has TV, then consumers' authenticity perceptions are not influenced by those organisational values.

In light of this, further analyses were conducted through simple pairwise comparisons for participants in the CV condition with a Bonferroni adjustment applied. These analyses were conducted to investigate the direction in which $\mathrm{CV}$ affected the relationship between branding (OB and $\mathrm{MB}$ ) and perceived authenticity. It was found that the presence of CV had a negative influence on the effect of MB on perceived authenticity. This finding was evidenced by the significantly negative effect on perceived authenticity within the CV group between the OB and MB conditions $(t(565)=-5.134, p<.001)$. In conclusion, consumers' authenticity perceptions are significantly reduced when an organisation possesses and communicates $\mathrm{CV}$, and at the same time introduces MB.

\subsubsection{Three-way Interaction Effect: H3}

Hypothesis 3, the three-way interaction between indigenous (e.g. Māori) branding, brand communication emphasising indigenous (e.g. Māori) organisational values and ethnic (Māori) identification will be significant, tested the relationship between branding, organisational values and ethnic identification. It was found that the interaction between branding and organisational values differed depending on the ethnic identification of the consumer. This was evidenced by a statistically significant three-way interaction between branding, values and ethnic identification $(F(1,561)=3.083, p=.080)$. The most significant difference emerging from this analysis is that for the Māori population, TV do significantly influence the effect of branding on consumers' authenticity perceptions (refer to Figure 5). In contrast, TV do not significantly influence the effect of branding on consumers' authenticity perceptions for nonMāori population (refer to Figure 5), or for the general population (refer to Figure 4). Another interesting finding that was revealed through this three-way interaction is that the effect of $\mathrm{CV}$ on branding becomes more extreme for Māori consumers, as evidenced by the significantly lower authenticity attributions in the CV condition for Māori consumers compared to nonMāori consumers (refer to Figure 5). Thus, H5, the three-way interaction between indigenous (e.g. Māori) branding, brand communication emphasising indigenous (e.g. Māori) 
organisational values and ethnic (Mäori) identification will be significant, was supported. This interaction is illustrated in Figure 5.

Figure 5: Three-way Interaction Effect of Ethnic Identification, Values and Branding

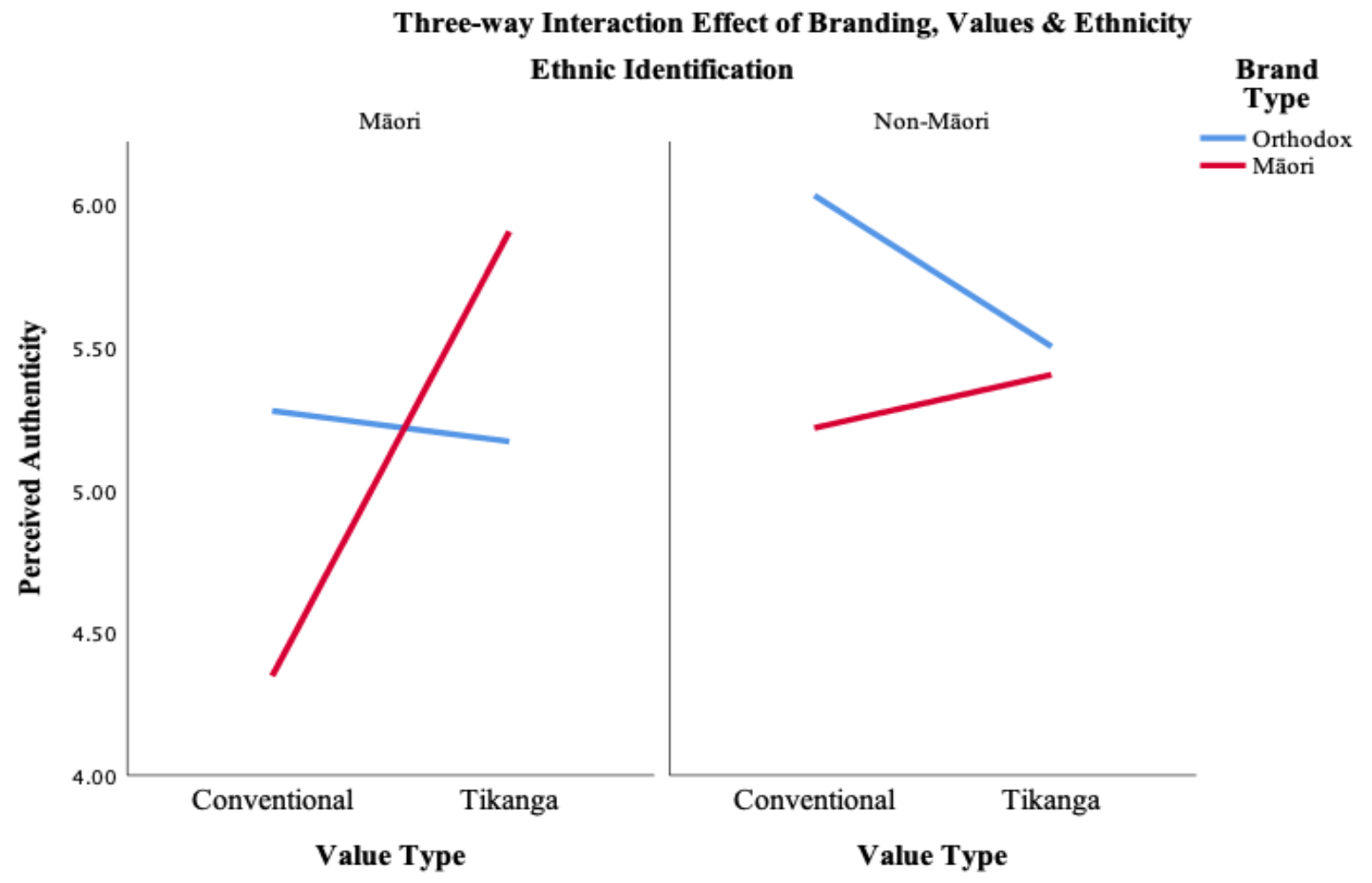

Simple effects analyses were used to further examine the interaction between branding and values, for Māori and non-Māori participants. First, the interaction effects will be discussed for Māori participants, and then non-Māori participants.

Simple Effects and Pairwise Comparisons for Branding for Māori participants

These analyses indicated that, for Māori participants, branding has a statistically significant effect on perceived authenticity both when CV are present, $F(1,153)=6.253 p=.013$, and when TV are present, $F(1,153)=3.555, p=.061$.

In light of this, further analyses were conducted through simple pairwise comparisons for participants in the $\mathrm{CV}$ condition with a Bonferroni adjustment applied. The analyses revealed that Māori consumers perceived organisations with $\mathrm{CV}$ and $\mathrm{OB}$ as being very authentic $(M=$ $5.278, S D=0.279$ ). In contrast, Māori consumers perceived organisations with $\mathrm{CV}$ and $\mathrm{MB}$ to be significantly less authentic $(M=4.348, S D=0.246)$. Moreover, it was found that when $C V$ 
were present, the difference in consumers' authenticity perceptions between the two conditions $(\mathrm{OB}, \mathrm{MB})$ were significantly negative, $t(153)=-2.500, p=.013$. Thus, Māori consumers' authenticity perceptions are significantly enhanced when an organisation with CV introduces a brand with OB. However, Māori consumers' authenticity perceptions are significantly reduced if said organisation introduced a brand with $\mathrm{MB}$.

Next, simple pairwise comparisons were conducted for participants in the TV condition with a Bonferroni adjustment applied. The analyses revealed that Māori consumers perceived organisations with TV and MB as being very authentic $(M=5.906, S D=0.295)$. In contrast, Māori consumers perceived organisations with TV and OB as being significantly less authentic $(M=5.171, S D=0.255)$. Moreover, it was found that when TV were present, the difference in consumers' authenticity perceptions between the two conditions (OB, MB) were significantly positive, $t(153)=1.887, p=.061$. Therefore, Māori consumers' authenticity perceptions are significantly enhanced when an organisation with TV introduces a brand with MB. However, Māori consumers' authenticity perceptions are significantly reduced if said organisation were to introduce a brand with OB.

Simple Effects and Pairwise Comparisons for Branding for non-Māori Participants The simple effects analyses indicated that for non-Māori participants, branding has a statistically significant effect on perceived authenticity when $\mathrm{CV}$ are present, $F(1,408)=$ $19.268 p<.001$, but not when TV are present, $F(1,408)=0.287, p=.592$. Therefore, the effect of branding on perceived authenticity is influenced by $\mathrm{CV}$ when the consumers are nonMāori. However, the effect of branding on perceived authenticity is not influenced by TV for non-Māori consumers.

In light of this finding, further analyses were conducted through simple pairwise comparisons for participants in the CV condition with a Bonferroni adjustment applied. The pairwise comparisons revealed that non-Māori consumers perceived organisations with $\mathrm{CV}$ and $\mathrm{OB}(M$ $=6.033, S D=0.132)$ as relatively more authentic than organisations with $\mathrm{CV}$ and $\mathrm{MB}(M=$ $5.218, S D=0.130$ ). This finding was further illustrated by the significant negative effect on perceived authenticity within the $\mathrm{CV}$ group between the $\mathrm{OB}$ and $\mathrm{MB}$ conditions, $t(408)=-$ 4.382, $p<.001$. Therefore, it can be inferred that non-Māori consumers' authenticity perceptions are significantly reduced when an organisation with $\mathrm{CV}$ introduces a brand with MB. 


\subsection{Summary of Hypotheses Outcomes}

Table 4 states the hypotheses, their significance, and whether they were supported. As evidenced by the table, two of the three hypotheses were supported.

Table 4: Summary of Hypotheses Outcomes

\begin{tabular}{|c|c|c|}
\hline Hypothesis & Significance & Outcome \\
\hline $\begin{array}{l}\text { H1. Indigenous (e.g. Māori) branding will } \\
\text { positively affect consumers' perception of } \\
\text { brand authenticity (purchase intention). }\end{array}$ & $p=.040$ & Not supported \\
\hline $\begin{array}{l}\text { H3: Brand communication emphasising } \\
\text { indigenous (Māori) organisational values (e.g. } \\
\text { tikanga Māori) will moderate the effect of } \\
\text { indigenous (e.g. Māori) branding on } \\
\text { consumers'perception of brand authenticity }\end{array}$ & $p<.001$ & Supported \\
\hline $\begin{array}{l}\text { H5. The three-way interaction between } \\
\text { indigenous (Māori) branding, brand } \\
\text { communication emphasising indigenous } \\
\text { (Māori) organisational values and ethnic } \\
\text { (Māori) identification will be significant }\end{array}$ & $p=.080$ & Supported \\
\hline
\end{tabular}




\section{Chapter 5: Discussion}

The following chapter systematically discusses the results of each hypothesis in light of the literature discussed in the Chapter 2.

\subsection{Research Objective One}

The first research objective of this dissertation was to investigate the effect of indigenous branding practices (exemplified in the cultural appropriation of Māori language and symbols) on consumers' authenticity perceptions. The results of the analysis provided insights of the effect branding has upon perceived authenticity. An interesting finding that emerged from the analysis uncovered that although branding was found to have an effect on consumers' perceptions of authenticity, Māori branding did not have a stronger effect on perceived authenticity compared to orthodox branding. Therefore, consumers presented with Māori branding perceived the brand as relatively less authentic than consumers presented with orthodox branding. This finding contradicts earlier research suggesting that indigenous branding elements (language and iconography) can communicate authentic attributes (e.g., a connection to the past and a commitment to values and principles) (Thomson, 2015). Although a significant body of research suggests that branding elements can enhance consumer perceptions of authenticity (Beverland, Lindgreen \& Vink, 2008; Grayson \& Martinec, 2004; Morhart, et al., 2015; Napoli, et al., 2014), this research was not in the context of indigenous branding. Therefore, it may be that orthodox branding is better able to enhance consumers' authenticity perceptions relative to Māori branding.

Another potential explanation for this finding is the current perceptions surrounding Māori indigenous branding in New Zealand. A primary issue with the perceptions of Māori indigenous branding is that the widespread adoption of Māori cultural elements is coupled with both intellectual property rights challenges, and issues around cultural appropriation. Contested issues around Māori intellectual property (IP) rights and branding have long been in the public eye, as exemplified by the publicity surrounding the WAI262 claim on Māori IP rights (Waitangi Tribunal, 2011). Potentially emerging out of this public contention are a number of studies which have examined the use of Māori IP, such as Feetham, Wright and Joe (2018), who identified that organisations are utilising aspects of Māori culture regardless of whether they have ancestral connections to the indigenous culture or not. As a result of such controversy regarding IP rights, and more specifically within Māori branding, it was thought that consumers 
may be cognizant of and sensitive towards the use of Māori culture in Māori branding. This cognizance and sensitivity towards Māori branding could potentially serve as an underlying reason as to why consumers perceived Māori branding as relatively less authentic than orthodox branding. The relationship between the commercialisation and commodification of culture, and cultural appropriation, may also be an underlying reason for the finding of this analysis. Cultural appropriation is defined as instances where indigenous culture has been commercialised and commodified in a way that degrades the culture and perpetuates power imbalances, and in turn, negatively influences consumer perceptions of an organisation (Matthes, 2016; Riley \& Carpenter, 2015). Furthermore, previous research has found that both indigenous and non-indigenous consumers exhibit sensitivity towards the authentic use or cultural appropriation of indigenous cultures within tourism offerings (Bunten, 2010; Butler \& Hinch, 2007). When considering the findings exposed within the analysis of the current study in light of the above research, a possible conclusion that could be drawn is that consumers' may be wary of cultural appropriation, which in turn, negatively influences their authenticity perception when Māori branding is used exclusively (rather than in conjunction with other attributes, such as organisational values, or CSR initiatives).

A secondary issue arising within the perceptions of Māori indigenous branding in New Zealand is that Māori could be seen as commonplace, and as such, does not enhance consumers' authenticity perceptions. As mentioned, the presence of Māori indigenous branding is both popular and continuously growing in its use within both local and global scales - a growth which is at least partially owed to the indigenous Māori population, ongoing efforts of cultural revitalisation, and the presence of Māori cultural elements in New Zealand's nation branding (Albury, 2016; Harmsworth \& Tahi, 2008; Wilson, 2005). As a result of the significant presence of Māori branding in New Zealand, consumers in New Zealand may not perceive Māori branding as anything out of the ordinary, which could therefore have no positive influence on their perceptions of Māori branding.

The conclusion of hypothesis one is that Māori branding does not enhance consumers' perceptions of authenticity. Therefore, it is not beneficial for organisations wishing to be perceived as authentic to implement Māori branding alone. A number of underlying factors, such as issues around intellectual property rights and cultural appropriation, lead to the implication that Māori branding is not, on its own, enough to significantly leverage consumers' 
authenticity perceptions. However, when strengthened with other attributes, Māori branding may exert greater leverage upon consumers' authenticity perceptions.

\subsection{Research Objective Two}

The second research objective of this dissertation was to investigate the boundary conditions of the effect of indigenous branding practices (exemplified in the cultural appropriation of Māori language and symbols) on consumers' authenticity perceptions, involving indigenous organisational values (exemplified in tikanga Māori values). The results of the analysis provided insights into the moderating effect that values have upon both branding and perceived authenticity. The third hypothesis of this study was supported, as it was found that brand communication emphasising indigenous (Māori) organisational values (tikanga Māori) moderated the effect of indigenous (Māori) branding on consumers' perceptions of brand authenticity. Refer to Table 5 for a full summary of simple effects and pairwise comparisons, illustrating the effects of congruence and incongruence for branding and organisational values.

Table 5: Summary of two-way Interaction Analyses

\begin{tabular}{|l|l|l|l|l|}
\hline $\begin{array}{l}\text { Firm's original } \\
\text { value }\end{array}$ & $\begin{array}{l}\text { Decides to } \\
\text { introduce }\end{array}$ & $\begin{array}{l}\text { Effect on } \\
\text { Perceived } \\
\text { Authenticity }\end{array}$ & Significance & Strategy \\
\hline Conventional & Orthodox brand & Positive & $\mathrm{p}<.001$ & Congruent \\
\hline Tikanga & Māori brand & Not significant & $\mathrm{n} / \mathrm{a}$ & Congruent \\
\hline Conventional & Māori brand & Negative & $\mathrm{p}<.001$ & Incongruent \\
\hline Tikanga & Orthodox brand & Not significant & $\mathrm{n} / \mathrm{a}$ & Incongruent \\
\hline
\end{tabular}

These simple effects analyses show consumers' authenticity perceptions are enhanced when branding and values are congruent, unless a brand with tikanga values introduces Māori branding, in which case, there is no significant effect upon consumers' authenticity perceptions. In contrast, consumers' authenticity perceptions are reduced when branding and values are incongruent, unless a brand with tikanga values introduces orthodox branding, in which case, there is no significant effect upon consumers' authenticity perceptions. In conclusion, it can be inferred that for the general population, organisations with tikanga values are able to implement either orthodox branding or Māori branding without risking negative authenticity perceptions, but also without benefitting from positive authenticity perceptions.

The finding of this analysis is in line with previous research on perceived authenticity which has indicated that both branding (Beverland, Lindgreen \& Vink, 2008; Grayson \& Martinec, 
2004; Morhart, et al., 2015; Napoli, et al., 2014) and values (Auster \& Freeman, 2013; Mazutis \& Slawinski, 2015) influence consumers' perceptions of authenticity. Of importance, the current study extends the aforementioned literature into a new context of indigenous (Māori) branding.

The results of analysis revealed interesting insights into the effects of congruence and incongruence between branding and values. Specifically, it was found that consumers had relatively higher authenticity perceptions towards congruent branding and values (e.g., Māori branding and tikanga values), rather than incongruent branding and values (e.g., Māori branding and conventional values). Keller and Lehmann (2006) explain this finding to some extent with their suggestion that the success of brands can be enhanced when brand attributes work together to create synergistic effects. However, the findings of the current study could also be seen to extend the work of Keller and Lehmann (2006). Firstly, the current study provides evidence of the adverse outcomes (e.g., negative effect on perceived authenticity) for brands when their brand attributes do not work together synergistically. Another way that this study extends the works of Keller and Lehmann (2006) is by placing this concept in an indigenous branding context and finding that although congruent Māori branding and tikanga values did enhance consumers' authenticity perceptions, this difference was not significant for the general population. Thus, for consumers in the general population, synergy and congruence among Māori brand attributes (branding and values) does not enhance their authenticity perceptions.

Arguably the most interesting insight emerging from this analysis concerned incongruence between branding and organisation values. More specifically, consumers perceived organisations utilising Māori branding and conventional values as the least authentic out of all four conditions. This study proposes three possible explanations for this finding, all of which are thought to be highly relevant. The first explanation is encapsulated by Matthes (2016), who describes cultural appropriation as the implementation of cultural aspects in a manner which perpetuates power asymmetries and homogenises stereotypes of marginalised groups, whereby dominant groups speak for and gain from marginalised groups. The use of Māori branding in conjunction with conventional values fits well with Matthes (2016) description of cultural appropriation, such that the findings of the current analysis may indicate that consumers are cognizant of this fit. Additionally, prior research suggests that both indigenous and nonindigenous consumers are sensitive towards the authentic use or cultural appropriation of 
indigenous cultures (Bunten, 2010; Butler \& Hinch, 2007). This may explain why both indigenous and non-indigenous consumers have negative authenticity perceptions towards organisations with incongruent conventional values and Māori branding. However, Matthes' (2016) argument does not fully explain the current findings. This is because his description of cultural appropriation is somewhat removed, describing non-indigenous organisations' utilisation of indigenous branding in a way that refers to the higher-level impacts on indigenous populations. The current study therefore extends Matthes' (2016) argument, as it indicates that consumers may be cognizant of the adverse effects of non-indigenous organisations' cultural appropriation through indigenous branding, which in turn, negatively affects their authenticity perceptions.

The final explanation may lie in the differences in organisations' motivation for utilising indigenous branding. Previous research by Harmsworth, Gilbert, Taylor and Stafford (2013) suggested that the motivation behind implementing Māori branding could be related to cultural pride and personally held values, beliefs, and knowledge perspectives. On the contrary, they found that non-Māori organisations had strategic motivations for implementing Māori branding elements, such as profit gain or brand position. With the widespread contention which surrounds the use of Māori branding, consumers' may be sensitive to the usage of Māori branding, and as such, use other available information to make attributions about the company. It is possible therefore that consumers may perceive organisations implementing Māori branding with conventional values as inauthentic, as these attributes do not work together synergistically. Despite there being scant literature examining this issue in an indigenous branding context, research investigating organisations who attempt to economically benefit from engaging with social issues has found that consumers are sceptical, and believe that the motivation for these organisations to engage with these issues is merely for attention, and commercial gain (Webb \& Mohr, 1998). Similarly, consumers may be prescribing motivations to organisations when their values and branding are incongruent, particularly when their values are conventional and their branding is Māori, which in turn, negatively impacts consumers' authenticity perceptions.

The conclusion for this research objective is that values do moderate the effect of branding on perceived authenticity, especially for organisations with conventional values. When organisations with conventional values implement orthodox branding, this causes the strongest, most positive effect on consumers' authenticity perceptions. In contrast, when organisations 
with conventional values implement Māori branding, this causes the strongest, most negative effect on consumers' authenticity perceptions. Therefore, congruence among branding and values is most important for organisations with conventional values. When organisations with tikanga values implement congruent Māori branding, this has a positive effect on consumers' authenticity perceptions - however this effect is not statistically significant, nor is the effect significant when organisations with tikanga values implement orthodox branding. Therefore, organisations with tikanga values are able to implement either orthodox branding or Māori branding, without risking significantly adverse effects.

\subsection{Research Objective Three}

The third research objective of this dissertation was to investigate the boundary conditions of the interaction effect between indigenous branding practices (exemplified in the cultural appropriation of Māori language and symbols) and indigenous organisational values (exemplified in tikanga Māori values) on consumers' authenticity perceptions based on ethnic identification. The final hypothesis of this study suggested that there would be a significant three-way interaction between indigenous (Māori) branding, brand communication emphasising indigenous (Māori) organisational values, and ethnic (Māori) identification. This hypothesis was supported, meaning that the effect of values and branding on consumers' perceptions of authenticity was moderated by the ethnic identification (both non-Māori and Māori) of the consumer. Please refer to Table 6 for a full summary of simple effects and pairwise comparisons which illustrates the effects of congruence and incongruence between branding, organisational values, and the ethnic identification of the consumer.

Table 6: Summary of Three-way Interaction Analyses

\begin{tabular}{|c|c|c|c|c|c|}
\hline $\begin{array}{l}\text { Firm's } \\
\text { original } \\
\text { value }\end{array}$ & $\begin{array}{l}\text { Decides to } \\
\text { introduce }\end{array}$ & $\begin{array}{l}\text { Ethnic } \\
\text { identification } \\
\text { of consumer }\end{array}$ & $\begin{array}{l}\text { Effect on } \\
\text { Perceived } \\
\text { Authenticity }\end{array}$ & Significance & Strategy \\
\hline \multirow[t]{2}{*}{ Conventional } & \multirow{2}{*}{$\begin{array}{l}\text { Orthodox } \\
\text { brand }\end{array}$} & Non-Māori & Positive & $\mathrm{p}<.001$ & \multirow[t]{2}{*}{ Congruent } \\
\hline & & Māori & Positive & $p=.013$ & \\
\hline \multirow[t]{2}{*}{ Tikanga } & \multirow[t]{2}{*}{ Māori brand } & Non-Māori & $\begin{array}{l}\text { Not } \\
\text { significant }\end{array}$ & $\mathrm{n} / \mathrm{a}$ & \multirow[t]{2}{*}{ Congruent } \\
\hline & & Māori & Positive & $\mathrm{p}=.061$ & \\
\hline \multirow[t]{2}{*}{ Conventional } & \multirow[t]{2}{*}{ Māori brand } & Non-Māori & Negative & $\mathrm{p}<.001$ & \multirow[t]{2}{*}{ Incongruent } \\
\hline & & Māori & Negative & $p=.013$ & \\
\hline \multirow[t]{2}{*}{ Tikanga } & \multirow[t]{2}{*}{$\begin{array}{l}\text { Orthodox } \\
\text { brand }\end{array}$} & Non-Māori & $\begin{array}{l}\text { Not } \\
\text { significant }\end{array}$ & $\mathrm{n} / \mathrm{a}$ & \multirow[t]{2}{*}{ Incongruent } \\
\hline & & Māori & Negative & $\mathrm{p}=.061$ & \\
\hline
\end{tabular}


The results of the analysis illuminate the effects of congruence and incongruence between branding, organisational values, and consumers' ethnic identification. In terms of congruence, two key findings emerge. Firstly, the analyses revealed that consumers perceive branding and values which align with their ethnic identification (either Māori or non-Māori) as the most authentic. Secondly, the analyses revealed that while Māori consumers are sensitive towards both orthodox and Māori congruence, non-Māori consumers are only sensitive to orthodox congruence.

The current body of literature which has examined consumer self-identity and brand authenticity is consistent with the findings revealed in the current study, specifically regarding how consumers perceive branding and values that align with their ethnic identification as the most authentic. Of particular relevance is the literature which has focussed on the level to which consumers perceive similarity and connections between themselves and brands (Rifon, Choi, Trimble \& Li, 2004). This literature has established that congruence between a brand's values and norms, and those of its' consumers, is a key driver of brand authenticity (Beverland and Farelly, 2010; Kates, 2004; Leigh, Peters \& Shelton, 2006). Moreover, this literature underpins the findings of the current study; specifically, as to why consumers' favour organisations with branding and values that are congruent with their ethnicity. However, it should be noted that despite many studies considering the relationship between self-identity and authenticity perceptions, to the author's knowledge, no studies have specifically considered the relationship between ethnic identification and authenticity perceptions, nor has the current body of literature explicitly investigated this relationship in an indigenous context. Therefore, the current study extends the existing body of literature by confirming that congruence is also an important predictor of authenticity outcomes in an indigenous context, with indigenous consumers, branding, and organisational values.

An interesting finding emerging from the analyses of the third hypothesis is that Māori consumers' authenticity perceptions are significantly enhanced by both types of congruence (e.g. orthodox branding \& conventional values; Māori branding \& tikanga values). In contrast, non-Māori consumers' authenticity perceptions are only significantly enhanced by branding and organisational values that are congruent with their ethnic identification (e.g. orthodox branding, conventional values). While the finding regarding non-Māori consumers is consistent with the aforementioned literature on self-identity and perceived authenticity, the 
finding regarding Māori consumers is less consistent with this literature. A reason for this inconsistency between existing literature and Māori consumers' authenticity, is that prior literature posits consumers to have strong authenticity perceptions towards a brand when they perceive similarity and connections between themselves and the brand; as well as perceiving congruence between their personal values and norms, and those of the brand (Beverland and Farelly, 2010; Kates, 2004; Leigh, Peters \& Shelton, 2006; Rifon, Choi, Trimble \& Li, 2004). Therefore, it would follow that consumers with high levels of Māori ethnic identification would perceive greater similarity and connections between themselves, their norms and values, and brands with Māori attributes (e.g. branding and values), as opposed to brands with non-Māori attributes (e.g. branding and values). Although this was found to be true, it was also found that Māori consumers perceived brands with non-Māori attributes (e.g. branding and values) as authentic.

A possible reason for Māori consumers perceiving both types of congruence as authentic, is that consumers require levels of cultural knowledge to understand, evaluate and discern the use of marketing messages in order to form authenticity perceptions (Appiah, 2001; Grier \& Brumbaugh, 1999; Holland \& Gentry, 1997). As Māori consumers and non-Māori consumers live in the same Westernised society in New Zealand, it is probable that both consumer groups have the knowledge necessary to understand, evaluate and discern Western marketing messages (e.g. orthodox branding, conventional values). Moreover, through having similar Western life experiences, both Māori and non-Māori consumers are likely to share certain norms, and alignment between the norms of a consumer and of a brand is a key driver of authenticity (Beverland \& Farelly, 2010; Kates, 2004; Leigh, Peters \& Shelton, 2006; Rifon, Choi, Trimble \& Li, 2004).

In addition, it would follow that Māori consumers with high levels of Māori ethnic identification would also have high levels of Māori cultural immersion and cultural knowledge (Appiah, 2001; Grier \& Brumbaugh, 1999), thus enabling Māori consumers to be equally able to understand, evaluate and discern Māori marketing messages (e.g. branding and values) in order to make authenticity attributions (Appiah, 2001; Grier \& Brumbaugh, 1999; Holland \& Gentry, 1997). Moreover, it is likely that Māori consumers would be motivated to perceive Māori branding and tikanga values as authentic, as a way to endorse products that are authentically characteristic of Māori, and to distinguish themselves from cultural outsiders (Tajfel \& Turner, 1979). Thus, as an indigenous group living in a Westernized society, Māori 
are afforded the ability to have a more fluid experience of social life and can negotiate the extent to which they want to experience life through a Māori or Western lens. In contrast, it is unlikely that non-Māori consumers will have the same degree of cultural knowledge necessary to understand, evaluate and discern the use of Māori marketing messages (e.g. Māori branding and tikanga values), which is necessary when making authenticity attributions. Therefore, the insignificant effect congruent Māori brand attributes (branding and values) have on non-Māori consumers' authenticity perceptions, may also be explained by these consumers not having the cultural knowledge, or tools needed to make relative authenticity attributions.

An interesting finding relating to incongruence, was that both Māori and non-Māori participants perceived the combination of Māori branding and conventional values to be the least authentic. A potential explanation for this finding is current issues circulating within New Zealand regarding Māori branding, intellectual property rights and cultural appropriation. Both currently, and historically, New Zealand organisations have commercialised and commodified aspects of Māori culture even when these organisations do not have organic connections to Māori culture (Feetham, Wright \& Joe, 2018). Intellectual property rights issues relating to the commercial use of Māori culture formed one of the largest Waitangi Tribunal claims in New Zealand history - the WAI262 report (Waitangi Tribunal, 2011). The popularity of the commercialisation of Māori culture, coupled with the widespread contention surrounding such commercialisation, may result in both Māori and non-Māori consumers being sensitive towards the commercialisation of Māori culture. As a result, consumers may be sceptical towards the use of Māori branding by organisations with mainstream, conventional values. This use may be perceived as exploitative, rather than genuine.

Another reason why consumers may have negative authenticity perceptions towards organisations which implement Māori branding alongside conventional values, is that consumers are sensitive towards cultural appropriation. Cultural appropriation is defined as instances where indigenous culture has been commercialised and commodified in a way that degrades the culture and perpetuates power imbalances, and in turn, negatively influences consumers' perceptions of an organisation (Matthes, 2016; Riley \& Carpenter, 2015). When Māori branding, which is the face of the brand, is paired with incongruent conventional values, which may be seen as the heart of the brand, consumers may perceive this as an organisation gaining from Māori culture, and thus perpetuating power imbalances. This suggestion that Māori and non-Māori consumers are sensitive towards cultural appropriation is consistent with 
prior research indicating that both indigenous and non-indigenous consumers exhibit sensitivity towards the authentic use or cultural appropriation of indigenous cultures within tourism offerings (Bunten, 2010; Butler \& Hinch, 2007).

Another thought-provoking insight in relation to incongruence emerging from the analysis of the current hypothesis, was that the incongruence between orthodox branding and tikanga values only had a significantly negative effect on Māori consumers' perceptions of authenticity. Whereas, this combination did not have a significantly negative affect on nonMāori consumers' perceptions of authenticity. This finding is consistent with prior literature as it illustrates how consumers with high levels of ethnic identification are more discerning of the authentic use of Māori brand attributes (e.g. branding and values) (Appiah, 2001; Grier \& Brumbaugh, 1999; Holland \& Gentry, 1997). This finding is also consistent with social identity theory (Tajfel \& Turner, 1979) which posits that consumers are motivated to endorse brands which they perceive as authentically characteristic of their cultural group, and to distinguish themselves from cultural outsiders. Therefore, it is probable that organisations with incongruent brand attributes (e.g. branding and values) are perceived as inauthentic and cultural outsiders. A potential reason why Māori consumers may exhibit greater sensitivity towards organisations with tikanga values and orthodox branding, is that tikanga values in an organisation are usually coupled with Māori branding (Harmsworth, Gilbert, Taylor \& Stafford, 2013). In addition, these values are usually implemented by organisations because of personally held beliefs, values, or knowledge systems, and importantly, pride in being Māori (Harmsworth, Gilbert, Taylor \& Stafford, 2013). These factors most notably pride in being Māori (Harmsworth, Gilbert, Taylor \& Stafford, 2013), would naturally reconcile with choosing Māori branding elements, as opposed to orthodox branding elements. Māori consumers, with higher levels of Māori ethnic identification and cultural knowledge, may have a greater awareness of the motivations behind Māori (tikanga) values, and as such, perceive the coupling of Māori (tikanga) values and orthodox branding as an inauthentic representation of who and what the organisation stands for. This higher awareness and sensitivity towards incongruence is supported by literature pertaining to ethnic identification theory and social identity theory. Ethnic identification theory argues that consumers with higher levels of ethnic identification are better able to understand, evaluate and discern the authentic use of Māori marketing messages (Appiah, 2001; Grier \& Brumbaugh, 1999; Holland \& Gentry, 1997). Moreover, social identity theory posits that consumers are motivated only to endorse brands 
which they perceive as authentically characteristic of their cultural group (Tajfel \& Turner, 1979).

In conclusion, congruence between ethnic identification, branding, and values significantly enhances consumers' authenticity perceptions. However, congruence among orthodox branding and conventional values also significantly enhances Māori consumers' authenticity perceptions, perhaps due to Māori consumers' fluid life experiences. In contrast, non-Māori consumers predominantly Western life experiences results in these consumers only having positive authenticity perceptions when there is congruence among branding, organisational values and their ethnic identification. Moreover, it was found that incongruence between Māori branding and conventional values significantly reduces both Māori and non-Māori consumers' authenticity perceptions. In contrast, Māori consumers' authenticity perceptions were also significantly reduced when presented with orthodox branding and tikanga values. Therefore, it can be inferred that Māori consumers are slightly more sensitive to incongruence than nonMāori consumers, resulting in their authenticity perceptions being more frequently reduced. 


\section{Chapter 6: Conclusions \& Implications}

The following chapter provides a conclusion of the research objectives of this study, followed by a discussion of the theoretical and managerial implications, limitations of the study, and future research suggestions.

\subsection{Overall Conclusions}

The purpose of this research was to understand consumers' perceptions of authenticity, particularly in the context of indigenous (Māori) brands and values. Specifically, the three primary research objectives were to:

- Firstly, investigate the effect of indigenous branding practices (exemplified in the cultural appropriation of Māori language and symbols) on consumers' authenticity perceptions.

- Secondly, investigate the boundary conditions of the effect of indigenous branding practices (exemplified in the cultural appropriation of Māori language and symbols) on consumers' authenticity perceptions, involving indigenous organisational values (exemplified in tikanga Māori values).

- Lastly, investigate the boundary conditions of the interaction effect between indigenous branding practices (exemplified in the cultural appropriation of Māori language and symbols) and indigenous organisational values (exemplified in tikanga Māori values) on consumers' authenticity perceptions based on ethnic identification.

This dissertation conducted a single study with a quantitative experimental design in order to investigate the above research objectives. Regarding the first objective, it was found that Māori branding did not have a significantly positive impact on consumers' authenticity perceptions when compared to orthodox branding. However, the second objective was satisfied as it was found that indigenous (tikanga Māori) values did have a significantly positive impact on consumers' authenticity perceptions. Additionally, it was found that indigenous organisational values (exemplified in Māori values) moderate the effect of indigenous (Māori) branding practices on consumers' authenticity perceptions. Finally, the third objective was satisfied as it was found that Māori ethnic identification moderates the effect of Māori indigenous branding and Māori indigenous organisational values on consumers' authenticity perceptions. 


\subsection{Theoretical Contributions}

Notwithstanding its limitations, the current study's primary contribution to the current body of literature is through a proposal of a new understanding, namely, indigenous branding congruence (IBC) theory. IBC theory finds that congruence among indigenous branding and values results in enhanced consumer authenticity perceptions, meanwhile, incongruence among indigenous branding and values results in reduced consumer authenticity perceptions. Importantly, IBC theory finds that incongruence among indigenous branding and values reduces consumers' authenticity perceptions, most particularly when organisations with conventional values implement indigenous branding. IBC theory is a new proposition that is both important and relevant, as it simultaneously integrates and extends upon current literature on authenticity, cultural appropriation, branding, ethnic identity theory, and self-identity theory.

The primary purpose of this research was to achieve a greater understanding of the relationship between indigenous branding and authenticity, a relationship which has yet to be fully examined by the existing body of academic literature (Fritz, Schoenmueller \& Bruhn, 2017; Ko, Lee \& Wang, 2013; Kolar \& Zabkar, 2010). Following a deeper analysis of current literature, a number of gaps within the indigenous branding and authenticity relationship emerged. The gaps that this dissertation sought to examine were the effect of Māori branding on perceived authenticity, and the effect of synergy and congruence among Māori branding and tikanga values on perceived authenticity. The current study contributed to the present body of literature through its efforts to shed light on these previously unanswered questions. Firstly, it was found that while branding does significantly enhance consumers' authenticity perceptions, Māori branding, relative to orthodox branding, does not significantly enhance consumers' authenticity perceptions. This present study illuminates prior research that's suggests branding elements can enhance consumer perceptions of authenticity (Beverland, Lindgreen \& Vink, 2008; Grayson \& Martinec, 2004; Morhart, et al., 2015; Napoli, et al., 2014), specifically through indicating that orthodox branding elements are better able to enhance consumers' authenticity perceptions as compared Māori branding. A potential reason offered to provide explanation for this finding is the public contention surrounding the commercialisation and commodification of Māori culture, which may have led to consumers' being sensitive towards the use of Māori branding, and in turn, negatively affecting authenticity perceptions. 
Secondly, it was found that while congruence among Māori branding and tikanga values enhances consumers' authenticity perceptions (for the general population), this effect was not significant. In contrast, congruence among orthodox branding and conventional values significantly enhances consumers' authenticity perceptions (for the general population). This study therefore illuminates a weakness within Keller's (1993) suggestion that synergy among brand attributes (e.g. branding and values) enhance consumers' perceptions of authenticity, as in an indigenous context, this does not hold true. Moreover, while Keller (1993) tended to focus on the positive outcomes of synergy and congruence, the current study highlights the negative outcomes which can occur when there is incongruence among brand attributes (branding and values), namely the reduction in authenticity perceptions. Continuing on from this finding, it was found that the incongruence that occurs when organisations with conventional values implement Māori branding is perceived as significantly less authentic than the incongruence that occurs when organisations with tikanga values implement orthodox branding. An underlying issue which was thought to explain this issue was that the former incongruence is resemblant of cultural appropriation (Matthes, 2016), whereas the latter is not.

Third, it was found that non-Māori consumers perceived congruence among orthodox branding and conventional values as authentic; a finding which is consistent with prior literature on social identity theory (Tajfel \& Turner, 1979). Notably, consumers shape their sense of self and distinguish themselves from others through endorsing products and services which they perceive to be authentically characteristic of their group (Ahearne, Bhattacharya \& Gruen, 2005; Cornwell \& Coote, 2005; Tajfel \& Turner, 1979). However, Māori consumers perceived both congruence among Māori branding and tikanga values, and orthodox branding and conventional values as authentic. This finding is enlightening, as social identity theory (Tajfel \& Turner, 1979) would imply that Māori consumers with strong ethnic identification would follow suit with non-Māori consumers, and only have favourable authenticity perceptions towards organisations with Māori branding and tikanga values, which would be characteristic of their group (Beverland \& Farelly, 2010; Kates, 2004; Leigh, Peters \& Shelton, 2006; Rifon, Choi, Trimble \& Li, 2004). On the contrary, Māori consumers had favourable authenticity perceptions to both types of congruence, a finding which may be owed to Māori consumers' norms being similar to non-Māori consumers, as Māori and non-Māori consumers do not live in separate societies. This rests upon the evidenced claim that alignment between the norms of a consumer and of a brand, is a key driver of authenticity (Beverland \& Farelly, 2010; Kates, 2004; Leigh, Peters \& Shelton, 2006; Rifon, Choi, Trimble \& Li, 2004). 
Finally, it was found that while both Māori and non-Māori consumers perceived incongruence between Māori branding and conventional values as the least authentic (perhaps due to its resemblance of cultural appropriation), incongruence between orthodox branding and tikanga values significantly reduced Māori consumers' authenticity perceptions. This finding was consistent with prior research on ethnic identification which suggests that consumers with high levels of ethnic identification, and therefore high levels of cultural knowledge, are more discerning of the authentic use of marketing messages targeted at their specific ethnicity (Appiah, 2001; Grier \& Brumbaugh, 1999; Holland \& Gentry, 1997). Furthermore, the findings of the current study extend the aforementioned research in two ways. Firstly, through providing some evidence that consumers with high levels of ethnic identification are discerning of congruence among marketing attributes (e.g. branding and values), which is distinct from the discernment of marketing messages which prior research identified. Secondly, this study extends prior research by placing it in an explicitly indigenous Māori context. It is important to affirm this research in an indigenous Māori context, as Māori have unique socio-cultural experiences that are different to many other ethnic groups, regardless of whether they are ethnic minorities or not.

Another key theoretical contribution of the current study was the implementation and adaptation of a Kaupapa Māori research paradigm in a quantitative, experimental design setting. Kaupapa Māori research is most often used in conjunction with qualitative research, whereas there are relatively few quantitative studies which utilise a Kaupapa Māori approach. There are many valid reasons for the usual coupling of qualitative research and Kaupapa Māori research approach, however, a particularly salient reason for this coupling is that as a methodological approach, Kaupapa Māori has arisen out of resistance to dominant Western research paradigms (in particular positivist). Historically, these dominant Western research paradigms have been an integral part of research which has worked to create and maintain power imbalances and structural inequality between Māori and Pākehā in a manner which has continually benefitted Pākehā above Māori in social, economic and political arenas (Jahnke \& Taiapa, 2003; Smith 1999; Walker, Eketone \& Gibbs, 2006). This research has often been deficit based and constructed in a manner which reinforces the superiority of Pākehā knowledge and denies the legitimacy of Māori knowledge and experiences (Jahnke \& Taiapa, 2003; Smith 1999; Walker, Eketone \& Gibbs, 2006). In resistance to Western research and 
research paradigms, Kaupapa Māori emerged as a way to embraces a Māori worldview and empower Māori aspirations (Te Ariki \& Spoonley, 1992).

The importance of a Māori world view has clearly been translated into the six general principles and seven ethical principles of Kaupapa Māori research (Walker, Eketone \& Gibbs, 2006), specifically through the emphasis on reciprocity and connections between the researcher and the researched. This emphasis on reciprocity and connections is reflective of the Māori principle of whakapapa. Examples of this principle in action are the whanau principle, which requires the researcher to embrace collective responsibility, and to emphasise cultural values, customs and practises throughout the research process (Pihama, Smith, Taki \& Lee, 2004); and the kanohi kitea principle, which requires the researcher to be willing and comfortable to cross the role divide between the researchers and the researched (Cram, 2001). Naturally, these principles lend themselves to qualitative research methods where there is no physical divide between the researcher and researched.

While kaupapa Māori scholars have argued that both qualitative and quantitative research methods can be employed to serve the purpose of Kaupapa Māori research, there are significantly less Kaupapa Māori studies which have employed quantitative research methods. A result of this scant body of quanitative, Kaupapa Māori literature is that it is difficult to execute a Kaupapa Māori study. A result which is only compounded by the principles of Kaupapa Māori not always naturally lending themselves to quantitative research methods. While some critics may argue that quantitative research methods are not a necessary part nor addition to the current body of Kaupapa Māori research, this dissertation argues that Kaupapa Māori scholars have not explicitly stated that quantitative research methods do not belong within the Kaupapa Māori literature. In contrast, Kaupapa Māori scholars have explicitly stated that there are no specific research methods attached to the Kaupapa Māori research approach, and both qualitative and quantitative approaches can be adopted (Moewaka-Barnes, 2000). It is a weakness of Kaupapa Māori to create space for both qualitative and quantitative research, but to only clearly demarcate this space for qualitative research. If there is space for quantitative research methods within the Kaupapa Māori literature, as Moewaka-Barnes (2000) argues there is, then this space should be clearly demarcated so that researchers wanting to employ quantitative research methods in this space are able to do so successfully.

The contribution of this dissertation to the body of Kaupapa Māori literature is the adaptation of the general and ethical principles of Kaupapa Māori (refer Table 1,2). This dissertation will 
now turn to first discuss the significant adpatations of the general principles of Kaupapa Māori, followed by the significant adaptations of the ethical principles of Kaupapa Māori. Emphasis here will be placed on the principles which required significant adaptations, as not all did (e.g. tino rangitiratanga). For the general principles, there were two significant changes deemed necessary. The first significant change was to principe Ako Māori which requires researchers to prioritise Māori ways of teaching and learning that are unique to tikanga Māori (Pihama, Smith, Taki \& Lee, 2004). Thus, this principle does not lend itself naturally to quantitative research. However, a deeper analysis of this principle revealed that Kaupapa Māori scholars think it is important to not ignore "borrowed" pedagogies from other cultures (Smith, 1997), and methods such as qualitative and quantitative approaches can be adopted to serve the purpose of the Kaupapa Māori research (Moewaka-Barnes, 2000). Therefore, it was thought that if the purpose of the study is best served by quantitative approaches then it is acceptable to employ them. As a result, the third principle was extended by elaborating on instances where it is appropriate to include other approaches (e.g. quantitative methods). Another way this principle can be applied in a quantitative, experimental design setting is to offer the questionnaire in both English and Māori. As this would be an approach of teaching and learning through the questionnaire that is unique to Māori. Unfortunately, due to time constraints this was not a factor employed in the current study. The second significant change was to whannau principle, which requires the researcher to embrace collective responsibility, and to emphasise cultural values, customs and practises throughout the research process (Pihama, Smith, Taki \& Lee, 2004). It was thought that even though this principle lends itself more to qualitative studies where researchers can enact this principle in interactions with their research subjects. However, researchers employing quantitative methods could employ this principle through engaging with multiple Māori stakeholders in the creation, analysis and dissemination of the research. From these interactions Kaupapa Māori researchers can create research that aligns with the cultural values, customs and practices of Māori. As a whole, the general principles of Kaupapa Māori were more amenable to quantitative action than ethical principles of Kaupapa Māori which will be discussed below.

For the ethical principles of Kaupapa Māori research, four of the seven principles were deemed to require significant adaptation. The first principle, aroha ki tangata, requires the researcher to ensure that participants are able to meet on terms that the participants create, and ensure that the participants can define their own space (Cram, 2001). This principle speaks to the physical space of the research environment, and as such lends itself more naturally to qualitative 
research where the researcher and researched do physically interact. However, it was thought that quantitative research can also respond to this need as pressure for participants to participate in the research is alleviated through the researcher being removed from the physical space. More so, if participants do choose to engage with the research they are able to create and define their own space in a multiplicity of ways as the survey can be done on mobile phones, anywhere. The second principle requiring significant adaptation was kanohi kitea. This principle requires the researcher to be willing and comfortable to cross the role divide between the researchers and the researched (Cram, 2001). This principle lends itself to physical interaction, where steps can be taken through tone of voice, word choice and body language to ameliorate power inequalities between the researcher and the researched. However, in a quantitative setting, this step can be applied prior to and post data collection. Prior to data collection researchers can state their contact details to allow for communication with participants if they choose. Post data collection, researchers can share the research with key community groups and stakeholders. The application of this principle in a quantitative setting is more indirect than when this principle is applied a qualitative setting, as researchers in a qualitative setting are able to directly address participants and break down divides. The third principle requiring significant adaptation was manaaki ki te tangata, which is guided by the idea of sharing and reciprocity (Cram, 2001; Smith 2005). Researchers are encouraged to view the research process as an equally constructed collaboration with participants. This principle also requires the researcher to share the research findings with participants. As quantitative research, specifically experimental design, does not allow for researchers to express manaakitanga in a physical sense, this principle does not naturally lend itself to a quantitative context. However, through ensuring that the place where participants are hosted is respectful and comfortable, this principle can still be applied. Specifically, through implementing a clean and professional design, communicating in clear language (whilst avoiding overly technical jargon), and having a reasonable length of survey. Another issue with not being able to express manaakitanga, through reciprocity is the inability to give back to participants when the number is large. Here, researchers can offer participants the equal opportunity to win a voucher of some kind in return for participating in the study. For example, the current study provided all participants with the opportunity to win one of four $\$ 50$ New World vouchers. The fourth principle requiring significant adaptation was kia tupato, which requires researchers to be "politically astute, culturally safe, and reflective about their insider/outsider status" (Smith, 2005, p. 98). Despite appearing to have implications most relevant to situations where the researcher and researched physically interact, this principle quite easily extended to a 
quantitative setting. This is because the limited interaction between researcher and researched in a quantitative, experimental design setting (e.g. online questionnaire) requires planning. Through this planning researchers are able to maximise the extent to which they are politically astute, culturally safe, and reflective about her insider/outsider status. Understanding how to do this can be achieved through engaging with multiple Māori researchers, family and friends throughout the research process. This is especially beneficial for Māori researchers who may have lower levels of cultural knowledge and experience. These researchers may be able to enact kia tupato principle in a controlled environment (e.g. online questionnaire), better than in an open environment (e.g. focus group).

In conclusion, the current study's implementation and adaptation of a Kaupapa Māori research approach in a quantitative, experimental design setting provided a valuable contribution to the current body of academic literature. Moreover, this contribution is actionable for future researchers who may want to employ a Kaupapa Māori research approach. These researchers can utilise the adapted principles (refer table 1,2) to ensure their research meets the general and ethical principles of Kaupapa Māori.

\subsection{Managerial Implications}

This dissertation also provides valuable insights for marketing practitioners who may in future, or currently do, implement (Māori) indigenous branding elements and (Māori) indigenous organisational values. These insights can be used to inform marketing practitioners strategic decision making. The implications for marketing practitioners can be split into two categories: congruent tactics and incongruent tactics.

Firstly, the findings indicate that congruence between branding, organisational values, and the ethnic identification of consumers exerts the most positive leverage on consumers' authenticity perceptions. Organisations should thus ensure that their values and branding align with the ethnic identification of their target market. Specifically, if the target market is Māori, then so too should be the branding and values. In contrast, if the target market is non-Māori, then orthodox branding and conventional branding is most effective. This finding is supported by previous literature which suggests that congruence between a brand's values and norms, and those of its consumers, is a key driver of brand authenticity (Beverland \& Farelly, 2010; Kates, 2004; Leigh, Peters \& Shelton, 2006). 
Secondly, the findings indicate that incongruence among branding, values, and consumers' ethnic identification significantly reduces consumers' authenticity perception, especially when incongruent Māori branding and conventional values are present. This finding is perhaps linked to issues around intellectual property rights and cultural appropriation (Bunten, 2010; Butler \& Hinch, 2007; Matthes, 2016; Riley \& Carpenter, 2015; Waitangi Tribunal, 2011). Even though some organisations will not be motivated or able to change their branding to create congruence, the findings of this study can inform their strategic decisions. For example, if an organisation with conventional values wants to implement Māori branding, then they should be less transparent about their organisational values as the findings of the current study show that consumers analyse these attributes in conjunction when making authenticity attributions. Organisations with tikanga values who wish to implement orthodox branding should also aim to be less transparent with their values, although this is less important compared to organisations with conventional values.

\subsection{Limitations and Future research}

This dissertation now turns to the limitations of this study, as it is through analysis of the limitations of the current study that the foundations of future research are built.

A primary weakness of the current study was the use of water as the product stimulus. Water is inexpensive and, as such, is a low involvement product. It is possible that if high involvement products were to be used instead (e.g. jewellery), the results might have been different. Therefore, future research should consider using both high and low involvement products to ascertain whether (Māori) indigenous branding elements and values impact consumers' authenticity perceptions differently when higher involvement is required from consumers.

Another weakness of this study was that the scope was limited to New Zealand consumers. It is recognised that a global perspective may be of interest since (Māori) indigenous branding is equally prominent in New Zealand export goods sold in offshore markets. The results of the current study show that perceptions between New Zealanders (Māori and non-Māori) differ; therefore, it is equally likely that the perceptions of international consumers will differ too. Understanding the perceptions of global markets will be of particular importance to organisations wishing to implement Māori branding for export goods. 


\section{References}

Aaker, D. A. (2012). Building Strong Brands. London, UK: Simon and Schuster.

Ahearne, M., Bhattacharya, C. B., \& Gruen, T. (2005). Antecedents and consequences of customer-company identification: Expanding the role of relationship marketing. Journal of Applied Psychology, 90(3), 574-585.

Anyon-Peters, C. (2017). Protecting Taonga Works: Does the WAI262 Report Measure Up? Retrieved from https://cdn.auckland.ac.nz/assets/auckland/law/ourresearch/researchgroupsandpublications/2018tetaiharurujournal/tth-anyon-peters.pdf

Appiah, O. (2001). Ethnic identification on adolescents' evaluations of advertisements. Journal of Advertising Research, 41(5), 7-22.

Arvidsson, A. (2005). Brands: A critical perspective. Journal of Consumer Culture, 5(2), 235-258.

Auster, E. R., \& Freeman, R. E. (2013). Values and poetic organizations: Beyond value fit toward values through conversation. Journal of Business Ethics, 113(1), 39-49.

Baker, W. E. (2003). Does brand name imprinting in memory increase brand information retention?. Psychology \& Marketing, 20(12), 1119-1135.

Balmer, J. M. (2013). Corporate brand orientation: What is it? What of it?. Journal of Brand Management, 20(9), 723-741.

Barnes, H. M. (2000). Kaupapa Maori: explaining the ordinary. Pacific Health Dialog, 7(1), 13-16.

Bastos, W., \& Levy, S. (2012). A history of the concept of branding: Practice and theory. Journal of Historical Research in Marketing, 4(3), 347-368.

Best, P., \& Love, M. (2010). Māori values for Māori business: Cultural capital in indigenous organisations. Wellington, New Zealand: Victoria University of Wellington.

Best, P., Adds, P., \& Mercier, O. (2013). The Best of Both Worlds - How Mãori Small Businesses Engage with their Pākehā and Mãori Values. Retrieved from http://hdl.handle.net/10063/3051

Bethlehem, J., \& Biffignandi, S. (2011). Handbook of Web Surveys (Vol. 567). London, UK: John Wiley \& Sons.

Beverland, M. B., \& Farrelly, F. J. (2010). The quest for authenticity in consumption: Consumers' purposive choice of authentic cues to shape experienced outcomes. Journal of Consumer Research, 36(5), 838-856. doi:10.1086/615047 
Beverland, M. B., Lindgreen, A., \& Vink, M. W. (2008). Projecting authenticity through advertising: Consumer judgments of advertisers' claims. Journal of Advertising, 37(1), 5-15. doi:10.2753/JOA0091-3367370101

Blodgett, M. S., Dumas, C., \& Zanzi, A. (2011). Emerging trends in global ethics: A comparative study of US and international family business values. Journal of Business Ethics, 99(1), 29-38.

Brewer, K. M., Harwood, M. L., McCann, C. M., Crengle, S. M., \& Worrall, L. E. (2014). The use of interpretive description within Kaupapa Māori research. Qualitative Health Research, 24(9), 1287-1297.

Brown, S. (2001). Marketing - The Retro Revolution. London, UK: Sage.

Butler, R., \& Hinch, T. (2007). Tourism and indigenous peoples: Issues and implications. Oxford, MA: Butterworth-Heinemann.

Bunten, A. C. (2008). Sharing culture or selling out? Developing the commodified persona in the heritage industry. American Ethnologist, 35(3), 380-395.

Bunten, A. C. (2010). More like ourselves: Indigenous capitalism through tourism. American Indian Quarterly, 34(3), 285-311.

Chu, K., Lee, D.-H., \& Kim, J. Y. (2016). The effect of non-stereotypical gender role advertising on consumer evaluation. International Journal of Advertising, 35(1), 106134.

Clark, F.E. (1927). Principles of Marketing. New York, NY: Macmillan.

Cornwell, T. B., \& Coote, L. V. (2005). Corporate sponsorship of a cause: the role of identification in purchase intent. Journal of Business Research, 58(3), 268-276.

Cova, B. (1997). Community and consumption: Towards a definition of the "linking value" of product or services. European Journal of Marketing, 31(3/4), 297-316.

Cova, B., \& Cova, V. (2001). Tribal aspects of postmodern consumption research: the case of French in-line roller skaters. Journal of Consumer Behaviour: An International Research Review, 1(1), 67-76.

Cram, F. (2001). Rangahau Māori: Tona tika, tona pono - the validity and integrity of Māori research. In M. Tolich (Ed.), Research ethics in Aotearoa New Zealand (pp. 35-52). Auckland: Reed Publishing Ltd.

Creswell, J. W. (2014). Research design: Qualitative, Quantitative, and Mixed Methods Approaches (4th ed.). Thousand Oaks, CA: Sage.

Cui, G. (1997). Marketing strategies in a multi-ethnic environment. Journal of Marketing Theory and Practice, 5(1), 122-134. doi:10.1080/10696679.1997.11501756 
Davies, P., Lattimore, R., \& Ikin, K. (2005). Maori economic development: Overview and prospects. In J. E. Rowe (Ed.), Economic development in New Zealand: The dynamics of economic space (pp. 107-126). Aldershot: Ashgate.

Deshpande, R. (1983). "Paradigms lost": on theory and method in research in marketing. Journal of Marketing, 47(4), 101-110.

Dodds, W. B., Monroe, K. B., \& Grewal, D. (1991). Effects of price, brand, and store information on buyers' product evaluations. Journal of Marketing Research, 28(3), 307-319.

Dong, L., \& Tian, K. (2009). The use of western brands in asserting Chinese national identity. Journal of Consumer Research, 36(October), 504-523.

Euromonitor. (2018). Fortified/Functional Beverages in New Zealand. Retrieved from http://www.portal.euromonitor.com.helicon.vuw.ac.nz/portal/analysis/tab

E Tū. (2006, November 29). Air NZ claims property rights over koru. Scoop Politics. Retrieved from http://www.scoop.co.nz/stories/PO0611/S00424.htm

Evans, J. R., \& Mathur, A. (2005). The value of online surveys. Internet Research, 15(2), 195-219.

Forbes, S. L., \& Dean, D. L. (2013). Consumer perceptions of wine brand names. Wine \& Viticulture Journal, 29(5), 55-58.

Fritz, K., Schoenmueller, V., \& Bruhn, M. (2017). Authenticity in branding-exploring antecedents and consequences of brand authenticity. European Journal of Marketing, 51(2), 324-348.

Grayson, K., \& Martinec, R. (2004). Consumer perceptions of iconicity and indexicality and their influence on assessments of authentic market offerings. Journal of Consumer Research, 31(2), 296-312. doi:10.1086/422109

Grier, S. A., \& Brumbaugh, A. M. (1999). Noticing cultural differences: Ad meanings created by target and non-target markets. Journal of Advertising, 28(1), 79-93.

Geuens, M., \& De Pelsmacker, P. (2017). Planning and conducting experimental advertising research and questionnaire design. Journal of Advertising, 46(1), 83-100.

Hair, J. F., Jr., Black, W. C., Babin, B. J., Anderson, R. E., \& Tatham, R. L. (2010). Multivariate Data Analysis (7th ed.). Upper Saddle River, NJ: Pearson Prentice Hall.

Harmsworth, G. (2002, November). Indigenous concepts, values and knowledge for sustainable development: New Zealand case studies. In 7th Joint Conference on the Preservation of Ancient Cultures and the Globalization Scenario, India (pp. 22-24). Hamilton, New Zealand: University of Waikato Press. 
Harmsworth, G., Barclay-Kerr, K., \& Reedy, T. M. (2002). Maori sustainable development in the 21st century: The importance of Maori values, strategic planning and information systems. He Puna Korero: Journal of Maori and Pacific Development, 3(2), 40-68.

Harmsworth, G., Gilbert, K., Taylor, R., \& Stafford, J. (2013). Māori Business Branding: Achieving Competitive Advantage in Global Markets. He Pukenga Korero, 9(1), 3645.

Harmsworth, G., \& Tahi, M. (2008, July). Indigenous branding: Examples from Aotearoa New Zealand. In Proceedings of the FIBEA-Fostering Indigenous Business \& Entrepreneurship in the Americas Conference (pp. 22-25). Manaus, Brazil: who was the publisher?

Holland, J., \& Gentry, J. W. (1999). Ethnic consumer reaction to targeted marketing: A theory of intercultural accommodation. Journal of Advertising, 28(1), 65-77. doi:10.1080/00913367.1999.10673577

Holt, D. B. (2002). Why do brands cause trouble? A dialectical theory of consumer culture and branding. Journal of Consumer Research, 29(1), 70-90.

Ilieva, J., Baron, S., \& Healey, N. M. (2002). Online surveys in marketing research: Pros and cons. International Journal of Market Research, 44(3), 361-382.

Intellectual Property Office of New Zealand. (n.d.). Concepts to Understand. Retrieved from https://www.iponz.govt.nz/about-ip/maori-ip/concepts-to-understand/

Jahnke, R., \& Jahnke, H. T. (2003). The politics of Māori image and design. He Pukenga Kōrero, 7(1), 5-31.

Jahnke, H., \& Taiapa, J. (2003). Maori research. In C. Davidson \& M. Tolich (Eds.), Social Science Research in New Zealand (pp. 39-50). Auckland: Longman.

Jhang, J. H., Grant, S. J., \& Campbell, M. C. (2012). Get it? Got it. Good! Enhancing new product acceptance by facilitating resolution of extreme incongruity. Journal of Marketing Research, 49(2), 247-259.

Kadirov, D. (2015). Private labels ain't bona fide! Perceived authenticity and willingness to pay a price premium for national brands over private labels. Journal of Marketing Management, 31(17-18), 1773-1798.

Kates, S. M. (2002). The protean quality of subcultural consumption: An ethnographic account of gay consumers. Journal of Consumer Research, 29(3), 383-399.

Kates, S. M. (2004). The dynamics of brand legitimacy: An interpretive study in the gay men's community. Journal of Consumer Research, 31(2), 455-464.

Keller, K. L. (1993). Conceptualizing, measuring, and managing customer-based brand equity. Journal of Marketing, 57(January), 1-22. 
Keller, K. L. (2001). Building customer-based brand equity: A blueprint for creating strong brands. Marketing Management, 10(July/August), 15-19.

Keller, K. L. (2003). Brand synthesis: The multidimensionality of brand knowledge. Journal of Consumer Research, 29(4), 595-600.

doi:http://dx.doi.org.helicon.vuw.ac.nz/10.1086/346254

Keller, K. L., Heckler, S. E., \& Houston, M. J. (1998). The effects of brand name suggestiveness on advertising recall. The Journal of Marketing, 62(1), 48-57.

Keller, K. L., \& Lehmann, D. R. (2006). Brands and branding: Research findings and future priorities. Marketing Science, 25(6), 740-759.

Knobloch-Westerwick, S., \& Coates, B. (2006). Minority models in advertisements in magazines popular with minorities. Journalism \& Mass Communication Quarterly, 83(3), 596-614.

Koehn, N. F. (2001). Brand new: How entrepreneurs earned consumers' trust from Wedgwood to Dell. Boston, MA: Harvard Business School Press.

Koeman, J., Jaubin, K., \& Stesmans, A. (2010). Standardization or adaptation? Ethnic marketing strategies through the eyes of practitioners and consumers in Flanders. Communications: The European Journal of Communication Research, 35(2), 165185. doi:10.1515/comm.2010.009

Kolar, T., \& Zabkar, V. (2010). A consumer-based model of authenticity: An oxymoron or the foundation of cultural heritage marketing? Tourism Management, 31(5), 652-664.

Kuhn, T. S. (1996). The Structure of Scientific Revolutions (3rd ed.). Chicago, IL: University of Chicago Press.

Lai, J. C. (2016). Indigenous cultural heritage and intellectual property rights. New York, NY: Springer International.

Leigh, T. W., Peters, C., \& Shelton, J. (2006). The consumer quest for authenticity: The multiplicity of meanings within the MG subculture of consumption. Journal of the Academy of Marketing Science, 34(4), 481-493.

Levy, S. J. (1959). Symbols for sale. Harvard Business Review, 37(4), 117-124.

Li, W. K., \& Wyer Jr, R. S. (1994). The role of country of origin in product evaluations: informational and standard-of-comparison effects. Journal of Consumer Psychology, 3(2), 187-212.

Matthes, E. (2016). Cultural appropriation without cultural essentialism? Social Theory and Practice, 42(2), 343-366.

Matthews, J. A. (2013). The urban 'Intangibles of Māori-ness': an ethnographic study of urban Marae curriculum as decolonial praxis (Doctoral dissertation, University of 
Southern Queensland). Retrieved from https://eprints.usq.edu.au/27834/3/Matthews 2013 whole.pdf

Mazutis, D. D., \& Slawinski, N. (2015). Reconnecting business and society: Perceptions of authenticity in corporate social responsibility. Journal of Business Ethics, 131(1), 137-150.

McCracken, G. (1986). Culture and consumption: A theoretical account of the structure and movement of the cultural meaning of consumer goods. Journal of Consumer Research, 13(1), 71-84.

McDaniel, C. G. (2010). Marketing research ( $8^{\text {th }}$ ed.). Hoboken, NJ: Wiley.

McIntosh, A. (2004). Tourists' appreciation of Maori culture in New Zealand. Tourism Management, 25(1), 1-15.

McIntosh, A. J., \& Ryan, C. (2007). The market perspective of indigenous tourism: Opportunities for business development. In R. Butler \& T. Hinch (Eds.), Tourism and Indigenous Peoples: Issues and Implications (pp. 73-83). Oxford: ButterworthHeinemann.

McIntosh, A., Zygadlo, F., \& Matunga, H. (2004). Rethinking Maori tourism. Asia Pacific Journal of Tourism Research, 9(4), 331-352.

Meade, A. W., \& Craig, S. B. (2012). Identifying careless responses in survey data. Psychological Methods, 17(3), 437- 455.

Mihaere, R. (2015). A kaupapa Māori analysis of the use of Mãori cultural identity in the prison system. Retrieved from http://hdl.handle.net/10063/4185

Minor-Cooley, D., \& Brice, J., Jr. (2007). Please check the appropriate box: the problems with ethnic identification and its potential in cross-cultural marketing. Academy of Marketing Science Review, 2007(9), page range?.

Morhart, F., Malär, L., Guèvremont, A., Girardin, F., \& Grohmann, B. (2015). Brand authenticity: An integrative framework and measurement scale. Journal of Consumer Psychology, 25(2), 200-218. doi:10.1016/j.jcps.2014.11.006

Morgan, P., \& Mulligan, W. (2006). Hei Whakamarama i ngā āhuatanga o te tūrua pō: Investigating key Māori business characteristics for future measures: Thinking paper. Wellington, New Zealand: Te Puni Kōkiri.

Napoli, J., Dickinson, S. J., Beverland, M. B., \& Farrelly, F. (2014). Measuring consumerbased brand authenticity. Journal of Business Research, 67(6), 1090-1098.

NZPA. (2001, October 31). Lego says maori influenced toys were legal. The New Zealand Herald. Retrieved from https://www.nzherald.co.nz/nz/news/article.cfm?c_id=1\&objectid=225763 
Park, C. W., Jun, S. Y., \& Shocker, A. D. (1996). Composite branding alliances: An investigation of extension and feedback effects. Journal of Marketing Research, 33(4), 453-466.

Peirce, C. S. (1974). Collected papers of Charles Sanders Peirce (Vol. 5). Cambridge, MA: Harvard University Press.

Phinney, J. S. (1992). The multigroup ethnic identity measure: A new scale for use with diverse groups. Journal of adolescent research, 7(2), 156-176.

Pihama, L., Cram, F., \& Walker, S. (2002). Creating methodological space: a literature review of Kaupapa Maori research. Canadian Journal of Native Education, 26(1), $30-43$.

Pihama, L., Smith, K., Taki, M., \& Lee, J. (2004). A literature review on kaupapa Maori and Maori education pedagogy. Prepared for ITP New Zealand by The International Research Institute for Maori and Indigenous Education (IRI).

Pires, G. D., \& Stanton, P. J. (2002). Ethnic marketing ethics. Journal of Business Ethics, 36 (1-2), 111-118.

Porter, M. E., \& Kramer, M. R. (2006). The link between competitive advantage and corporate social responsibility. Harvard Business Review, 84(12), 78-92.

Rifon, N. J., Choi, S. M., Trimble, C. S., \& Li, H. (2004). Congruence effects in sponsorship: The mediating role of sponsor credibility and consumer attributions of sponsor motive. Journal of Advertising, 33(1), 30-42.

Riley, A. R., \& Carpenter, K. A. (2015). Owning red: a theory of Indian (cultural) appropriation. Texas Law Review, 94(5), 859-931.

Sachdeva, S. (2010, January 29) Thrown-together uniforms disrespect Māori. Retrieved from www.stuff.co.nz/national/3272904/Thrown-together-uni forms-disrespect-Maori

Schneider, A. (2003). On 'appropriation'. A critical reappraisal of the concept and its application in global art practices. Social Anthropology, 11(2), 215-229.

Schulz, H., \& Stout, P. (2010). Negotiating the boundary between the self and the other: individuation and association through socially-visible brand use. Paper presented at the 2010 Association for Consumer Research Conference, Jacksonville, Florida.

Skarmeas, D., \& Leonidou, C. (2013). When consumers doubt, Watch out! The role of CSR skepticism. Journal of Business Research, 66(10), 1831-1838.

Smith, G.H. (1997). The Development of Kaupapa Māori: Theory and Praxis (Unpublished doctoral dissertation). University of Auckland, Auckland, New Zealand.

Smith, L. T. (1999). Decolonizing methodologies. Dunedin: Otago Press. 
Smith, L. T. (2005). Building a research agenda for indigenous epistemologies and education. Anthropology \& Education Quarterly, 36(1), 93-95.

Smith, L. T. (2015). Kaupapa Māori Research-Some Kaupapa Māori Principles. In L. Pihama \& K. South (Eds.), Kaupapa Rangahau A Reader: A Collection of Readings from the Kaupapa Maori Workshop Series (pp. 46-53). Auckland, New Zealand: Te Kotahi Research Institute.

Solomon, M. (2000). Intellectual property rights and indigenous peoples rights and obligations. In Workshop on instruments for access and benefit sharing from genetic resources and related traditional knowledge issues, Global Biodiversity Forum (Vol. 15)

Spiller, C., Pio, E., Erakovic, L., \& Henare, M. (2011). Wise up: Creating organizational wisdom through an ethic of Kaitiakitanga. Journal of Business Ethics, 104(2), 223235.

Stayman, D. M., \& Deshpande, R. (1989). Situational ethnicity and consumer behavior. Journal of Consumer Research, 16(3), 361-371.

Statista. (2018). Breakdown of Facebook users in New Zealand as of January 2018, by age group. Retrieved from https://www.statista.com/statistics/681512/new-zealandfacebook-users-by-age/

Stern, B. B. (2006). What does brand mean? Historical-analysis method and construct definition. Journal of the Academy of Marketing Science, 34(2), 216-223.

Sung, Y., \& Tinkham, S. F. (2005). Brand personality structures in the United States and Korea: Common and culture-specific factors. Journal of Consumer Psychology, 15(4), 334-350.

Suter, B. (2014). The contra proferentem rule in the reports of the Waitangi Tribunal. Retrieved from http://hdl.handle.net/10063/4404.

Taiuru, K. (2019, January 4). NZ Businesses continue to appropriate Māori culture. Scoop Business. Retrieved from http://www.scoop.co.nz/stories/BU1901/S00012/nzbusinesses-continue-to-appropriate-maori-culture.htm

Tajfel, H., \& Turner, J. C. (1979). An integrative theory of intergroup conflict. In W. G. Austin \& S. Worchel (Eds.), The Social Psychology of Intergroup Relations (pp. 3347). Monterey, CA: Brooks/Cole.

Te Ariki, C., \& Spoonley, P. (1992). The politics and process of research for Maori. Palmerston North: University of Massey.

Thomson, S. (2015). Indigenous branding: creating a point of difference to the New Zealand primary sector. Retrieved from https://researcharchive.lincoln.ac.nz/bitstream/handle/10182/6712/Thomson_2015.pdf ? sequence $=1 \&$ is Allowed $=\mathrm{y}$ 
Victoria University. (2018a). Māori at Victoria - a brief history. Retrieved from https://www.victoria.ac.nz/maori-at-victoria/rangatiratanga/history-of-maori-atvictoria

Victoria University. (2018b). Victoria at a glance. Retrieved from https://www.victoria.ac.nz/about/victorias-story/statistics

Walker, S., Eketone, A., \& Gibbs, A. (2006). An exploration of Kaupapa Maori research, its principles, processes and applications. International Journal of Social Research Methodology, 9(4), 331-344.

Webb, D. J., \& Mohr, L. A. (1998). A typology of consumer responses to cause-related marketing: From skeptics to socially concerned. Journal of Public Policy \& Marketing, 17(2), 226-238.

Wilkinson, I. F., \& Cheng, C. (1999). Perspectives: Multicultural marketing in Australia: Synergy in diversity. Journal of International Marketing, 7(3), 106-125.

Wright, K. B. (2005). Researching internet-based populations: Advantages and disadvantages of online survey research, online questionnaire authoring software packages, and web survey services. Journal of Computer-Mediated Communication, 10(3), https://doi.org/10.1111/j.1083-6101.2005.tb00259.x

Zikmund, W. G., D'Alessandro, S., Winzar, H., Lowe, B., \& Babin, B. J. (2014). Marketing Research (3rd ed.). Melbourne: Cengage Learning. 


\section{Appendices}

\section{Appendix}

Appendix A: Full Questionnaire

\begin{tabular}{|c|c|c|}
\hline Q\# & Item & Action \\
\hline $\begin{array}{l}\text { Participant } \\
\text { Information }\end{array}$ & $\begin{array}{l}\text { My name is Brittany Baltus, and I am a Masters student in the } \\
\text { School of Marketing and International Business at Victoria } \\
\text { University. I would like to invite you to participate in research } \\
\text { that I am doing as part of my dissertation at Victoria University. } \\
\text { The purpose of this research is to evaluate the proposed brand } \\
\text { concepts. This data will be used to conduct an analysis on New } \\
\text { Zealand consumers. } \\
\text { The survey is completely voluntary, and it is not possible for any } \\
\text { respondent to be identified personally in conjunction with this } \\
\text { survey. By choosing to continue with this survey, consent is } \\
\text { implied. The survey should take around } 7 \text { minutes to complete. } \\
\text { Instructions on how to answer the survey are on the following } \\
\text { page. Results from the study will be compiled into a written } \\
\text { report. Ethics approval has been obtained for this research from } \\
\text { Victoria University (RM } 26910 \text { ). Please only complete this } \\
\text { survey once. } \\
\text { This is a secure website and all responses collected will remain } \\
\text { anonymous. All of the material related to survey responses will } \\
\text { only be viewed by the researcher and the supervisors. All printed } \\
\text { information will be kept in a locked file with access restricted to } \\
\text { the researcher. All electronic data will be kept in a password } \\
\text { protected file only accessible by the researcher. Data collected } \\
\text { in this survey will be destroyed after three years. It is possible } \\
\text { that summary results from this survey may appear in academic } \\
\text { or professional journals and may also be presented at academic } \\
\text { or professional conferences. } \\
\text { If you have any comments or questions about this research, } \\
\text { please do not hesitate to contact me: } \\
\text { Student Researcher - Brittany Baltus } \\
\text { baltusbrit@myvuw.ac.nz } \\
\text { Supervisor - Dr Janet Davey } \\
\text { Lecturer, School of Marketing and International Business } \\
\text { janet.davey@vuw.ac.nz } \\
\text { Supervisor - Dr Djavlonbek Kadirov } \\
\text { djavlonbek.kadirov@ vuw.ac.nz }\end{array}$ & Accept \\
\hline
\end{tabular}




\begin{tabular}{|c|c|c|}
\hline & $\begin{array}{l}\text { Thank you for your participation! } \\
\text { Human Ethics Committee information } \\
\text { If you have any concerns about the ethical conduct of the } \\
\text { research, you may contact the Victoria University HEC } \\
\text { Convenor: Dr Judith Loveridge. Email hec@vuw.ac.nz or } \\
\text { telephone+64-4-4636028. }\end{array}$ & \\
\hline \multirow[t]{3}{*}{ Q1 } & Participants were asked: Are you over 18 years of age? & \multirow[t]{3}{*}{ Select one } \\
\hline & Yes & \\
\hline & No & \\
\hline \multirow[t]{3}{*}{ Q2 } & $\begin{array}{l}\text { Participants were asked: Do you currently live in New } \\
\text { Zealand? }\end{array}$ & \multirow[t]{3}{*}{ Select one } \\
\hline & Yes & \\
\hline & No & \\
\hline \multirow[t]{8}{*}{ Q3 } & Participants were asked: Which group do you identify as? & \multirow[t]{8}{*}{ Select one } \\
\hline & Māori & \\
\hline & NZ European & \\
\hline & Asian & \\
\hline & Pacific Island nations & \\
\hline & European & \\
\hline & Middle Eastern/ Latin American/ African (MELAA) & \\
\hline & American/ Canadian & \\
\hline \multirow[t]{2}{*}{ Q4 } & $\begin{array}{c}\text { Participants were presented with: ONE of the FOUR } \\
\text { possible scenarios listed below }\end{array}$ & \multirow[t]{2}{*}{$\begin{array}{l}\text { No action } \\
\text { required }\end{array}$} \\
\hline & $\begin{array}{l}\text { Scenario 1 } \\
\text { BeStill is a food and drink company that is wanting to introduce } \\
\text { a new fortified water drink into the New Zealand Market. } \\
\text { Fortified water drinks are drinks infused with functional } \\
\text { ingredients such as vitamins, minerals or herbs. BeStill is } \\
\text { particularly interested in releasing a drink infused with } \\
\text { kawakawa, which has been used in New Zealand for centuries } \\
\text { by Māori as a natural remedy for digestive functions. } \\
\text { BeStill is owned by the Duke of Sussex Trust in partnership } \\
\text { with Wengbao Corporation. As an organisation, BeStill is } \\
\text { directed by a range of values centred around a triple bottom line } \\
\text { - people, planet and profit. BeStill enacts these values in a } \\
\text { number of ways, for example, the staff at BeStill spend one } \\
\text { weekend of every month working around New Zealand on a } \\
\text { range of activities to make our waterways cleaner and clearer } \\
\text { (planet). BeStill also provides school uniforms, shoes and } \\
\text { stationery equipment for all of the children of their staff, and } \\
\text { lunches are always provided for all staff (people). } \\
\text { In what follows, you will first be presented with the potential } \\
\text { product design for BeStill's new fortified water product. } \\
\text { Following this, you will be asked some questions on the design } \\
\text { of the product. }\end{array}$ & \\
\hline
\end{tabular}




\section{Scenario 2}

BeStill is a food and drink company that is wanting to introduce a new fortified water drink into the New Zealand Market. Fortified water drinks are drinks infused with functional ingredients such as vitamins, minerals or herbs. BeStill is particularly interested in releasing a drink infused with kawakawa, which has been used in New Zealand by Māori for centuries as a natural remedy for digestive functions.

Bestill is owned by the Te Puni Kōkiri Community Trust. As an organisation, BeStill is directed by a range of Tikanga Māori values such as kaitiakitanga (guardianship of resources), whanaungatanga (a sense of belonging) manaakitanga (respect and sharing). BeStill enacts these values in a number of ways, for example, the staff at BeStill spend one weekend of every month working around New Zealand on a range of activities to make our waterways cleaner and clearer (kaitiakitanga). BeStill also provides school uniforms, shoes and stationery equipment for all of the children of their staff (whangaungatanga). And lunches are always provided for all staff (manaakitanga).

In what follows, you will first be presented with the potential product design for BeStill's new fortified water product. Following this, you will be asked some questions on the design of the product.

\section{Scenario 3}

$\bar{A}$ io is a food and drink company that is wanting to introduce a new fortified water drink into the New Zealand Market. Fortified water drinks are drinks infused with functional ingredients such as vitamins, minerals or herbs. Āio is particularly interested in releasing a drink infused with kawakawa, which has been used in New Zealand by Māori for centuries as a natural remedy for digestive functions.

$\bar{A}$ io is owned by the Duke of Sussex Trust in partnership with Wengbao Corporation. As an organisation, Āio is directed by a range of values centred around a triple bottom line - people, planet and profit. Āio enacts these values in a number of ways, for example, the staff at Āio spend one weekend of every month working around New Zealand on a range of activities to make our waterways cleaner and clearer (planet). Āio also provides school uniforms, shoes and stationery equipment for all of the children of their staff, and lunches are always provided for all staff (people).

In what follows, you will first be presented with the potential product design for Āio's new fortified water product. Following 


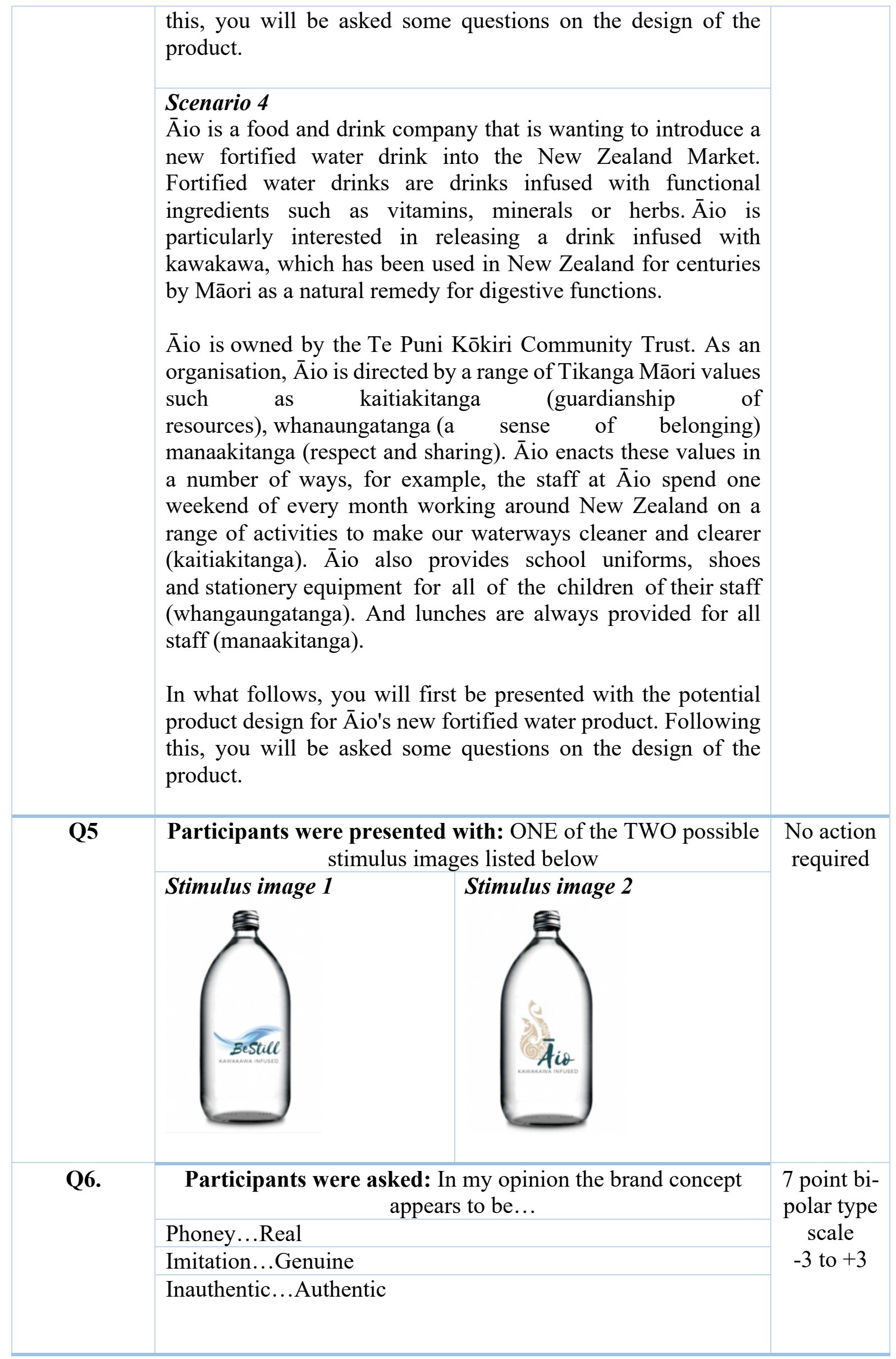




\begin{tabular}{|c|c|c|}
\hline Q7. & $\begin{array}{l}\text { Heading: Purchase Intent } \\
\text { How likely is it that you would purchase this product for } \\
\text { yourself? }\end{array}$ & $\begin{array}{l}\text { 7-Point } \\
\text { Likert } \\
\text { type } \\
\text { scale. } \\
\text { Extremely } \\
\text { unlikely } \\
\text { to } \\
\text { extremely } \\
\text { likely }\end{array}$ \\
\hline Q8. & $\begin{array}{l}\text { Heading: Branding Elements and Values } \\
\text { I think this product has a Māori brand name and symbol. } \\
\text { I think that Māori values are embedded in the values of this } \\
\text { company. } \\
\text { I think the packaging looks good. }\end{array}$ & $\begin{array}{l}\text { 5-Point } \\
\text { Likert } \\
\text { type } \\
\text { scale. } \\
\text { Strongly } \\
\text { Agree to } \\
\text { Strongly } \\
\text { Disagree }\end{array}$ \\
\hline Q9. & $\begin{array}{l}\text { Heading: Cultural Engagement and Identification } \\
\text { I have a strong sense of belonging to Māori culture. } \\
\text { I am happy that I am Māori. } \\
\text { I participate in Māori cultural practices such as spending time } \\
\text { at the marae, going to hui or kapa haka. } \\
\text { I have not spent much time trying to learn about Māori culture } \\
\text { and history, and I don't intend to. } \\
\text { I only try to become friends with people who are Māori. }\end{array}$ & $\begin{array}{l}\text { 5-Point } \\
\text { Likert } \\
\text { type } \\
\text { scale. } \\
\text { Strongly } \\
\text { Agree to } \\
\text { Strongly } \\
\text { Disagree }\end{array}$ \\
\hline Q10. & $\begin{array}{l}\text { Participants were asked: How old are you? } \\
18-25 \\
26-35 \\
36-55 \\
56-65 \\
66-75 \\
75 \text { and over }\end{array}$ & Select one \\
\hline Q11. & $\begin{array}{l}\text { Participants were asked: Which gender do you identify as? } \\
\text { Male } \\
\text { Female } \\
\text { If none of the above, please state [insert text option] }\end{array}$ & Select one \\
\hline Q12. & $\begin{array}{l}\text { Participants were asked: What is your personal annual } \\
\text { income? } \\
0-\$ 25,000 \\
\$ 25,001-\$ 50,000 \\
\$ 50,001-\$ 75,000 \\
\$ 75,001-\$ 100,000 \\
\$ 100,001-\$ 150,000 \\
\$ 150,001-\text { or more } \\
\text { I'd rather not say }\end{array}$ & Select one \\
\hline Q13. & $\begin{array}{l}\text { Participants were asked: Are you currently studying at } \\
\text { university? } \\
\text { Yes }\end{array}$ & Select one \\
\hline
\end{tabular}




\begin{tabular}{|c|c|c|}
\hline Q14. & $\begin{array}{c}\text { No } \\
\text { Participants were asked: Thank you for taking the time to } \\
\text { complete my survey! If you'd like to go in the draw to win 1 of } \\
4 \$ 50 \text { New World vouchers then please click here. If you don't } \\
\text { wish to, then please proceed to the end of the survey. }\end{array}$ & $\begin{array}{c}\text { Select to } \\
\text { either } \\
\text { enter the } \\
\text { draw or } \\
\text { end the } \\
\text { survey. }\end{array}$ \\
\hline END OF THE SURVEY \\
\hline
\end{tabular}

Appendix B: Scenarios

\section{Scenario A}

[BRAND NAME: BeStill/Aio] is a food and drink company that is wanting to introduce a new fortified water drink into the New Zealand Market. Fortified water drinks are drinks infused with functional ingredients such as vitamins, minerals or herbs. [BRAND NAME: BeStill/Aio] is particularly interested in releasing a drink infused with kawakawa, which has been used in New Zealand for centuries by Māori as a natural remedy for digestive functions.

[BRAND NAME: BeStill/Aiio] is owned by the Duke of Sussex Trust in partnership with Wengbao Corporation. As an organisation, [BRAND NAME: BeStill/Aiio] is directed by a range of values centred around a triple bottom line - people, planet and profit. [BRAND NAME: BeStill/Aio] enacts these values in a number of ways, for example, the staff at [BRAND NAME: BeStill/Aiio] spend one weekend of every month working around New Zealand on a range of activities to make our waterways cleaner and clearer (planet). [BRAND NAME: BeStill/Äio] also provides school uniforms, shoes and stationery equipment for all of the children of their staff, and lunches are always provided for all staff (people).

In what follows, you will first be presented with the potential product design for [BRAND NAME: BeStill/Äio] new fortified water product. Following this, you will be asked some questions on the design of the product.

\section{Scenario B}

[BRAND NAME: BeStill/Aiio] is a food and drink company that is wanting to introduce a new fortified water drink into the New Zealand Market. Fortified water drinks are drinks infused with functional ingredients such as vitamins, minerals or herbs. [BRAND NAME: $B e S t i l l / \bar{A} i o]$ is particularly interested in releasing a drink infused with kawakawa, which has been used in New Zealand by Māori for centuries as a natural remedy for digestive functions.

[BRAND NAME: BeStill/Aìio] is owned by the Te Puni Kōkiri Community Trust. As an organisation, [BRAND NAME: BeStill/Aiio] is directed by a range of Tikanga Māori values such as kaitiakitanga (guardianship of resources), whanaungatanga (a sense of belonging) manaakitanga (respect and sharing). [BRAND NAME: BeStill/Aio] enacts these values in a number of ways, for example, the staff at [BRAND NAME: BeStill/Aiio] spend one weekend of every month working around New Zealand on a range of activities to make our waterways cleaner and clearer (kaitiakitanga). [BRAND NAME: BeStill/Äio] also provides school 
uniforms, shoes and stationery equipment for all of the children of their staff (whangaungatanga). And lunches are always provided for all staff (manaakitanga).

In what follows, you will first be presented with the potential product design for [BRAND NAME: BeStill/Aiio] new fortified water product. Following this, you will be asked some questions on the design of the product.

Appendix C: Pretesting: Authenticity Scale

Napoli et al., (2014)

\section{Original Item}

The brand has a strong connection to an historical period in time, culture and/or specific region.

The brand refuses to compromise the values upon which it was founded.

The brand has stuck to its principles.

The brand has a strong link to the past, which The brand has a strong link to the past, which is still perpetuated and celebrated to this day. is still perpetuated and celebrated to this day.

Please note that the original scale by Napoli et al., (2014) was comprised of 15 items, however only four items were adapted for pretesting in line with Bethlehem \& Biffignandi's (2011) suggestion to use scales with fewer items in order to reduce the overall time of the survey.

Appendix D: Pretesting: Māori Symbols

\section{Adapted Version}

This brand has a strong connection to Māori culture in New Zealand.

This brand refuses to compromise the values upon which it was founded.

This brand will stick to its principles.

\begin{tabular}{|l|l|l|l|l|}
\hline Style & Version & N & Mean & Std. Deviation \\
\hline Hook & 2 & 130 & 4.381 & 0.640 \\
\hline Tiki & 2 & 130 & 4.377 & 0.745 \\
\hline Koru & 2 & 130 & 4.227 & 0.699 \\
\hline Hook & 1 & 130 & 3.950 & 0.673 \\
\hline Hook & 3 & 130 & 3.900 & 0.827 \\
\hline Map & 3 & 130 & 3.708 & 0.966 \\
\hline Koru & 1 & 130 & 3.646 & 0.798 \\
\hline Tiki & 2 & 130 & 3.146 & 0.776 \\
\hline Kiwi & 3 & 130 & 3.035 & 0.863 \\
\hline Tiki & 3 & 130 & 2.923 & 0.683 \\
\hline Map & 2 & 130 & 2.892 & 0.766 \\
\hline Map & 1 & 130 & 2.457 & 1.000 \\
\hline Koru & 3 & 130 & 2.454 & 0.867 \\
\hline Kiwi & 2 & 130 & 1.812 & 0.898 \\
\hline Kiwi & 1 & 130 & 1.569 & 0.769 \\
\hline & & & & \\
\hline
\end{tabular}


Appendix E: Outliers

\begin{tabular}{|c|c|c|c|c|c|c|c|c|c|c|c|c|c|c|}
\hline Line & Condition & Ethnicity & A1 & A2 & A3 & P1 & BRAND & VALS & PACKAGING & EI1 & EI2 & EI3 & EI4 & EI5 \\
\hline 33 & MT & $\mathrm{M}$ & 1 & 1 & 1 & 1 & 3 & 3 & 3 & 5 & 5 & 5 & 3 & 3 \\
\hline 268 & MT & N-M & 2 & 2 & 2 & 5 & 5 & 4 & 5 & 4 & 4 & 1 & 4 & 1 \\
\hline 267 & MT & N-M & 2 & 2 & 2 & 5 & 5 & 2 & 4 & 4 & 4 & 2 & 5 & 5 \\
\hline 270 & MT & $\mathrm{N}-\mathrm{M}$ & 1 & 1 & 1 & 1 & 5 & 5 & 5 & 1 & 2 & 1 & 2 & 1 \\
\hline 272 & MT & N-M & 1 & 1 & 1 & 1 & 3 & 3 & 5 & 5 & 3 & 5 & 1 & 3 \\
\hline 374 & $\mathrm{MC}$ & $\mathrm{N}-\mathrm{M}$ & 2 & 1 & 2 & 1 & 4 & 3 & 4 & 1 & 3 & 4 & 1 & 1 \\
\hline 375 & $\mathrm{MC}$ & N-M & 1 & 1 & 1 & 1 & 5 & 1 & 4 & 4 & 4 & 3 & 3 & 2 \\
\hline 376 & $\mathrm{MC}$ & N-M & 1 & 1 & 1 & 1 & 3 & 3 & 5 & 3 & 5 & 5 & 1 & 5 \\
\hline 377 & $\mathrm{MC}$ & N-M & 1 & 1 & 1 & 7 & 4 & 4 & 4 & 4 & 3 & 2 & 1 & 1 \\
\hline 467 & OT & N-M & 3 & 2 & 1 & 6 & 2 & 5 & 4 & 4 & 3 & 4 & 1 & 3 \\
\hline 472 & OT & N-M & 2 & 2 & 1 & 6 & 4 & 4 & 5 & 3 & 3 & 3 & 2 & 3 \\
\hline 473 & OT & N-M & 2 & 2 & 2 & 4 & 3 & 3 & 3 & 3 & 3 & 3 & 3 & 3 \\
\hline 575 & OC & N-M & 2 & 1 & 2 & 6 & 6 & 2 & 2 & 2 & 3 & 1 & 4 & 1 \\
\hline 576 & $\mathrm{OC}$ & N-M & 1 & 2 & 1 & 6 & 6 & 1 & 5 & 1 & 3 & 1 & 3 & 1 \\
\hline 578 & $\mathrm{OC}$ & N-M & 1 & 1 & 1 & 6 & 6 & 2 & 3 & 2 & 3 & 1 & 3 & 2 \\
\hline 579 & $\mathrm{OC}$ & N-M & 1 & 1 & 1 & 5 & 5 & 2 & 5 & 5 & 3 & 3 & 4 & 2 \\
\hline
\end{tabular}

M: Māori branding; T: tikanga values; $O$ : orthodox branding; $C$ : conventional values

Appendix F: Ethics Approval

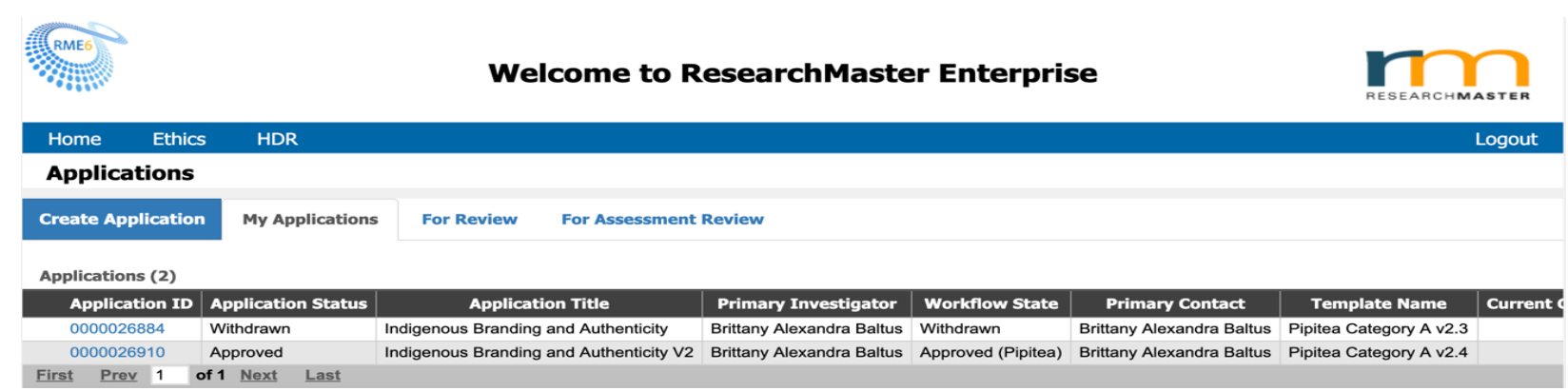


Appendix G: Factorial ANOVA

\begin{tabular}{|c|c|c|c|c|c|c|}
\hline Hypothesis & Source & $\begin{array}{l}\text { Type III } \\
\text { sum of } \\
\text { squares }\end{array}$ & df & $\begin{array}{l}\text { Mean } \\
\text { Square }\end{array}$ & $\mathbf{F}$ & Sig. \\
\hline & Corrected Model & $106.721^{\mathrm{a}}$ & 7 & 15.246 & 7.450 & .000 \\
\hline & Intercept & 12844.204 & 1 & 12844.204 & 6276.006 & .000 \\
\hline \multirow[t]{3}{*}{ H1 } & Branding & 8.595 & 1 & 8.595 & 4.200 & .041 \\
\hline & Organisational Values & 8.582 & 1 & 8.582 & 4.193 & .041 \\
\hline & Ethnic Identification & 14.827 & 1 & 14.827 & 7.245 & .007 \\
\hline \multirow[t]{3}{*}{ H2 } & $\begin{array}{l}\text { Branding * } \\
\text { Organisational Values }\end{array}$ & 39.647 & 1 & 39.647 & 19.372 & .000 \\
\hline & $\begin{array}{l}\text { Branding * Ethnic } \\
\text { Identification }\end{array}$ & 3.627 & 1 & 3.627 & 1.772 & .184 \\
\hline & $\begin{array}{l}\text { Organisational Values * } \\
\text { Ethnic Identification }\end{array}$ & 22.514 & 1 & 22.514 & 11.001 & .001 \\
\hline \multirow[t]{4}{*}{ H3 } & $\begin{array}{l}\text { Branding * } \\
\text { Organisational Values * } \\
\text { Ethnic identification }\end{array}$ & 6.310 & 1 & 6.310 & 3.083 & .080 \\
\hline & Error & 1148.118 & 561 & 2.047 & & \\
\hline & Total & 17941.333 & 569 & & & \\
\hline & Corrected Total & 1254.839 & & & & \\
\hline
\end{tabular}

